\title{
Learning to diagnose using patient video cases in paediatrics : perceptive and cognitive processes
}

Citation for published version (APA):

Balslev, T. (2011). Learning to diagnose using patient video cases in paediatrics : perceptive and cognitive processes. [Doctoral Thesis, Maastricht University]. Universitaire Pers Maastricht. https://doi.org/10.26481/dis.20111124tb

Document status and date:

Published: 01/01/2011

DOI:

10.26481/dis.20111124tb

Document Version:

Publisher's PDF, also known as Version of record

\section{Please check the document version of this publication:}

- A submitted manuscript is the version of the article upon submission and before peer-review. There can be important differences between the submitted version and the official published version of record.

People interested in the research are advised to contact the author for the final version of the publication, or visit the DOI to the publisher's website.

- The final author version and the galley proof are versions of the publication after peer review.

- The final published version features the final layout of the paper including the volume, issue and page numbers.

Link to publication

\footnotetext{
General rights rights.

- You may freely distribute the URL identifying the publication in the public portal. please follow below link for the End User Agreement:

www.umlib.nl/taverne-license

Take down policy

If you believe that this document breaches copyright please contact us at:

repository@maastrichtuniversity.nl

providing details and we will investigate your claim.
}

Copyright and moral rights for the publications made accessible in the public portal are retained by the authors and/or other copyright owners and it is a condition of accessing publications that users recognise and abide by the legal requirements associated with these

- Users may download and print one copy of any publication from the public portal for the purpose of private study or research.

- You may not further distribute the material or use it for any profit-making activity or commercial gain

If the publication is distributed under the terms of Article $25 \mathrm{fa}$ of the Dutch Copyright Act, indicated by the "Taverne" license above, 


\title{
Learning to diagnose using patient video cases in paediatrics:
}

\author{
Perceptive and cognitive processes
}


This research reported was carried out at

\section{Maastricht University}

in the School of Health Professions Education

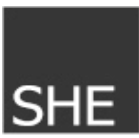

The research studies in this thesis were supported financially by the KUL-fund for quality improvement in postgraduate medical education, Aarhus County, Denmark.

(C) Copyright, Thomas Balslev, Aarhus, Denmark, 2011

ISBN 9789461590879

Production: Datawyse, Universitaire Pers Maastricht

Cover illustration: Thomas Balslev 


\title{
Learning to diagnose using patient video cases in paediatrics:
}

\author{
Perceptive and cognitive processes
}

\author{
DISSERTATION \\ to obtain the degree of Doctor at Maastricht University, \\ on the authority of the Rector Magnificus, Prof. dr. G.P.M.F. Mols, \\ in accordance with the decision of the Board of Deans,
}

to be defended in public on Thursday the $24^{\text {th }}$ of November 2011, at 16:00 hours

by

Thomas Balslev

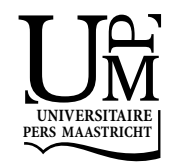




\section{Supervisor}

Prof. dr. A.J.J.A. Scherpbier

\section{Co-supervisors}

Dr. W. de Grave

Dr. A. Muijtjens

\section{Assessment committee}

Prof. dr. T.L. Dornan, University of Manchester, UK and University of Maastricht (chairman)

Dr. J. van Dalen

Dr. D.H.J.M. Dolmans

Prof. dr. C. Ringsted, Centre for Clinical Education, University of Copenhagen, Denmark 
"Imagination is more important than knowledge. For while knowledge defines all we currently know and understand, imagination points to all we might yet discover and create."

- Albert Einstein 


\section{Abbreviations}

AOI Areas of interest

EMME Eye movement modelling examples

PBL Problem-based learning

PVC Patient video case 


\section{Table of contents}

1 Introduction 9

2 Comparison of a text and video case in a postgraduate problem-based 21 learning format

T Balslev, WS de Grave, AMM Muijtjens \& AJJA Scherpbier

Published in Medical Education 2005;39:1086-1092

3 The development of shared cognition in paediatric residents analysing a 33 patient video versus a paper patient case

T Balslev, WS de Grave, AMM Muijtjens, B Eika \& AJJA Scherpbier

Published in Advances in the Health Sciences Education 2009;14(4):557-565

4 Enhancing diagnostic accuracy among non-experts by use of video-cases 45 T Balslev, WS de Grave, AMM Muijtjens \& AJJA Scherpbier

Published in Pediatrics 2010;125(3):e570-e576

5 Visual expertise in pediatric neurology

T Balslev, H Jarodzka, K Holmqvist, W de Grave, A Muijtjens,

B Eika, J van Merriënboer \& AJJA Scherpbier

Accepted for publication by the European Journal of Paediatric Neurology (2011), doi:10.1016/j.ejpn.2011.07.004

6 Conveying Clinical Reasoning based on Visual Observation via Eye

Movement Modelling Examples

H Jarodzka, T Balslev, K Holmqvist, K Scheiter, M Nyström, P Gerjets,

\& B Eika

Submitted to Instructional Science

7 Discussion

8 Summary 103

9 Resume (Summary in Danish) 109

10 Samenvatting (Summary in Dutch) 115

11 Acknowledgements 121

$\begin{array}{lr}\text { Curriculum vitae } & 125\end{array}$ 

Chapter 1

Introduction 
Making a working diagnosis or a definite diagnosis is clearly a core activity of physicians, creating the background for the work-up and management of a medical condition. In addition, the diagnosis is the basis for communication with the patient, family members, and also with members of the professional team at the workplace. As the majority of what clinicians learn takes place at work, through work, or from work (Swanwick, 2005), learning to diagnose at work must therefore be a priority.

There is a growing understanding that learning is a lifelong process, with the learner as an active knowledge-builder (Mann, 2011, Tynjälä, Nuutinen et al., 1997). At the same time, there is a shift of balance from a traditional understanding of teaching to the facilitation of learning. The learner integrates and assimilates the developing knowledge, rather than simply applying theoretical knowledge to the problems. These processes are critical for the development of diagnostic accuracy at an expert level (Boshuizen and Schmidt, 2000). Coincidentally, conditions for medical education in the context of work are changing rapidly: the complexity of medical disorders is increasing, work hours are being reduced, the economy is under restraint, and learners have competing duties (Morris and Blaney, 2010). These factors present a challenge to learning at work (Derrick, Badger et al., 2006, Josephson and Hauser, 2010).

In residency programmes, a variety of learning methods are seen, ranging from formal to informal methods (Eraut, 2000). Eraut described the typology of formal learning, i.e. learning within a prescribed learning framework, an organised learning event, and the presence of a designated teacher or trainer. This is in opposition to the more frequent informal (or nonformal) type of learning that may be on-thespot, near-spontaneous, and unplanned. Historically, work-based learning has provided opportunities for apprenticeship learning (Collins, 2006). Collins updated the model to a cognitive apprenticeship model to be used for cognitive skills. In this model, the cognitive processes of learners and teachers are brought into the open where learners can observe, enact, and practice them. Research now also provides knowledge about activities that may promote active learning at work, suggesting that opportunities to elaborate and make thinking visible, i.e. conveying one's own knowledge, beliefs, and cognitive processes are crucial (Dolmans et al 1998) (Bowen, 2006). This obviously requires team members to work together so that they can interact. Within the spectrum of formal and informal methods, there are a number of endangered species, and apprenticeship learning is one of them. This underlines the need for the illumination of new and effective approaches to learning, i.e. methods that allow interaction, supervision, and feedback. These methods must include well-defined tasks that gradually improve certain aspects of performance through repeated performance of a task. (Schuwirth and van der Vleuten, 2006). A wide range of technological improvements may help to recreate the clinical experiences of such tasks, so that they can be used for teaching and learning (Ker and Bradley, 2010). 
In paediatrics, paroxysmal or episodic neurological symptoms are common presentations. The symptoms may be caused by epilepsy or by disorders mimicking epilepsy (Crompton and Berkovic, 2009). The conditions are frequently misdiagnosed, with serious consequences like unnecessary testing or medication usage and patient or family anxiety (Uldall, Alving et al., 2006). To make a correct diagnosis, a careful history, consideration of differentials, careful observation of the patient, and not least, some conceptual knowledge is needed. Although electroencephalography (EEG), magnetic resonance imaging (MRI) studies, or genetic analysis may aid in diagnosis, descriptions of events are still critical in order to make correct and detailed diagnoses (Crompton and Berkovic, 2009).

Learning to diagnose these conditions is hampered because symptoms are periodic or paroxysmal (Singer, Mink et al., 2010, Nardocci and Fernandez-Alvarez, 2005). Therefore, an emphasis on the teaching and learning of these conditions is important. Learning to diagnose requires interactive learning so that residents (hospital doctors in specialty training) are stimulated to train perceptual skills and clinical reasoning skills (Bowen, 2006).

\section{Contextual, authentic learning from Patient Video Cases (PVCs)}

In paediatric neurology, the use of patient video cases (PVCs) is a long-standing tradition. They have been used for diagnostic purposes, for demonstration, and for in-context learning, and most clinicians are comfortable with their use. PVCs can be regarded as a multimedia instructional message, i.e. a presentation consisting of words and pictures designed to foster meaningful learning (Mayer, 1999). Multimedia can promote constructive learning, meaning a deep type of learning that occurs when learners try to make sense of presented material by constructing a coherent mental representation (Mayer, 1999). Multimedia use still pictures (photos) or dynamic pictures (video) or both. PVCs are dynamic pictures.

Instructional methods that use multimedia may enhance meaningful learning when active cognitive processing occurs: selecting, organizing, and integrating information (Mayer 1999, Mayer, 2001). Selecting occurs when the learner selects relevant aspects of the incoming images for further processing. Forming a coherent mental representation of the material is called organizing. A third process is to build connections between the mental representations and prior knowledge: integrating. The processes of selecting, organizing, and integrating generally do not occur in a rigid linear order, but rather in an iterative fashion. According to Mayer's cognitive theory of multimedia learning, meaningful learning depends on all three of these processes occurring in connection with the visual and verbal representations. According to this view, learners can engage in active learning (such as the processes of selecting, organizing, and integrating) even without hands-on activity. Importantly, 
learners can compare the PVCs with cases previously encountered and stored in long-term memory.

Learning by media in a broad sense has limitations (Clark, 1994, Clark and Salomon, 2001). Clark argues that media do not affect learning in and of themselves. Rather, some particular qualities of media may affect particular cognitions that are relevant for the learning or the knowledge or the skill required. Media may therefore have positive influences on the cost or the speed (efficiency) of learning, but only if adequate instructional methods are embedded with or in the media presentation. From this point of view, the methods, not the media, become crucial in learning. Building upon the constructivist point of view, research on learning with media therefore must include some way of measuring the cognitive processes involved. Clearly, media research must also develop and describe in detail the instructional methods with which the media are used (Clark, 1994, Clark and Salomon, 2001).

Publications dealing with visual diagnosis have focused mainly on still pictures in mammography and pathology, and in studies regarding the making of medical diagnoses; experts have been shown to be faster and more accurate than novices (Krupinski, 2005, Krupinsky et al., 2006). Research on the interpretation of complex, dynamic visual stimuli is still rare and limited to non-clinical domains (Moreno, Reino et al., 2002, Lowe, 1999). Little attention has been paid to the effect of the use of brief PVCs on the construction of new knowledge in learners with different levels of expertise and in different learning environments.

Research on human memory has shown that individuals recall information better if the context in which the information is applied closely resembles the context in which the information is learned (Godden and Baddeley, 1975, Brown, 1989). Work-based learning is a type of learning that reflects the nature of such tasks in the world (Lave and Wenger, 1991, Collins, 2006) and occurs when apprentices learn in the context of working on realistic tasks. This suggests that PVCs may be used in work-based learning formats: By including pictures as well as sounds, multimedia may improve the resemblance to the real-life situation and in this way enrich authenticity (Mayer, 1999). PVCs are likely to include all of the characteristics of authenticity: real-world authenticity (materials and activities reflect real practice), personal authenticity (students accept the activities as real or genuine), and disciplinary authenticity (problem solving builds on the intellectual tradition of a discipline) (Schaffer and Resnick, 1999). In particular, PVCs are superior at demonstrating movements of body parts as are seen with seizure disorders, movement disorders, and behavioural disorders, and are often used to facilitate diagnosis or for teaching (Dequeker and Jaspaert, 1998, Kamin, O'Sullivan et al., 2003, de Leng, Dolmans et al., 2007, Stephenson and King, 2010). In addition, PVCs can be slowed down, still-framed, or replayed (Albanese, 2005). PVCs are easy to obtain and can 
be used in postgraduate paediatric residency training. (Dequeker and Jaspaert, 1998)

Learning to diagnose with the use of PVCs may be associated with a risk of being overwhelmed by the complexity of the task (van Merriënboer, Kirschner et al., 2003). Cognitive load consists of the intrinsic nature of the learning task (intrinsic cognitive load) and the manner in which the task is presented (extraneous cognitive load). Both types of cognitive load are additive and processing may exceed the processing capacity of the cognitive system: a situation called cognitive overload. Cognitive load theory uses understanding of human cognition to direct instructional design so that sufficient cognitive processing capacity is left for genuine training (Sweller, van Merriënboer et al., 1998, van Merriënboer and Sweller, 2005). In line with this, cognitive load theory assumes that the working memory of human cognition has an extremely limited capacity. Cognitive load theory also assumes that there is no limitation to working memory capacity when dealing with information retrieved from long-term memory. Long-term memory has unlimited capacity and holds cognitive schemata that vary in their degree of complexity and automation. Expertise develops when learners mindfully combine simple ideas into more complex ones, i.e. cognitive schemata. These schemata organize and store knowledge but also greatly ease the load on working memory because even complex schemata can be dealt with as one element in working memory. Constructed schemata may become automated if they are repeatedly applied (van Merriënboer and Sweller, 2005). This may free working memory capacity for other activities, but it also requires practice.

Rich, real-life learning tasks like learning from clinical multimedia cases are a basis for complex learning (Merrill, 2002). The types of material involved in complex learning may incorporate a large number of interacting elements, and learning may be hampered by the limited capacity of the human mind. Multimedia in the form of authentic PVCs is such an example. As alluded to previously, PVCs can be used for real-life learning tasks in cognitive as well as procedural domains. Thus there is a need to develop new instructional methods that allow the designer to optimize cognitive load for such highly complex tasks (van Merriënboer and Sweller, 2005). Scaffolding, pertaining to support and then fading of this support (Putambekar and Hübscher, 2005, Collins, 2006), may reduce the cognitive load in complex learning (van Merriënboer and Sweller, 2010). Examples of such support are providing hints, prompts, and feedback; modelling cognitive strategies by thinking aloud, asking leading questions, and giving part of a solution (van Merriënboer, Kirschner et al., 2003).

Interpreting complex visualizations requires not only knowledge about a domain (i.e., conceptual knowledge), but also substantial visual search (i.e., perceptual skills). Refined perceptual skills enable experts to rapidly perceive the relevant out of the irrelevant and interpret it correctly. We know that experts surpass novices in 
those skills (Canham and Hegarty, 2010, Jarodzka, Scheiter et al., 2010, Underwood, Chapman et al., 2003, van Gog, Paas et al., 2005). Diagnosing medical images is a visually complex task, and research has indeed shown expertise differences on a perceptual level (Krupinski, 2005, Krupinski, Tillack et al., 2006, Kundel, Nodine et al., 2008). From a perceptual perspective, PVCs, i.e. moving pictures illustrating normal behaviour, seizures, and movement disorders, are expected to be particularly difficult. These features may be short-term, subtle, and not salient compared to other features evident in the PVC. However, there is little research so far that focuses on this aspect of clinical knowledge (Chen, Gale et al., 2009); (Jarodzka, van Gog et al., in preparation). Thus, there is a need to describe expertise-induced differences in the perception of clinical findings.

\section{Collaborative learning from PVCs}

Workplace learning not only views the learner as an individual learner. It also views the learner as an active participant, learning from and within a community of practice (Morris and Blaney, 2010; Teunissen, Stapel et al., 2007, Tynjälä et al., 2003, Dornan et al., 2007, Mann, 2011). An example is when medical students (novices) and residents (intermediates) work together with experienced staff physicians (experts) in the hospital environment. Interaction with more experienced clinicians is important for learners to understand the background for clinical activities (Teunissen et al., 2007). Collaborating learners may even be able to share cognition (Lebeau, 1998). The broadest definition of collaborative learning is a situation in which two or more people learn or attempt to learn something together. Nevertheless, collaborative learning has been applied in very different learning situations and environments: for groups of two or hundreds, for persons learning something faceto-face or computer-mediated, synchronous or not, frequent in time or not (Dillenbourg, 1999).

Groups of people are increasingly acknowledged as a substrate for knowledge construction. It is expected that teams, bringing together people with different experiences and knowledge, may be more effective in solving problems. On the other hand, teams also face the challenge of integrating these different perspectives and developing a shared understanding of the problem at hand (Eva, 2002, van den Bossche et al., 2006). Therefore, teamwork should only be emphasized when there is reason to believe that team members can supply unique skills that will enable the group to achieve goals that the individuals could otherwise not accomplish (Eva, 2002). This may occur when team members discuss the work-up of difficult patients, or when thinking aloud about management options on the ward round. Learning may therefore be an everyday practice, developed by newcomers and old-timers working together, and language is a central part of practice (Mann, 2011). 
Work-based learning favours interactive forms of learning in which individual interpretations, reflections, and understandings meet each other (Raelin, 2000) (Morris and Blaney, 2010). Vygotsky, a key contributor to the theory of social constructivism, described the "zone of proximal development" (Vygotsky, 1978), i.e. what the learner can do with some assistance or guidance. Thus, social interaction is seen as being crucial to cognitive development. Building on this, the notion of scaffolding describes how a teacher and a learner obtain a shared understanding of a learning activity. The teacher provides appropriate support based on an on-going diagnosis of the learners current understanding and carefully calibrates this support, and, when the learner has learned and is in control, finally fades out the support (Puntambekar and Hübscher, 2005). With the recent technological improvements in visualizations that support student learning, the concept of scaffolding has changed. Obviously, there is an urgent need to understand what kind of scaffolding works and what does not work.

Media, like PVCs, may have positive learning effects if an adequate instructional method is embedded with or in the media presentation (Clark, 1994, Clark and Salomon, 2001), and one such model is an interactive cognitive apprenticeship learning model. As learning is a part of social practice, a closer examination of the teams involved requires examination of cognitive processes of both newcomers (medical students and residents) as well as old timers (experts) (Morris and Blaney, 2010). Hence, there seems to be a need for studies of learning environments with media to show how powerfully these environments stimulate the cognitive processes. In traditional apprenticeship learning, the apprentices learn domain-specific knowledge or skills from a master through a combination of modelling, coaching, and practice with scaffolding (Brown et al., 1989, Collins, 2006). Brown and Collins updated the notion apprenticeship learning to make it relevant for the learning of complex tasks. The new term cognitive apprenticeship learning refers to a more indepth learning experience that is designed to bring the thinking processes out into the open. The methods articulation and reflection are designed to help apprentices gain conscious access to their own problem solving strategies and compare them with those of the experts.

Elaboration (or articulation) is a central method in cognitive apprenticeship learning (Collins 2006). Cognitive elaboration takes place when group members answer each other's questions. One of the most effective means of elaboration is explaining the material to someone else (Dolmans et al., 1998, Visschers-Pleijers et al., 2006, Baker, 2003). Interactivity is promoted by an approach like problem-based learning (Albanese et al., 1993) Problem-based learning is however primarily applied in pregraduate settings. Other approaches may promote interactivity in small or large groups by applying "brainstorming" or "buzz-group" techniques (Jaques, 2003) (Cantillon, 2003). 
In postgraduate medicine, the existence of teamwork with a wide spectrum of learners and teachers spanning from medical students over residents to staff physicians illustrates the necessity of collaborative learning and shared cognition (van den Bossche et al., 2006). The sharing of cognition is desirable, extending beyond the sharing of knowledge because it also includes the processes and products of clinical reasoning and builds upon individuals' inputs in the collaborative process. Shared cognition is an essential feature of collaborative learning from clinical encounters (Lebeau, 1998). Building of explanations by group members may lead to learning, but may also be a cognitively demanding task. As collaborative learning may apparently diminish and/or increase cognitive load (Dillenbourg, 1999), it is important to take risks of cognitive overload into consideration when planning collaborative learning environments.

Modelling involves an expert performing a task so that the apprentice can observe and build a conceptual model of the processes that are required to accomplish it (Collins 2006). For cognitive tasks like analysing a PVC, it is crucial that the student hears the expert's verbal explanations, and also sees the material the expert is looking at. However, this may not suffice, as the learner will have difficulty in identifying exactly what the expert is paying attention to in the PVC. Fostering perceptual skills by eye modelling examples is a recently developed approach (Jarodzka in preparation; van Gog et al., 2009). To develop such modelling examples, an expert model is recorded while performing a task. The model explains his or hers actions, and the eye movements are recorded. In cognitive tasks, the model verbalizes his/her cognitive actions while performing the task (Wouters et al., 2008). The PVC with the eye movements superimposed as an attentional guidance is then replayed along with the audio as an educational video (Bandura 1977). Recent research shows that guiding students' attention can improve learning, but the best method of modelling the attentional guidance in the PVC is not yet clear (Jarodzka in preparation). Such modelling techniques may have important implications for cognitive apprenticeship learning. Hence, modelling in videos may be used for scaffolding to help the teacher and the learner obtain a shared understanding of a dynamic stimulus. By the use of such a modelling technique, the teacher may give calibrated support based on an evaluation of the learner's current understanding, and when the learner has learned and is in control, finally fade out the support (Puntambekar and Hübscher, 2005, Azevedo et al, 2004).

\section{Main argument and research questions}

This thesis concerns learning to diagnose using PVC's as an integrated part of paediatric training, and focuses on the associated cognitive and perceptive processes. We know that meeting a large number of cases at work is important for the develop- 
ment of expertise. We also know that the use of media may speed up learning if they are used in interactive ways that promote elaboration. Technological improvements now allow for widespread recording, storing, and use of PVCs for teaching purposes. In spite of this, studies with video representations in medicine are still sparse. By seeking answers to a number of specific research questions, this thesis is intended to serve as a spring board to the implementation of the integrated use of PVCs in clinical learning environments in which junior as well as senior clinicians participate.

Firstly, the thesis seeks to answer how adding a PVC enhances the cognitive processes and the sharing of cognition among learners. Secondly, it seeks to illuminate and identify interactive approaches with PVCs that may improve diagnostic accuracy. Thirdly, it seeks to clarify what clinicians with varying experience pays attention to and what they think during analysis of PVCs. Fourth, it examines how attention guidance in PVCs might benefit learning.

Chapters 2 and 3 report a randomized controlled study of collaborating paediatric residents analysing a patient text-case or a PVC. In chapter 2 , the transcribed verbal interaction is investigated. In chapter 3 , additional in-depth analysis of a stimulated recall protocol triples the information on the underlying cognitive processes. Chapter 4 uses a stepwise, team-based, learning approach with a number of specific interventions including group discussions and modelling by a content expert to investigate how the level of diagnostic accuracy evolves and how the level of diagnostic accuracy differs between nonexperts and experts. Residents and paediatric neurologists participated. In chapter 5, eye-tracking and concurrent think-aloud procedures were performed to investigate the coupling of the attentional processes with the associated cognitive processes. A spectrum of clinicians with varying experience participated. In chapter 6 , a randomized controlled study of medical students exposed to three different types of attention guidance was performed to explore subsequent attentional and diagnostic skills. Chapter 7 assembles the results and weighs their strengths and limitations. Implications for instructional design and directions future research might take are discussed. 


\section{References}

Albanese M, Mitchell S. (1993). Problem-based learning: A review of literature on its outcomes and implementation issues. Academic Medicine, 68(1), 52-81.

Albanese M. (2005). Coming to a medical school near you: full motion video medical education. Medical Education, 39: 1081-1082.

Azevedo R, Cromley JG, Seibert D. (2004). Does adaptive scaffolding facilitate students' ability to regulate their learning with hypermedia? Contemporary Educational Psychology, 29, 344-370.

Baker M. (2003). Computer-mediated argumentative interactions for the co-elaboration of scientific notions. In: Andriessen, Baker M, Suthers D (eds) Arguing to learn: confronting cognitions in computer-supported collaborative learning environments. Netherlands: Kluwer Academic publishers, pp 47-78.

Bandura A. Social learning theory. (1977). Englewood Cliffs, New Jersey: Prentice-Hall.

Azevedo R, Cromley JG, Seibert D. (2004). Does adaptive scaffolding facilitate students' ability to regulate their learning with hypermedia? Contemporary Educational Psychology, 29, 344-370.

van den Bossche P, Segers M, Kirschner PA. (2006) Social and cognitive factors driving teamwork in collaborative learning environments. Small group Research 37(5), 490-517.

Boshuizen HPA, Schmidt HG. (2000) The development of clinical reasoning expertise; implications for teaching. In: Higgs J, Jones M, eds: Clinical reasoning in the health professions. 2nd ed. Oxford: Butterworth-Heinemann, p. 15-22.

Bowen JL. (2006). Educational strategies to promote clinical diagnostic reasoning. NEJM, 355, 2217-25.

Brown JS, Collins A, Duguid P. (1989). Situated cognition and the culture of learning. Educational Researcher, 18:32-42.

Canham M, Hegarty M.(2010). Effects of knowledge and display design on comprehension of complex graphics. Learning and Instruction, 20, 155-166.

Cantillon P. (2003). ABC of learning and teaching in Medicine. Teaching large Groups. BMJ, 326, 437-440.

Chen Y, Gale AG, Evans A. (2009). The feasibility of vision-supported computer-based training in digital mammography. Breast Cancer Research, 11: 10.

Clark RE. (1994). Media will never influence learning. Educational Technology, Research and Development, 42(2), 21-29.

Clark RE, Salomon G. (2001). Why should we expect media to teach anyone anything? In: Clark RE, ed. Learning from media. Arguments, analysis and evidence. Connecticut: IAP, pp 37-70.

Collins A. (2006). Cognitive apprenticeship. In Sawyer RK, ed. . The Cambridge Handbook of the learning sciences pp. 47-60. Cambridge: Cambridge University Press; 2006. pp 47-60.

Crompton DE, Berkovic SF. (2009) The borderland of epilepsy: clinical and molecular features of phenomena that mimic epileptic disorders. Lancet Neurology, 8, 370-81.

Derrick S, Badger B, Chandler J, Nokes T, Winch G. (2006).The training/service continuum: exploring the training/service balance of senior house officer activities. Medical Education, 40(4),355-362.

Dequeker J, Jaspaert R. (1998). Teaching problem-solving and clinical reasoning: 20 years' experience with video-supported small-group learning. Medical Education, 32, 384-389.

Dillenbourg P. (1999). What do you mean by collaborative learning? In Dillenbourg P, ed. Collaborative Learning: Cognitive and Computational Approaches. Oxford: Elsevier. pp 1-19.

Dolmans D, Wolfhagen IHAP, van der Vleuten CPM. (1998). Thinking about student thinking. Motivational and cognitive processes influencing tutorial groups. Academic Medicine, 73 (10), S22-24.

Dornan T, Boshuizen H, King N, Scherpbier A. (2007). Experience-based learning: a model linking the processes and outcomes of medical students' workplace learning. Medical Education 41, 84-91.

Eraut M. (2000). Non-formal learning and tacit knowledge in professional work. British Journal of Educational Psychology. 70(1), 113-136.

Eva KW. (2002). Teamwork during education: the whole is not always greater than the sum of the parts Medical Education, 36, 314-316. 
Godden DR, Baddeley AD. (1975). Context-dependent memory in two natural environments: on land and underwater, British Journal of Psychology, 66, 325-331.

van Gog T, Paas F, van Merriënboer JJG. (2005). Uncovering expertise-related differences in troubleshooting performance: combining eye movement and concurrent verbal protocol data. Applied Cognitive Psychology, 19, 205-221.

van Gog T, Kester L, Nievelstein F, Giesbers B, Paas F. (2009). Uncovering cognitive processes: Different techniques that can contribute to cognitive load research and instruction. Computers in Human Behaviour, 25, 325-331.

Jarodzka H, Scheiter K, Gerjets P, van Gog T. (2010). In the eyes of the beholder: How experts and novices interpret dynamic stimuli. Journal of learning and instruction 20, 146-154.

Jarodzka H, van Gog T, Dorr M, Scheiter K, \& Gerjets P. (in preparation). Guiding attentions guides thought, but what about learning? Eye movements in modeling examples. NN.

Jaques D. (2003). ABC of learning and teaching in Medicine. Teaching small groups. BMJ, 326, 492-494.

Josephsen SA, Hauser SL. (2010). Neurologic education 2011: New Challenges and Opportunities. Annals of Neurology, 68(6), A9-10.

Kamin C, O'Sullivan P, Deterding R, Younger M. (2003). A comparison of critical thinking in groups of third-year medical students in text, video and virtual PBL Case modalities. Acad Med, 78, 204-11.

Ker J, Bradley P. (2010). Simulation in medical education. In: Understanding Medical Education. Tim Swanwick,ed. Oxford: Wiley-Blackwell, pp. 164-180.

King DK, Stephenson JBP. (2010). Video with audio. In: King DK, Stephenson JBP eds. A Handbook of Neurological Investigations in Children. London: Mac Keith Press, pp.14-21.

Krupinski EA. (2005). Visual search of mammographic images: influence of lesion subtlety. Academic Radiology, 12(8), 965-969.

Krupinski EA, Tillack AA, Richter et al. (2006) Eye movement study and human performance using telepathology virtual slides. Implications for medical education and differences with experience. Human Pathology, 37(12), 1543-1556.

Kundel HJ, Nodine C, Krupinski E, Mello-Thoms C. (2008). Using gaze-tracking data and mixture distribution analysis to support a holistic model for the detection of cancers on mammograms. Academic Radiology, 15, 881-886.

Lave J, Wenger E. (1991). Situated learning: legitimate peripheral participation. New York: Cambridge University Press.

Lebeau RB. (1998). Cognitive tools in a clinical encounter in medicine: supporting empathy and expertise in distributed systems. Educ. Psychol. Rev.10, 3-24.

de Leng BA, Dolmans DHJM, van de Wiel MWJ, Muijtjens AMM, van der Vleuten CPM. (2007). How video cases should be used as authentic stimuli in problem-based medical education. Medical Education, 41:181.

Lowe, R. K. (1999). Extracting information from an animation during complex visual learning. European Journal of Psychology of Education, 14, 225-244.

Mann KV. (2011). Theoretical perspectives in medical education: past experience and future possibilities. Medical Education, 45, 60-8.

Mayer RE. (1999). Multimedia aids to problem-solving transfer. International J of Educational Research 31, 611-623.

Mayer RE. (2001). Multimedia Learning. Cambridge; Cambridge University Press 2001.

van Merriënboer JJG, Kirschner PA, Kester L. (2003). Taking the Load Off a Learner's Mind: Instructional Design for Complex Learning. Educational Psychologist, 38(1), 5-13.

van Merriënboer JJG, Sweller J. (2005). Cognitive load theory and complex learning: recent developments and future directions. Educational Psychology Review 17, 147-177.

van Merriënboer JJG, John Sweller. (2010). Cognitive load theory in health professional education: design principles and strategies. Med Educ, 44, 85-93.

Merrill MD. (2002). First principles of instructional design. Educ. Technol., Res., Dev. 50, 43-59. 
Moreno FJ, Reina R, Luis V, Sabido R. (2002). Visual search strategies in experienced and inexperienced gymnastic coaches. Perceptual and Motor Skills, 95, 901-902.

Morris C, Blaney C. (2010). Work-based learning. In: Understanding Medical Education. Evidence, Theory and Practice. Swanwick T, ed. London; Wiley-Blackwell, pp. 69-82

Nardocci N, Fernandez-Alvarez E. (2007) Movement disorders in children: a clinical update with video recordings. John Libbey Eurotext.

Puntambekar S, Hübscher R. (2005). Tools for scaffolding students in a complex learning environment: What have we gained and what have we missed? Educational psychologist, 40(1), 1-12.

Raelin JA. (2000)The grounds for work-based learning. In: Raelin JA. Work-based learning. The new frontier of management development. New Jersey; Prentice Hall, pp 8-26.

Shaffer DW, Resnick M. (1999). Thick authenticity: New media and authentic learning. Journal of Interactive Learning Research, 10(2), 195-215.

Schuwirth LWT, van der Vleuten CPM. (2006). Challenges for educationalists. BMJ, 333, 544-6.

Singer H, Mink JW, Gilbert D, Jankovic J. (2010). Diagnostic evaluation of children with movement disorders. In: Singer H, Mink JW, Gilbert D, Jankovic J eds. Movement disorders in childhood. Philadelphia; Saunders, pp 19-29.

Swanwick T. (2005). Informal learning in postgraduate medical education: from cognitivism to 'culturism' Medical Education, 39, 859-865.

Sweller J, van Merriënboer JJG, Paas F.(1998). Cognitive architecture and instructional design. Educ Psychol Rev, 10, 251-296.

Teunissen PW, Scheele F, Scherpbier AJJA, van der Vleuten C, Boor K, van Luijk S and van DiemenSteenvoorde JAAM. (2007) How residents learn: Qualitative evidence for the pivotal role of clinical activities. Medical Education, 41:763-770.

Tynjälä P, Nuutinen A, Eteläpelto A, Kirjonen J, Remes P. (1997). The Acquisition of Professional Expertise - a challenge for Educational research. Scand J Educational Research, 41.

Tynjälä P, Välimaa J, Sarja A. (2003). Pedagogical perspectives on the relationships between higher education and working life. Higher Education, 46, 147-166.

Uldall P, Alving J, Hansen LK, Kibæk M et al. (2006). The misdiagnosis of epilepsy in children admitted to a tertiary epilepsy centre with paroxysmal events. Arch Dis Child, 91, 219-21.

Underwood G, Chapman P, Brocklehurst N. (2003). Visual attention while driving: sequences of eye fixations made by experienced and novice drivers. Ergonomics, 468(6), 629-647.

Visschers-Pleijers AJS, Dolmans DHJM, de Grave WS, Wolfhagen IHAP, Jacobs JA, van der Vleuten CPM. (2006). Student perceptions about the characteristics of an effective discussion during the reporting phase in problem-based learning. Medical Education, 40:924-931.

Vygotsky L. In Cole M, HJohn-Spencer V, Scribner S, Souberman S, eds. (1978). Mind in Society: the development of higher psychological processes. Cambridge, MA; Harvard University Press.

Wouters P, Paas F, Merrienboer JJGV. (2008). How to optimize learning from animated models: A review of guidelines based on cognitive load. Review of Educational Research, 78, 645-675. 


\section{Chapter 2 \\ Comparison of a text and video case in a postgraduate problem-based learning format}

Published in Medical Education, 2005, Nov; 39(11): 1086-92.

Thomas Balslev

Willem $S$ de Grave

Arno MM Muijtjens

Albert JJ Scherpbier 


\begin{abstract}
Objective

To investigate whether adding a brief video case instead of an equivalent written text improves the cognitive and metacognitive processes (data exploration, theory building, theory evaluation and metareasoning) of residents in problem-based learning.
\end{abstract}

Subjects

Paediatric residents.

Setting

Department of Paediatrics, Aarhus University Hospital, Skejby, Denmark.

\title{
Methods
}

Eleven residents were each assigned to 1 of 2 groups. Both groups analysed an identical vignette of a patient case. Immediately after this, 1 group watched a 2.5minute video recording and the other group read a description of the same video recording. The groups then reanalysed the case. Thinking processes were tapped by recording and analysing the verbal group interaction. The frequencies of clause categories were calculated and compared using chi-square tests.

\section{Results}

The verbal interaction showed statistically significant improvements in data exploration, theory building and theory evaluation after the video case.

\section{Conclusions}

The greater improvement in clause frequency after the video case compared with the equivalent text suggests an improvement in data exploration, theory building and theory evaluation. The use of patient video recordings may be a valuable supplement to postgraduate paediatric training, particularly pertaining to movement disorders. 


\section{Introduction}

Inevitably, trainees have limited exposure to rare diseases and to disorders with symptoms that are only briefly observable. In order to become medical experts, however, students and residents must see many different patients and disorders. ${ }^{1}$ Moreover, it has been shown that the process of noticing obvious features in a patient's appearance is difficult and sensitive to a number of factors. ${ }^{2}$ This means that training programmes should look for ways to increase students' exposure to patients and disorders. Video cases may be a valuable addition to a training programme, especially in domains with a strong visual component, as they can show characteristic signs and symptoms of patient cases and are easy to obtain, highly authentic and suitable for use in different learning environments.

Some studies have reported on the effectiveness of so-called trigger videos that depict patient) doctor encounters; students have responded positively to the inclusion of video cases in a course. ${ }^{3}$ Presentations of the same patient case by video and as a paper case were compared as part of an experiment in a problem based learning (PBL) course in a paediatric clerkship. ${ }^{4}$ Compared with the group of students who were given a paper case, the group exposed to the video case had more difficulty extracting relevant information technology information from the patient case, spent more time interpreting what they saw, negotiated more learning issues and showed greater commitment. ${ }^{4}$ The results of another study by the same group showed that PBL groups working with a video case, either face to face or virtually through web-based discussions, obtained higher critical thinking ratios than groups working face-to-face with a paper case. ${ }^{5}$ Mayer found that multimedia learning can promote constructivist learning, meaning learning that occurs when learners seek to make sense of presented material by constructing a coherent mental representation. ${ }^{6}$

Our experience in postgraduate paediatric training has shown that movement disorders and seizures are topics that are often particularly difficult to grasp for trainees. This is consistent with the findings of Brooks et al. mentioned above. ${ }^{2} \mathrm{We}$ were interested in identifying ways to facilitate student learning in this area and in the use of video cases in particular. In order to investigate the effectiveness of a video case in paediatric specialist training, we compared the impact of a video case on residents' cognitive processes with that of a paper case. Both cases were used to present a patient problem for analysis in a small group. Problem-based learning has the potential to stimulate learners to construct their own knowledge. ${ }^{7}$ Although it is generally assumed that the characteristic elements of the tutorial process in PBL enhance conceptual change, there is no definitive understanding of how positive educational outcomes are brought about in PBL. ${ }^{8}$ No straightforward causal relationships have been identified and further studies are needed to investigate the cognitive and metacognitive processes involved in PBL. ${ }^{8,9}$ The inclusion of a video- 
tape in the presentation of a patient problem in PBL can play a unique role in complementing the narrative description of a patient. ${ }^{10,11}$ Because we wished to limit our study to the immediate cognitive and metacognitive processes, we focused on the first 5 steps of the problem-solving process as used in the Maastricht PBL approach:

- clarifying unknown terminology;

- problem definition;

- problem analysis;

- listing the explanations generated in step 3, and

- identifying learning objectives.

We studied the effect of using a video case with paediatric residents in Years 1 through 3 of their training, because these residents have gained some experience and are in the process of knowledge encapsulation as well as illness script construction, which renders them very receptive to script modelling. ${ }^{1,12}$ We investigated the cognitive and metacognitive processes using a coding system developed by Hassebrock and Prietula ${ }^{13}$ and adapted by de Grave et al. ${ }^{9}$ This schema comprises the categories of data exploration, theory building, theory evaluation and metareasoning in individual diagnostic reasoning. It is, however, also suitable for identifying these categories in reasoning or problem analysis by groups. We hypothesised that adding a video case to written information would lead to a greater increase in the frequency of data exploration, theory building, theory evaluation and metareasoning than would be achieved by a paper case.

\section{Methods}

\section{Participants}

All 16 residents who had completed up to 36 months of paediatric training in 3 departments in the same region in Denmark were invited to participate in the study. Twelve residents agreed to participate. They had completed 6-36 months (mean 21 months) of specialist training in paediatrics and child psychiatry. Prior to this study, the trainees had received training in PBL as part of a series of pilot studies with paediatric video cases. To optimise residents' comfort with video recording, video recording of residents also took place during the pilot studies. The first author acted as tutor in the group sessions. 


\section{Overview}

What is already known on this subject

Multimedia learning can promote learners' construction of coherent mental representations.

Recent research suggests that PBL groups spend more time working on video cases than on paper cases.

\section{What this study adds}

A video case provoked more frequent exploration, theory building and theory evaluation than a text case.

\section{Suggestions for further research}

The thinking processes of doctors at different levels of expertise who are exposed to video cases deserve to be studied in more detail in the context of workbased learning.

\section{Procedure}

\section{Intervention groups}

Clusters of matching residents were composed on the basis of gender and months of paediatric training. Half the residents in each cluster were randomly allocated to group $A$ and half to group $B$. The groups met once on the same day, to prevent any exchange of information between groups. Due to the illness of 1 resident, group $A$ consisted of 5 residents and group B of 6 residents.

\section{The case}

The case involved Sturge-Weber syndrome, a rare disease. Most trainees in a paediatric department should be familiar with some of the symptoms and signs illustrated by the case. This meant that the residents could be expected to have sufficient prior knowledge to start the problem analysis, but also that the problem was sufficiently challenging to stimulate their cognitive processes. The video excerpt showed a drowsy 2-month-old infant with a haemangioma on the forehead and an ongoing partial motor seizure on the right side of the body. The auditory information included respiratory wheezing. Sturge-Weber syndrome is a congenital disease with a venous angioma of the meninges and a frontal, facial angiomatous naevus. The venous angioma of the meninges may cause hypoxaemia and impaired neuronal metabolism of the underlying brain structures. Patients are at an increased 
risk of intractable epilepsy, mental retardation and hemiplegia and benefit from early diagnosis and treatment.

\section{Group sessions}

Both groups first analysed the same written vignette, using the first 5 steps of the Maastricht PBL approach. They were told that this would take about 20 minutes, but that they need not worry about time. After completing the analysis, group $B$ watched a brief (2.5-minute) video recording of the patient (intervention) and group A read a written description of the video recording (intervention) without watching the video. The groups then repeated the 5 steps of the problem analysis. Group B was allowed to watch the video more than once and group A was allowed to read the text more than once. Group B elected to watch the video twice. The tutor's main task was to promote collaboration among the trainees. He did not steer the direction of the group discussion in any way that might have been expected to affect the outcomes of the study. When no new theory building or theory evaluation emerged, the tutor asked the group to finish the analysis and proceed to the identification of learning objectives. After the group members had confirmed that the discussion was closed, video recording of the group discussion was terminated.

\section{Data collection and analysis}

The study was performed at Aarhus University Hospital, Skejby. Group interaction was recorded on videotape and subsequently transcribed verbatim. Two of the authors independently classified the clauses according to the following categories: process level, task level (data exploration, theory building, theory evaluation and metareasoning) and non-task level (Table 1). Differences of opinion were resolved by a consensus procedure. Two random samples, 1 from group $A$ and 1 from group $B$, were analysed to determine interrater reliability. Interrater reliability on the 7 categories was acceptable as indexed by Cohen's kappa $(k=0.80)$. The rate of agreement between the 2 independent coders was $87 \%$. 
Table 1 Coding system for the protocols of verbal interaction during problem analysis. (9) Representative examples are presented in italics.

\begin{tabular}{|c|c|c|}
\hline Process level & Task level & Non-task level \\
\hline $\begin{array}{l}\text { procedure } \\
\text { "I think we should } \\
\text { proceed to analysis } \\
\text { now" } \\
\text { cooperation } \\
\text { "Do we all agree on } \\
\text { that?" }\end{array}$ & $\begin{array}{l}\text { 2.1 data exploration: problem definition; reference to the } \\
\text { information in the case; identification; structuring; integrating } \\
\text { and initial interpretation of information; signalling lacking data } \\
\text { "The jerking seems to be on both sides of the body" } \\
2.2 \text { theory building: causal reasoning; hypothesis; associations' } \\
\text { specification; generalisation. } \\
\text { "I think this is an epileptic seizure" } \\
2.3 \text { theory evaluation, confirming evaluation; non-confirming } \\
\text { evaluation, evaluation about certainty. } \\
\text { "Yes, I agree that epilepsy is the most likely cause" } \\
2.4 \text { metareasoning: reflecting on prior knowledge, reflecting on } \\
\text { the learning process, reflecting on strategy of thinking } \\
\text { "I need to know more about which types of epilepsy are com- } \\
\text { mon at this age" }\end{array}$ & $\begin{array}{l}3.1 \text { irrelevant } \\
\text { "I'm thinking of } \\
\text { what I am going to } \\
\text { do tomorrow" }\end{array}$ \\
\hline
\end{tabular}

The numbers of clauses were calculated separately for the parts of the group sessions before and after the intervention. They were summed by category. Chi-square tests were used to determine the significance of the differences between groups $A$ and $B$ in the ratio of the frequency of clauses after and before the intervention. The ratio of clauses was reported to control for the difference in the numbers of individuals in groups $A$ and $B$. While a chi-square test is not strictly appropriate in a situation where the units of analysis have naturally occurring relationships with one another, such as sequential clauses, we report the P-values as a descriptive statistic for interpreting whether the differences in ratios are meaningful.

\section{Results}

The groups spent different amounts of time on analysing the first text and also on analysing the additional video and paper versions of the case. Groups A and B spent 20 and 22 minutes on the vignette, respectively; group $A$ spent 23 minutes on the paper case and group B spent 28 minutes on the video case.

The numbers of clauses generated by the residents after watching the video case and reading the paper case are reported in Table 3 . The differences between groups $A$ and $B$ in the after/before ratios of the numbers of clauses relating to data exploration, theory building and theory evaluation were statistically significant (Tables 2 and 3). Group B produced fewer clauses in the category of metareasoning compared with group A. This difference was statistically significant. Group B started the verbal interaction while the video was being replayed, whereas group A read the equivalent text silently. 
Table 2 The numbers of clauses are reported by clause type. The ratios of the numbers of clauses by category after/before the intervention are also reported. The asterisks indicate a statistically significant difference between the results before and after the intervention (chi square).

\begin{tabular}{lcc}
\hline Clause type & Number of clauses & Ratio (after/before) video/(after/before) text \\
\hline Data Exploration & 624 & $2.3^{*}$ \\
Theory Building & 298 & $2.2^{*}$ \\
Theory evaluation & 339 & $2.0^{*}$ \\
Meta Reasoning & 151 & $0.3^{*}$ \\
Total & 1412 & \\
\hline
\end{tabular}

Table 3 Differences between the video group (B) and the text group (A) in the number of clauses in the various categories produced during the verbal interaction in the groups. The numbers of clauses and the after/before intervention ratios of the numbers of clauses are shown. The final column shows the results of the chi-square analysis of the differences between group $A$ and group $B$

\begin{tabular}{|c|c|c|c|c|c|}
\hline \multirow[b]{2}{*}{ Categories } & \multicolumn{5}{|c|}{ Number of clauses } \\
\hline & $\begin{array}{c}\text { Before } \\
\text { intervention }\end{array}$ & $\begin{array}{c}\text { After } \\
\text { intervention }\end{array}$ & Total & $\begin{array}{l}\text { Ratio after/before } \\
\text { intervention }\end{array}$ & $\begin{array}{c}\text { Difference } \\
A \text { and } B\end{array}$ \\
\hline \multicolumn{6}{|c|}{ Data exploration } \\
\hline$A($ text) & 146 & 92 & 238 & 0.6 & $\mathrm{Chi}^{2}=23.9$ \\
\hline B (video) & 159 & 227 & 386 & 1.4 & $d f=1$ \\
\hline Total & 305 & 319 & 624 & & $\mathrm{p}<.0001$ \\
\hline \multicolumn{6}{|c|}{ Theory building } \\
\hline$A($ text) & 83 & 71 & 154 & 0.9 & $\mathrm{Chi}^{2}=12.8$ \\
\hline B (video) & 48 & 96 & 144 & 2.0 & $d f=1$ \\
\hline Total & 131 & 167 & 298 & & $p<.001$ \\
\hline \multicolumn{6}{|c|}{ Theory evaluation } \\
\hline$A($ text) & 94 & 88 & 182 & 0.9 & $\mathrm{Chi}^{2}=8.7$ \\
\hline B (video) & 56 & 101 & 157 & 1.8 & $\mathrm{df}=1$ \\
\hline Total & 150 & 189 & 339 & & $p<.01$ \\
\hline \multicolumn{6}{|c|}{ Metareasoning } \\
\hline$A($ text) & 31 & 54 & 85 & 1.7 & $\mathrm{Chi}^{2}=13.6$ \\
\hline B (video) & 44 & 22 & 66 & 0.5 & $d f=1$ \\
\hline Total & 75 & 76 & 151 & & $p<.001$ \\
\hline
\end{tabular}

df: degrees of freedom. Italics: marginal counts.

Table 4 presents representative quotes illustrating what the residents said and their coding from the verbal interaction. The quotes illustrate how one of the residents (who was exposed to text rather than video) had difficulty forming pictorial images on the basis of the text. The quotes also illustrate that residents in both groups hypothesised that the case might be depicting a seizure caused by an intracranial haemangioma. 
Table 4 Representative quotes from the verbal interaction following text and video. The numbers refer to the coding system presented in Table 1.

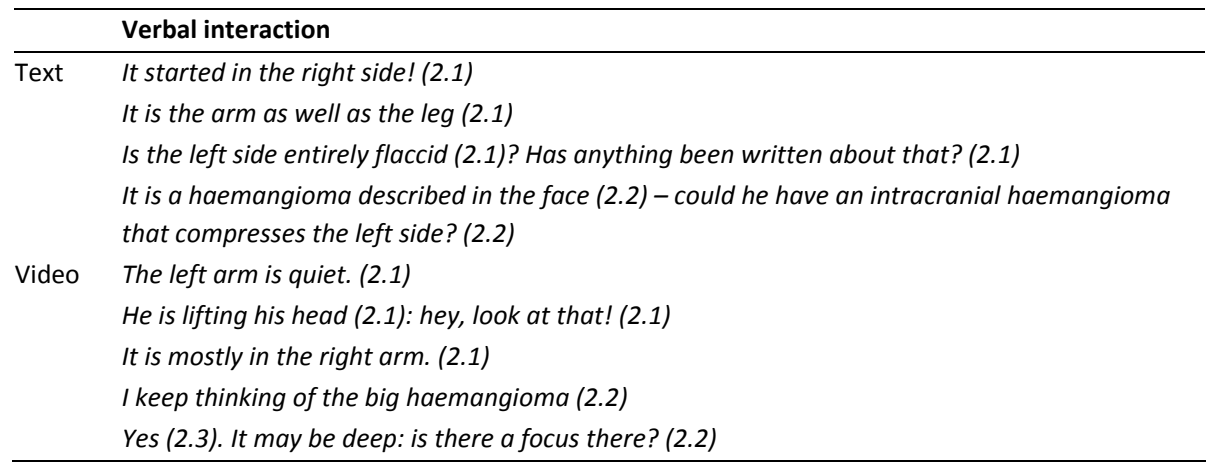

In an interview after the group sessions, all the residents in group B said that the video recording showed posture and or movements better than a text would be able to do. One of the residents in group A said that she thought the video case facilitated group members in helping each other to analyse visual information about a patient. One resident said that she had created simple pictorial models from the text and that a video would have improved these models.

\section{Discussion}

The results of the comparison between the effects of the video case and those of the paper case show that in the verbal group interaction, the video case yielded higher frequencies of clauses relating to data exploration, theory building and theory evaluation. This suggests that cognitive processes were stimulated by the video case. This finding is in accordance with cognitive load theory and multimedia learning: the limited capacity of human working memory seems to be expandable by the use of visual and auditory information. 6,14,15

A weakness of this study is that 1 of the authors tutored both groups. However, the design of the study was such that it prevented the tutor from guiding the discussion in an opportune direction. The low numbers of residents in the groups warrant humility about the results, however.

In the analysis we used the clause frequency ratio after/before the intervention as the effect measure because it offers the major advantage of being insensitive to between-group differences not associated with the intervention. For instance, although a larger group size might result in increased frequencies of all clauses (both before and after the intervention), the frequency ratio would be unaffected, because the increase would be present in both the nominator and the denominator. This means that the unfortunate difference in the group sizes did not invalidate the analysis. 
The findings regarding verbal interaction are similar to findings by Kamin et al, who reported that a video case instead of a text case increased almost all criticalthinking categories and resulted in learners spending more time analyzing the case. $^{4,5}$

It is unclear why the frequency of metareasoning was lower after the video case compared with the text case. It may be attributable to the following counterbalancing phenomenon. Assuming that the variables data exploration, theory building and theory evaluation, on the one hand, and metareasoning, on the other, are not independent variables, one might expect that higher frequencies of clauses pertaining to data exploration, theory building and theory evaluation would be accompanied by a lower frequency of metareasoning. This may explain why the frequency of metareasoning was lower in the discussion following the video case than in the discussion following the text case. An attractive explanation concerns the limited capacity of residents' working memory: cognitive load theory. ${ }^{14}$ The fact that residents spent more time analysing the video case than the text case suggests that different cognitive processes may be involved. The stringent planning of the present study, which included asking the groups to do their best during the discussion, not to worry about time and not to terminate the video recording before finishing the analysis and the identification of learning objectives, suggests that the differences in duration may be attributable to the intervention. The longer duration of the analysis following the videotape is consistent with the findings of a study carried out in a paediatric clerkship PBL course. The students in that study spent more time on interpreting the material they saw in a video than they did on that they read in the equivalent text. ${ }^{4}$ Further research will need to provide conclusive evidence that it does indeed take more time to analyse a video case than an equivalent written text. It is important to remember that our study involved only 1 group of 5 residents and another of 6 residents. The results must be interpreted in light of the small numbers and the fact that we did not have multiple groups in either treatment to assess how variable our findings would be. However, residency programmes are generally small and these numbers are probably quite typical of the usual residency programme. As such, we hope our research will stimulate others to investigate this issue. While there is extensive experience with PBL in undergraduate training contexts, and Ka$\min$ et al. have shown the relevance of video cases, 4,5 there is no strong, longstanding tradition of PBL in postgraduate training and PBL may not be the best possible approach.

Instead, video cases and small group discussions simulating collaborative teams may be implemented as part of a more comprehensive set-up for workbased learning to improve experimentation and reflection. ${ }^{16}$ These teams could meet at regular rounds with video cases and could include nurses, students and residents, as well as specialists. 
Contributors: TB conceived, designed and implemented the study and wrote the first draft of the paper. AMMM contributed to the design of the study and performed the statistical analysis. WSdG and AJJAS contributed to the design of the study. All authors participated in the writing of the paper.

Acknowledgement: the authors thank Mereke L B Gorsira for critically reading and correcting the English manuscript.

Funding: this research was supported by the Epilepsy and Education Foundation, Department of Paediatrics Aarhus University Hospital, Skejby.

Conflicts of interest: none.

Ethical approval: the study was approved by the local ethics committee. 


\section{References}

1. Boshuizen HPA, Schmidt HG. The development of clinical reasoning expertise: implications for teaching. In: Higgs J, Jones M, eds. Clinical Reasoning in the Health Professions. 2nd edn. Oxford: Butterworth-Heinemann 2000;15-22.

2. Brooks LR, Leblanc VR, Norman GR. On the difficulty of noticing obvious features in patient appearance. Psychol Sci 2000;11:112-7.

3. Parkin A, Dora N. Making videos for medical undergraduate teaching in child psychiatry: the development, use and perceived effectiveness of structured videotapes of clinical material for use by medical students in child psychiatry. Med Teacher 2000;6:568-71.

4. Kamin CS, O'Sullivan PS, Younger M, Deterding R. Measuring critical thinking in problem-based learning discourse. Teach Learn Med 2001;13:27-35.

5. Kamin C, O'Sullivan P, Deterding R, Younger M. A comparison of critical thinking in groups of third year medical students in text, video and virtual PBL case modalities. Acad Med 2003;78:204-11.

6. Mayer RE. Multimedia aids to problem-solving transfer. Int J Educational Res 1999;31:611-23.

7. Schmidt HG. Foundations of problem-based learning: some explanatory notes. Med Educ 1993;27:422-32.

8. Hak T. Group process: the black box of studies on problem-based learning. Acad Med 2000;75:76972.

9. De Grave WS, Boshuizen HPA, Schmidt HG. Problembased learning: cognitive and metacognitive processes during problem analysis. Instructional Sci 1996;24:321-41.

10. Schmidt HG, Moust JHC. Towards a taxonomy of problems used in problem-based curricula. J Excellence Coll Teach 2002;11:57-72.

11. Dolmans D, Snellen-Balendong H. Problem Construction. A Series on Problem-based Medical Education. Maastricht: Maastricht University, Department of Educational Development and Research 2000.

12. Charlin B, Tardif J, Boshuizen HPA. Scripts and medical diagnostic knowledge. Acad Med 2000;75:182-90.

13. Hassebrock F, Prietula MJ. A protocol-based coding scheme for the analysis of medical reasoning. Int J Man-machine Studies 1992;37:613-52.

14. Sweller J, Van Merriënboer JJG, Paas FGWC. Cognitive architecture and instructional design. Educational Psychol Rev 1998;10:251-96.

15. Mayer RE. Multimedia Learning. Cambridge: Cambridge University Press 2001.

16. Raelin JA. Work-based learning. The New Frontier of Management Development. Boston: Prentice Hall 2000;49-65. 


\section{Chapter 3}

\section{The development of shared cognition}

in paediatric residents analysing a patient video versus a paper patient case

Published in Advances in the Health Professions Education. 2009,14(4); 557-565.

Thomas Balslev

Willem de Grave

Arno M. M. Muijtjens

Berit Eika

Albert J. J. A. Scherpbier 


\begin{abstract}
In a previous study, we established that compared to a written case, a video case enhances observable cognitive processes in the verbal interaction in a postgraduate problem-based learning format. In a new study we examined non-observable cognitive processes using a stimulated recall procedure alongside a reanalysis of the data from the first study. We examined the development of shared cognition as reflected in collaborative concept link formation, an approach to connecting a series of concepts related to a particular topic. Eleven paediatric residents were randomly allocated to two groups. After both analysing the same written case vignette, one group watched a video of the case in the vignette and the other group read a written description of the video. Both groups then reanalysed the vignette. After the group sessions, time-logged transcripts were made of the verbal interaction in both groups and all residents individually took part in a stimulated recall procedure. Causal reasoning concept links were labelled as individual or collaborative depending on whether they originated from individual residents or were directly elicited by verbal utterances from others. The video led to a significantly increased frequency ratio (after intervention : before intervention) of collaborative concept links but did not affect the frequency of individual concept links. This novel process approach to chronological registration of concept link formation offered additional evidence that shared cognition by means of co-elaboration of concept formation is stimulated by the use of patient video recordings in small group learning.
\end{abstract}




\section{Introduction}

Diagnosing clinical cases is not always a straightforward task for residents in paediatric training. Residents can improve their clinical reasoning skills by tackling clinical cases where the diagnosis is not given, because such cases mimic the reality of clinical practice (Eva, 2005). It also appears desirable to supplement the number of real patients that residents can see during their training with extra cases, since expertise is largely built through the matching of problems against previously encountered similar problems. Additional cases will enable residents to generate and store in memory an increased number of instance scripts (Schmidt et al., 1990). The extra cases may take the form of patient video cases (PVC), which can present characteristic signs and symptoms, are highly authentic and easy to obtain.

Watching PVCs and discussing them with peers may give learners challenges they might not otherwise have (Westberg and Jason, 1994). When learners interact and exchange ideas in a group, cognitive processes are stimulated. In one of these processes, that of co-elaboration, knowledge is generated when participants in a discussion extend each other's ideas (Slavin, 1996; Dolmans, 1998; Visschers-Pleijers et al., 2006). It can be helpful to learning when learners discern links between a series of concepts related to a particular topic, so-called concept link formation (Novak et al., 1984).

Shared cognition is an essential feature of collaborative learning from clinical encounters (Lebeau 1998). It extends beyond shared knowledge because it also includes the processes and products of clinical reasoning and builds upon individuals' inputs in the collaborative process. Collaborating individuals share cognition when they meaningfully integrate new knowledge into their cognitive structure using a similar frame of reference to interpret this knowledge. (Bossche and Gijselaers, 2006)

There is a paucity of instruments to measure change in individuals' cognitive structures during group interaction (Mohammed S et al. 2000). Hence, we know little about the cognitive processes that occur when learners collaboratively analyse video or paper patient cases. Our previous study of verbal interaction in a group of paediatric residents showed that a PVC induced cognitive processes that were superior to those triggered by paper cases (Balslev et al., 2005). However, the analysis of the cognitive processes in this study was restricted to the recorded verbal interactions in the group.

As the observable verbal interactions alone do not yield enough information to gain in-depth insight into the cognitive processes of shared cognition, we also explored the residents' unexpressed thoughts generated during the group interaction (Barrows, 2000). During verbal interaction in a group only one person is speaking at a time and thus it is only the thoughts of one person that are being voiced at that moment, although presumably the others will be thinking as well. This implies that 
only the tip of the iceberg of participants' individual thought processes is revealed during verbal group interaction.

We expected that concept links would evolve over time depending on collaboration among the residents. In our previous study, we focused on concept links related to causal clinical reasoning. We were specifically interested in the interaction between individual and group as evidenced by the frequency of concept link formation in individual residents as a result of the verbal interaction in the group. The group's shared goal of diagnosing an authentic patient was assumed to be a strong stimulus for co-elaboration by means of collaborative concept link formation, particularly in the group who watched the PVC. In the current paper, we present a reanalysis of the data from the verbal interaction alongside new data from a stimulated recall procedure to explore if a PVC not only generates increased verbal interaction but also enhances shared cognition.

We formulated the following research question: Will supplementing a written case vignette by a PVC as opposed to an equivalent paper case increase shared cognition as measured by the frequency of collaborative concept link formation in the context of collaborative learning about movement disorders in the first three years of paediatric residency?

\section{Methods}

\section{Participants and groups}

Sixteen eligible residents who had completed up to 36 months of paediatric training (mean 21 months) in the same region in Denmark were invited to participate, and 12 residents agreed to participate. The residents were familiar with the format and were comfortable with video recording after their participation in a series of pilot studies with paediatric video cases. The first author acted as tutor in the group sessions. Clusters of matching residents composed on the basis of gender and months of paediatric training were formed. Of each cluster $50 \%$ of the residents were randomly allocated to Group A, and the remaining ones to Group B. One resident did not participate due to illness. Group A consisted of five residents and group B of six residents. A flow-chart (Figure 1 ) summarizes the study process. 


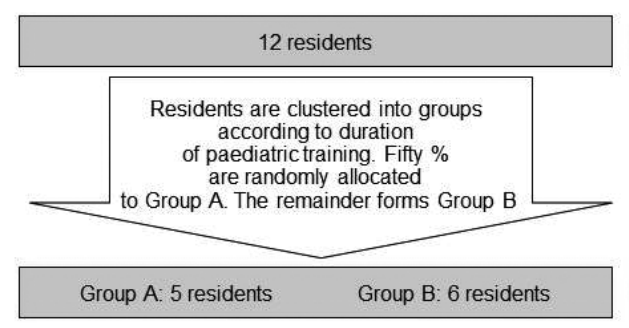

Group A (text)

Group B (video)

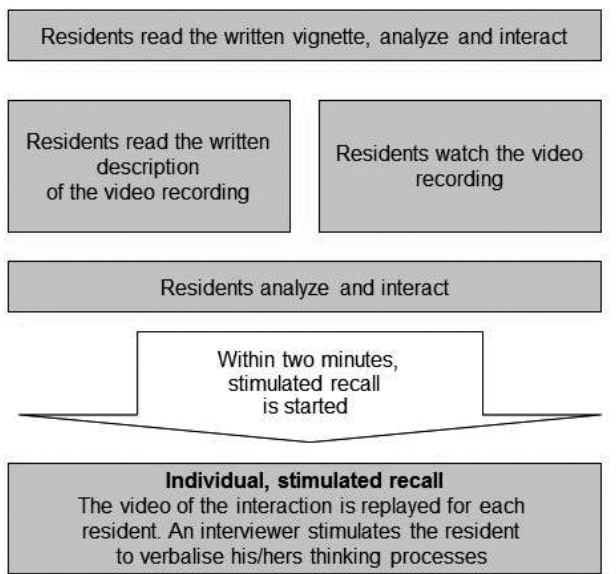

Two time-logged transcripts of the two videorecordings and $5+6$ audiotapes with stimulated recall are made. Causal reasoning concept links are identified

Figure 1 This flow diagram summarizes the one-day study process.

\section{The case}

The case involved a 2-month-old male infant with Sturge-Weber syndrome, a rare congenital disease of which a facial haemangioma is a common symptom. The video showed an infant with a haemangioma on the forehead and an on-going partial motor seizure on the right side of the body. The problem was chosen because most paediatric residents can be expected to be familiar with some of the signs and symptoms while the problem is sufficiently challenging to trigger cognitive processes.

\section{Group sessions}

Both groups analysed the same written vignette of the case and formulated learning objectives after the analysis (Balslev et al., 2005). Next, group B was shown a brief ( 2.5 minutes) video of the patient in the vignette, whilst group $A$ read a written description of the video without actually watching it. The written description listed 
what could be seen in the video without any diagnostic hints. For instance, in the text the terms "jerking" instead of "seizure" and "blue spot" instead of haemangioma; were used. The groups then repeated the analysis. While analysing the case group $B$ could watch the video and group A could read the text more than once. Group A initially read the text silently. Group B watched the video twice. More details on study design and methods have been published elsewhere (Balslev, 2005).

\section{Stimulated recall}

Since it is not possible to register individual residents' thinking processes unobtrusively while the discussion is on-going, we used stimulated recall as a means to tap into these processes.

The stimulated recall procedure involved one-on-one contact of a resident and an interviewer. The interviewers were not blinded. Two of the authors, TB and BE, and four paediatric specialists conducted the interviews. The interviewer introduced him/herself and explained the stimulated recall procedure to the resident. Within two minutes, the video of the group session was played to the resident to trigger recall of the discussion. The residents were invited to recount all that they remembered of what they had been thinking during the discussion and the video was stopped every time a resident remembered something. It was the interviewer's task to stimulate the residents to verbalise their thinking processes. After the actual recall procedure, brief individual interviews were conducted to validate the stimulated recall. The residents from group A were asked "Please describe what it was like to analyse a case from a printed text" and the residents from group B were asked the same question but about a PVC.

\section{Data collection and analysis}

Interaction in the groups was recorded on video and transcribed verbatim. Our aim was to capture concept link formation over time as clinical reasoning processes were on-going in the group and in individual residents. We assumed that concept link formation was highly dependent on collaboration in the group and would emerge chronologically in the time-logged transcription of the verbal interaction in the group and in the stimulated recall. As concept mapping is not adequate for measuring the sharing of concepts, (Mohammed 2000) we used verbal protocol analysis (Ericsson and Simon, 1993) to better capture the cognitive processes. Timelogged transcripts were produced with columns for verbal group interaction and individual stimulated recall. Two raters independently identified causal reasoning concept links in both the verbal interaction and the stimulated recall. To map the processes of concept link formation, we identified the concept links as they occurred chronologically. 
We distinguished two types of causal reasoning concept links (Table 1), both of them easily recognizable in the time logged transcripts. The first type was the collaborative concept link, directly elicited by verbal utterances of other participants, i.e. following within a few seconds, and linked to it in content. One utterance by one of the residents could prompt a number of collaborative concept links in one or more residents at the same time. These could be verbalized, or more frequently, not verbalized. The second type was the individual causal reasoning concept link, produced by individual residents. An example was an utterance by a residence followed by an individual concept link in that particular resident only and not in the other residents. The inter-rater reliability of this categorisation was determined by generalisability analysis and calculation of intra-class correlation coefficients. The two raters analysed four representative data sets, each consisting of six two-minute samples of the discussions in groups $A$ and $B$ before and after reading the text and watching the video, respectively. With two raters, generalisability = Var(sample) / [Var(sample)+ Var(rater $x$ sample)/Nrater] was 0.76 for individual links and 0.94 for collaborative links. Thus two raters were sufficient for the final analysis of our data.

We calculated the mean frequencies of the two types of concept links. Chisquare tests were used to determine the significance of any differences between Groups A and B after and before the intervention.

\section{Results}

A total of 455 causal reasoning concept links were identified, $112(25 \%)$ in the verbal interaction and $343(75 \%)$ during the stimulated recall procedure. This appears to confirm the importance of stimulated recall for in-depth analysis of cognitive processes. The video group showed a significant increase in collaborative concept links but not in individual concept links after watching the video (Table 1). 
Table 1 Differences between Group A (text) and Group B (video) in the number of collaborative and individual concept links. The number of concept links and the after/before intervention ratios of the numbers of links are shown.

\begin{tabular}{|c|c|c|c|c|c|}
\hline Categories & $\begin{array}{c}\text { Before } \\
\text { intervention }\end{array}$ & $\begin{array}{c}\text { After } \\
\text { intervention }\end{array}$ & Total & $\begin{array}{c}\text { Ratio after/before } \\
\text { intervention }\end{array}$ & $\begin{array}{c}\text { Difference } \\
\text { A and } \mathrm{B}^{*}\end{array}$ \\
\hline \multicolumn{6}{|c|}{ Collaborative concept links } \\
\hline$A$ (text) & 60 & 61 & 121 & 1.0 & $\mathrm{Chi}^{2}=7.20$ \\
\hline B (video) & 73 & 138 & 211 & 1.9 & d.f. $=1$ \\
\hline Total & 133 & 199 & 332 & & $P<.01$ \\
\hline \multicolumn{6}{|c|}{ Individual concept links } \\
\hline$A($ text) & 22 & 31 & 53 & 1.4 & $\mathrm{Chi}^{2}=0.02$ \\
\hline B (video) & 30 & 40 & 70 & 1.3 & d.f. $=1$ \\
\hline Total & 52 & 71 & 123 & & N.S. \\
\hline
\end{tabular}

*The final column shows the results of the chi-square analysis of the differences between Group $A$ and Group B. d. f. = degrees of freedom.

In Table 2, sample clauses from the stimulated recall are shown to give an impression of the intense co-elaboration of visual representations (pictorial models) when the group was viewing the video. The shared cognitive processes as assessed by collaborative concept link formation were more intense after the group had watched the video for the second time.

Table 2 Sample clauses from the verbal interaction and the stimulated recall after small group analysis of a Sturge Weber case, illustrating co-elaboration of the pictorial model during the first viewing of the patient video.

\begin{tabular}{ll}
\hline Verbal interaction & Stimulated recall \\
\hline A: He has a convulsion & B: Immediately, I see the haemangioma. \\
C: There is something in the right foot. & B: When I see the jerking I think epileptic seizure. \\
D: The arm too, yes... & D: I see the fine jerking of the foot. \\
E: I see it ... & E: We are looking at a child in a serious condition: he is not \\
& sleeping! \\
C: This is clonic ... & C: I see the little tics of the foot. That is the first thing I see. \\
& Later I see the arm and eyes. I can make a good description of \\
& the seizure. \\
& F: I think the right arm is jerking, and I think of the spot on the \\
& forehead. I think he has secretions or maybe he is hyperventi- \\
lating. & B: I observe him, trying to see what I can see concerning the \\
B: He has a spot over the eye. & seizure. \\
\hline
\end{tabular}

Many residents in group $B$ commented the video while watching it in contrast to the silence observed during the initial reading of the residents of the text group. Individual as well as collaborative concept links were noted during both of the reviews 
of the video. During the silent reading of the text in the text group, causal concept links were scarce or absent.

A small difference was observed in the duration of the problem analysis before and after the interventions: Group A (text): 20/23 minutes, Group B (video): 22/28 minutes.

In the validating interviews some of the residents who had analysed the text said a video recording would have been helpful in analysing the case or creating pictorial models. All the residents who had watched the PVC reported that it showed posture and/or movements better than a text would do.

\section{Discussion}

The results show that adding a PVC to a written vignette enhanced shared cognition through collaborative concept link formation among paediatric residents analysing a case in a small group. We used a novel process approach to chronological registration of concept link formation, which showed that co-elaboration of concept formation is stimulated when residents watch a PVC during small group learning. This information is new and in line with theory of collaborative learning (Dillenbourg, 1999). It seems that, compared to a paper case, a video case is more effective in facilitating the sharing of cognitive processes by learners engaged in team learning.

The observation that many residents commented the video while watching it in contrast to the silence during the initial reading of the residents of the text group may have contributed to an earlier onset of both types of causal concept links formation. This is important to note as the use of video in stead of a text case may help learners to obtain an immediate effect on learning.

The results of this study suggest that the construction of similar pictorial models in the residents' working memories facilitated collaborative concept formation. This is consistent with cognitive theory of multimedia learning (Mayer, 2001). It is worth mentioning that very intense 'brainstorming', leading to collaborative concept link formation was only seen after the group had watched the PVC for the second time. This delay suggests that watching and processing the PVC may have caused cognitive overload (Paas et al., 2003), thereby slowing down concept link formation. Very importantly, the intense collaborative concept link formation after the second viewing suggests that multiple replays of PVCs interspersed with discussion will be beneficial to learners engaged in collaborative analysis of a PVC. Perhaps an approach that involves repeated viewing of a PVC after group co-elaboration can be regarded as a new addition to load-reducing methods for overload scenarios in multimedia instruction as listed by Mayer et al. (Mayer et al., 2003). 
The finding of a higher inter-rater reliability for collaborative links may indicate that identification of individual links is more difficult than delineation of collaborative links in a transcript.

The main strength of this study is that it affords additional insight into collaborative activation of concept links by the use of stimulated recall to tap into residents' thoughts that were not expressed during group discussion.

The fact that more time was spent analysing the case after watching the video than after reading the text suggests that these different media trigger different cognitive processes. The longer duration of the analysis after watching the video is consistent with findings from a previous controlled study in a paediatric clerkship where students spent more time interpreting a video than interpreting a corresponding text (Kamin et al., 2001). However, the present study consisted of a single experiment in a limited number of participants and more research will be needed to establish with greater certainty whether and why analysis of a PVC requires more time than that of an equivalent text.

Some shortcomings of the present study must be kept in mind. Firstly, this is a small study of 11 residents only, analysing a single case. Secondly, the frequency of collaborative concept links is only one facet of shared cognition among others that can also be taken as a measure of shared cognitive processes. The validity and reliability of stimulated recall have not yet been conclusively established. Researchers cannot be sure that all cognitive processes are recalled nor that all cognitive processes are verbalised during stimulated recall. However, the fact that the stimulated recall procedure took place immediately after the verbal interaction in the group and yielded $75 \%$ of the identified concept links, suggests that a substantial part of the concepts formed were indeed picked up. Thirdly, the interviewers were not blinded to the group origin of their residents, a potential bias to the study-design used. We believe, however, that the dependent variables were unlikely to be affected by suggestions of the interviewers. The interviewers were instructed to stimulate the residents to verbalize their thoughts, and not to stimulate verbalization of selective cognitive processes.

This study illuminates shared cognition among junior doctors analysing a video case. Day-to-day clinical practice, however, usually implies teams consisting of medical students, residents and specialists, with different clinical experience and backgrounds. Therefore, new research might focus on interactive approaches involving video cases supporting cognitive processes in a spectrum of learners as well as experienced clinicians, by simulating clinical work in clinical departments. Learning gains may be greater for some learners than for others (Clark 2001). 


\section{References}

Balslev, T., de Grave, W.S., Muijtjens A.M.M., Scherpbier, A.J.J.A. (2005) Comparison of text and video cases in a postgraduate pbl-format with respect to the cognitive and metacognitive processes induced. Medical Education 39: 1086-1092.

Barrows, H.S. (2000) Stimulated recall (personalized assessment of clinical reasoning) Southern Illinois University, School of Medicine, Illinois

Bossche PV den. Gijselaers WH. (2006) Social and Cognitive Factors Driving Teamwork in Collaborative Learning Environments. Team Learning Beliefs and Behaviours. Small Group Research 37; 490-517

Clark, RE, Craig, TB. (2001) What about multimedia effects on learning? In: Clark RE, Learning from media. Arguments, analysis and evidence. Information Age Publishing, Greenwich, Connecticut pp 89-101

Dillenbourg, P. (1999) What do you mean by "collaborative learning"? In: Dillenbourg P (ed), Collaborative learning: Cognitive and computational approaches, pp 1-19. Oxford: Elsevier.

Dolmans, D.H.J.M. (1998). Motivational and cognitive processes influencing tutorial groups. Academic Medicine 73: 22-24.

Ericsson, K, Simon H.A (1993) Protocol analysis: Verbal reports as data. Cambridge, MA: The MIT Press

Eva, K.W. (2005). What every teacher needs to know about clinical reasoning. Medical Education 39: 98106

Kamin, C.S., O'Sullivan, P.S., Younger, M., Derterding, R. (2001). Measuring critical thinking in problembased learning discourse. Teaching and Learning in Medicine 13: 27-35.

Lebeau, RB. (1998). Cognitive tools in a clinical encounter in medicine: supporting empathy and expertise in distributed systems. Educational Psychology Review 10: 3-24.

Mayer, R.E. (2001). Multimedia Learning. Cambridge; Cambridge University Press.

Mayer, R.E.; Moreno, R. (2003). Nine ways to reduce cognitive load in multimedia learning. Educational psychologist 38(1): 43-52

Mohammed, S, Klimoski, R, Rentsch J. (2000) The measurement of team mental models: we have no shared schema. Organizational Research Methods 3:123-165.

Novak, J.D., Gowin D.B. (1984) Learning how to learn, pp 15-54. Cambridge: Cambridge University Press.

Paas, F., Renkl, A., Sweller, J. (2003). Cognitive load theory and instructional design: recent developments. Educational psychologist 38(1), pp. 1-4

Schmidt, H.G., Norman, G.R., Boshuizen, H.P.A. (1990). A cognitive perspective on medical expertise: Theory and implications. Academic Medicine 65: 611-621.

Slavin, R.E. (1996). Research on cooperative learning and achievement: what we know and what we need to know. Contemporary Educational Psychology 21: 43-69.

Visschers-Pleijers AJS, Dolmans DHJM, de Grave W.S, Wolfhagen IHAP, Jacobs JA, van der Vleuten CPM. (2006). Student perceptions about the characteristics of an effective discussion during the reporting phase in problem-based learning. Medical Education 40: 924-931

Westberg J, Jason H. (1994). Teaching creativity with video. New York: Springer Publishing Company. 

Chapter 4

Enhancing diagnostic accuracy among non-experts by use of video-cases

Published in Pediatrics, 2010; 125(3): e570-576.

Balslev T

de Grave W

Muijtjens A

Scherpbier A 


\begin{abstract}
Background

Teaching and learning in clinical settings may improve diagnostic accuracy, but are often hampered by heavy service demands. New and effective approaches are needed to stimulate the development of diagnostic accuracy in clinical settings such as morning hand-over reports. Interactive use of patient video cases may stimulate diagnostic accuracy but there is limited knowledge on the most efficient use of these videos.
\end{abstract}

\title{
Objective
}

To determine if the diagnostic accuracy of non-experts will improve in selected learning environments using patient video cases.

\section{Methods}

We designed a stepwise teamwork learning approach: 1) text-based patient presentation; 2) first review of a patient video case; 3) small group discussion; 4) second review of a patient video case; 5) large group discussion and finally listening to think-aloud modelling by a content expert. Four paediatric neurology video cases were analysed by 44 physicians. After each step, the diagnostic accuracy was assessed by a questionnaire with open ended questions measuring the frequency of relevant diagnoses and clinical diagnostic reasoning processes.

\section{Results}

The first review of the video-case was followed by a large number of relevant clinical diagnostic reasoning processes. Small group discussions and listening to a thinkaloud procedure by an expert were particularly effective in increasing diagnostic accuracy of the non-experts.

\section{Conclusion}

The diagnostic accuracy of non-experts was clearly enhanced by the interaction in small group discussions and subsequent listening to a think-aloud procedure by a content expert. Learning by video-cases in clinical settings will thus be improved by the interactive participation of junior as well as senior clinicians. Such an environment, a 'virtual examination room', may be introduced at grand rounds, case conferences or morning rounds to stimulate the development of diagnostic accuracy in non-experts. 


\section{Introduction}

Development of clinical diagnostic reasoning skills surely happens when residents encounter patients. Clinical teachers can facilitate this development by using a number of specific, practical strategies. ${ }^{1-3}$ Among the known strategies are; going to the bedside, examination room or medical record; asking for and modelling summary statements. ${ }^{1}$

Training sessions and apprenticeship learning is, however, often hampered by reduced hours or heavy service demands. ${ }^{4-5}$ In addition, some diagnoses may be periodic, paroxysmal or very rare, making joint observation by clinical teachers and learners difficult.

Recent research on the use of patient video cases (PVC) in paediatric training provides compelling evidence that video-cases may indeed stimulate desirable cognitive processes, ${ }^{6}$ also including shared cognition, i.e. collaborating individuals meaningfully integrating new knowledge using similar frames of reference to interpret this knowledge. ${ }^{7}$ Very importantly, learning from media will depend on underlying cognitive knowledge construction processes generated by the interactive processes as well as the media itself. ${ }^{8}$

Hence, a PVC and the accompanying interactive analysis can support learning. Expanding our knowledge on this topic would be highly relevant, as environments that will permit interactive analysis of PVCs already exist in most clinical departments. These may take the form of meetings or grand rounds where staff physicians as well as fellows, residents and medical students participate and can discuss clinical cases.

On this background, we found it interesting to identify an interactive teamwork model with review of a PVC in a 'virtual examination room'. In this 'virtual examination room' professionals would interact and not be moderated or restrained by the presence of a real patient and relatives.

We wished to identify strategies for use in clinical settings particularly focused on enhancing diagnostic accuracy among the younger clinicians, i.e. non-experts. We thus planned to investigate the differences between non-experts and experts. We hypothesised that interaction with more experienced participants in the groups or listening to a think-aloud procedure by a content expert would be effective in increasing diagnostic accuracy among the non-experts.

The research questions were: How does the level of diagnostic accuracy evolve during an interactive teamwork approach using PVCs? Does the level of diagnostic accuracy differ between non-experts and experts? 


\section{Methods}

We developed a teamwork approach using a repeated measure design. We included small groups (buzz groups) ${ }^{9}$ to allow for interaction with stimulation of cognitive processes. ${ }^{10,11}$ We also included a large group discussion, as large groups hold more knowledge, and benefit from the diversity of expertise among its members. ${ }^{12} \mathrm{~A}$ large group discussion may thus lead to more complete clinical reasoning. ${ }^{13}$ Listening to think-aloud modelling by a content expert analysing the PVC was also included. This procedure is a known approach to help students build a conceptual model. ${ }^{14}$ The value of expert analysis accompanying a PVC has also been highlighted in a recent study. ${ }^{15}$

To maximise relevance in clinical settings a series of pilot studies were performed at rounds in an academic paediatric department. We learned that the steps in the learning process were intricately entangled with a clear sequential pattern. We therefore decided to test the hypotheses in a sequential study.

As measures for diagnostic accuracy ${ }^{16}$ we studied the frequency of relevant diagnoses. Moreover, we considered the associated relevant clinical reasoning processes. We hypothesised that the interaction in the groups or listening to the expert might result in improved diagnostic accuracy in the non-experts. ${ }^{1}$

\section{Subjects}

To obtain a sufficient number of participants the study was conducted during a 2hour postgraduate course session in paediatric neurology. In Denmark, paediatric neurology is not recognized as a separate subspecialty and posts in paediatric neurology are held by paediatricians with additional neurology training or by paediatricians with a special interest in this field. Twenty non-experts (residents, fellows or paediatricians with $<3$ years of experience in paediatric neurology), and 24 experts (paediatricians with $>3$ years of experience in paediatric neurology) were enrolled in the study. Participants were informed about potential individual learning benefits of the study, and that response to questionnaires was anonymous. Informed consent was obtained and all invited accepted to participate.

\section{Materials}

Four PVCs were selected. The first case was a newborn infant with abrupt, jerking movements vanishing upon awakening (benign sleep myoclonus). The second case was a 3-month-old girl, lying on her back with distal movements of the limbs and an alert look (spinal muscular atrophy). The third case was a 9-month-old girl sitting in her high chair with sudden vocalisation, head turning and tonic extensor posturing of the facial arm (frontal lobe epileptic seizure). The fourth case was a 14-year-old 
boy with chronic, continuous jerky movements and atrophy of the left arm (epilepsia partialis continua). In all PVCs careful observation of movements was crucial to arrive at an accurate diagnosis. The cases were selected, so that most of the experts were expected to appreciate the main findings and to recognize a probable diagnosis. The non-experts, however, were expected to have diagnostic difficulties. The videos were digital MPEG-1 files of good quality played by Windows Media Player and projected onto a large screen clearly visible to all participants. The videos lasted 30-90 seconds. The cases were selected from different areas of paediatric neurology to minimise transfer of knowledge.

\section{Procedure}

On the day of the experiment, participants were informed verbally and in writing. Twelve groups of at least members with uneven levels of expertise were formed, i.e. each group included at least one senior paediatrician (expert) and a resident or a junior paediatrician (non-experts). All participants simultaneously analysed the first PVC and then proceeded to the second, third and fourth. For each PVC the participants:

- read a brief clinical vignette ( example in Appendix A);

- watched the PVC (no discussion);

- discussed the PVC in small groups of three or more participants;

- watched the PVC again (no discussion);

- discussed the PVC in one large group;

- watched the PVC again and listened to a think-aloud procedure by a content expert paediatric neurologist.

Immediately following each step all participants simultaneously completed individual questionnaires. Instructions on completing the questionnaire were given orally and in writing. The next step did not start until all participants had completed the previous step. Sample questions are shown in Appendix A.

Each case, including filling in the corresponding part of the questionnaire, was completed in 25 minutes. The study was approved by the local ethics committee.

\section{Analysis}

Two content expert paediatric neurologists blinded to the study and the identity of the participants constructed lists of the main relevant diagnoses and relevant clinical reasoning processes for each PVC. The lists included literally identical diagnoses and clinical reasoning processes, or included diagnoses or clinical reasoning processes in a paraphrased form, suggesting that the videos would elicit similar cognitive processes in other experts. The lists were collated and used as the standard by a third content expert when coding the new diagnoses and new clinical 
reasoning processes for each participant as relevant or less relevant. The frequency of new diagnoses and new clinical reasoning processes formed for each of the six steps across the four PVCs were summarised. In the first PVC showing a newborn with benign sleep myoclonus, an example of a relevant diagnosis could be: "This infant has benign sleep myoclonus". An example of relevant clinical diagnostic reasoning process could be: "This is benign sleep myoclonus, as the jerking disappears when she wakes up!" In the same case, a less relevant diagnosis with a less relevant clinical diagnostic reasoning process would be: "This is a seizure. The jerking may be caused by physical abuse."

To obtain a measure of new diagnoses and new clinical diagnostic clinical reasoning processes for each participant and step, we calculated the average frequency per step for each participant per PVC. The average frequencies were calculated separately for the relevant and the less relevant diagnoses and clinical reasoning processes in order to explore the step-wise learning process. In addition to relevant new diagnoses and clinical reasoning processes the average frequencies were calculated for non-experts and experts in order to investigate the inter-group differences across the six steps. To indicate the variability in the frequency, 95\% confidence intervals $(\mathrm{Cl})$ were calculated on the basis of a normal approximation of the Poisson distribution of the frequencies:

Confidence Interval: $\hat{\mu}+\frac{1}{2} u_{\alpha}^{2} \pm u_{\alpha} \sqrt{\hat{\mu}+\frac{1}{4} u_{\alpha}^{2}}$

where $\hat{\mu}$ is the observed frequency and $u_{\alpha}$ is the normal deviate associated with the two-sided significance level $\alpha$ (for the $95 \% \mathrm{Cl} \alpha=0.05$ and $u_{\alpha}=1.96$ ).

The inter-group differences (non-experts versus experts) were tested for statistical significance by applying a Chi-square test to the frequencies at each step. Bonferroni corrected $p$-values were obtained by multiplying the Chi-square $p$-value by the number of comparisons equal to six for inter-group comparisons.

\section{Results}

An average rate of 0.53 new diagnoses and 1.32 new clinical reasoning processes were formed at each step per participant. Table 1 shows sample diagnoses and clinical reasoning processes for an expert and a non-expert, respectively interacting in a small group.

The frequencies of diagnoses and clinical diagnostic reasoning processes are shown in Figure 1. The frequencies of new relevant diagnoses were fairly stable across the steps (Figure 1, upper panel), whereas new less relevant diagnoses de- 


\section{creased steadily with each step. This suggests that learning occurred throughout the experiment.}

Table 1 Improvement of diagnostic accuracy in an expert and a non-expert participant with a case of epilepsia partialis continua.

\begin{tabular}{|c|c|c|c|c|c|c|c|}
\hline \multirow[b]{2}{*}{$\begin{array}{l}\text { m } \\
\frac{\mathrm{x}}{0} \\
\frac{\mathrm{D}}{7}\end{array}$} & \multirow[b]{2}{*}{$\begin{array}{l}\text { Most } \\
\text { probable } \\
\text { diagnosis }\end{array}$} & \multicolumn{2}{|c|}{$\begin{array}{c}\text { Reading text Watching } \\
\text { video }\end{array}$} & \multirow{2}{*}{$\begin{array}{l}\text { Small group } \\
\text { Focal, simple } \\
\text { epilepsy }\end{array}$} & \multirow{2}{*}{$\begin{array}{l}\text { Watching video } \\
\text { again } \\
\text { Focal, simple } \\
\text { status epilepticus } \\
\text { (epilepsia parti- } \\
\text { alis congenita) }\end{array}$} & \multirow{2}{*}{$\begin{array}{l}\text { Large group } \\
\text { Epilepsia partialis } \\
\text { s congenita }\end{array}$} & \multirow{2}{*}{$\begin{array}{l}\text { Listening to think-aloud from } \\
\text { content expert } \\
\text { Epilepsia partialis congenita }\end{array}$} \\
\hline & & $\begin{array}{l}\text { Generalized } \\
\text { epilepsy }\end{array}$ & $\begin{array}{l}\text { Focal, simple } \\
\text { epilepsy }\end{array}$ & & & & \\
\hline \multirow{3}{*}{ 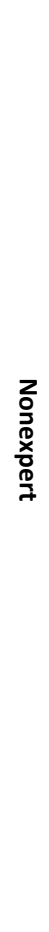 } & $\begin{array}{l}\text { Clinical } \\
\text { reasoning } \\
\text { processes }\end{array}$ & $\begin{array}{l}\text { Side effect } \\
\text { of drug? }\end{array}$ & $\begin{array}{l}\text { Under- } \\
\text { treatment? If } \\
\text { progressive, } \\
\text { consider } \\
\text { Rasmussen } \\
\text { encephalopa- } \\
\text { thy. Pseu- } \\
\text { doepileptic } \\
\text { seizure is } \\
\text { unlikely }\end{array}$ & $\begin{array}{l}\text { Under- } \\
\text { treatment? If } \\
\text { progressive, } \\
\text { consider Ras- } \\
\text { mussen en- } \\
\text { cephalopathy. } \\
\text { Pseudoepilep- } \\
\text { tic seizure is } \\
\text { unlikely }\end{array}$ & $\begin{array}{l}\text { Hemiatrophy (ie, } \\
\text { right sided } \\
\text { cerebral affec- } \\
\text { tion); hemipare- } \\
\text { sis, epilepsy }\end{array}$ & $\begin{array}{l}\text { Rasmussen en- } \\
\text { cephalopathy or } \\
\text { congenital brain } \\
\text { malformation; } \\
\text { hemiparesis; } \\
\text { epilepsy }\end{array}$ & $\begin{array}{l}\text { Rasmussen encephalopathy or } \\
\text { congenital brain malforma- } \\
\text { tion. Jerking persists at night, } \\
\text { which excludes movement } \\
\text { disorder/tics. Hemiatrophy } \\
\text { suggests congenital defect, no } \\
\text { hemiatrophy may suggest } \\
\text { Rasmussen encephalopathy. }\end{array}$ \\
\hline & $\begin{array}{l}\text { Most } \\
\text { probable } \\
\text { diagnosis }\end{array}$ & $\begin{array}{l}\text { I do not } \\
\text { know }\end{array}$ & $\begin{array}{l}\text { Choreiform } \\
\text { dystonia }\end{array}$ & $\begin{array}{l}\text { Chronic motor } \\
\text { tics }\end{array}$ & - & $\begin{array}{l}\text { Myoclonus or } \\
\text { pseudoepilepsy }\end{array}$ & Epilepsia partialis congenita \\
\hline & $\begin{array}{l}\text { Clinical } \\
\text { reasoning } \\
\text { processes }\end{array}$ & - & - & $\begin{array}{l}\text { Partial status } \\
\text { epilepticus; too } \\
\text { erratic to be a } \\
\text { tic. }\end{array}$ & $\begin{array}{l}\text { Face is not } \\
\text { involved and left } \\
\text { arm is weak. }\end{array}$ & $\begin{array}{l}\text { Partial status } \\
\text { epilepticus? }\end{array}$ & $\begin{array}{l}\text { Not pseudoseizure. Atrophy } \\
\text { on left side? Progressive } \\
\text { pathology? Functional im- } \\
\text { pairment on left side; clonic } \\
\text { brisk contraction of muscle, } \\
\text { repetitive; epilepsia partialis } \\
\text { congenital (progressive); } \\
\text { atrophy of arm and shoulder; } \\
\text { tumour or Rasmussen en- } \\
\text { cephalopathy. Look for pro- } \\
\text { gressive hemiatrophy on MRI } \\
\text { scans. }\end{array}$ \\
\hline $\begin{array}{l}\text { Aut } \\
\text { mer } \\
\text { per } \\
\text { acc }\end{array}$ & $\begin{array}{l}\text { hors' com- } \\
\text { tt on nonex- } \\
\text { 's diagnostic } \\
\text { uracy }\end{array}$ & $\begin{array}{l}\text { The nonex- } \\
\text { perts does } \\
\text { cnot have a } \\
\text { clue }\end{array}$ & $\begin{array}{l}\text { A less-relevant } \\
\text { diagnosis } \\
\text { appears }\end{array}$ & $\begin{array}{l}\text { Another less- } \\
\text { relevant diag- } \\
\text { nosis appears }\end{array}$ & $\begin{array}{l}\text { No likely diagno- } \\
\text { sis is given. More } \\
\text { information is } \\
\text { being picked up. }\end{array}$ & $\begin{array}{l}\text { Two more less- } \\
\text { likely diagnoses } \\
\text { appear. A relevant } \\
\text { diagnosis is in } \\
\text { abeyance. }\end{array}$ & $\begin{array}{l}\text { The diagnosis is relevant and } \\
\text { correct. The clinical reasoning } \\
\text { processes are all relevant. }\end{array}$ \\
\hline
\end{tabular}

The 2 participants were collaborating in a small group 

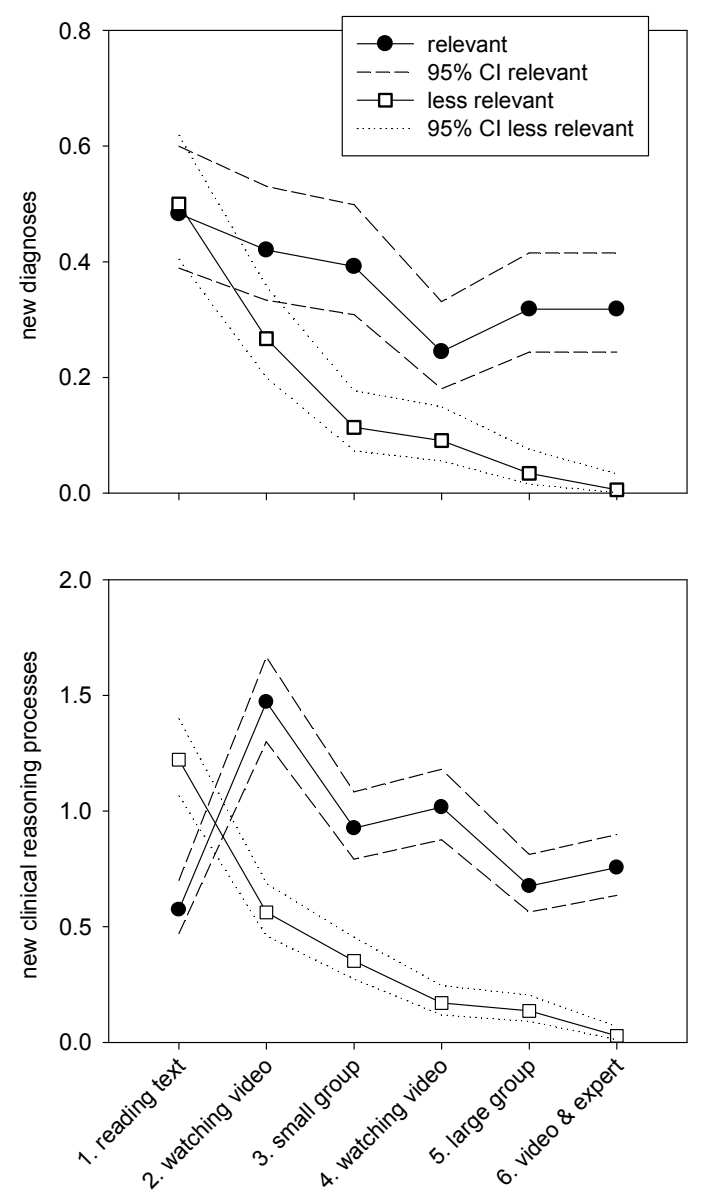

Figure 1 Diagnostic accuracy measured by emerging new diagnoses (upper panel), and new clinical reasoning processes (lower panel) per participant and per PVC in each step.

The new clinical diagnostic reasoning processes were most frequent at first review of the PVC, suggesting that using PVCs strongly stimulates diagnostic clinical reasoning processes (Figure 1, lower panel). After the burst at first review, the frequency of new clinical diagnostic reasoning processes remained high during the following steps. A decreasing frequency of less relevant clinical diagnostic reasoning processes was noted with subsequent steps, indicating intense focus on the cognitive processes. 

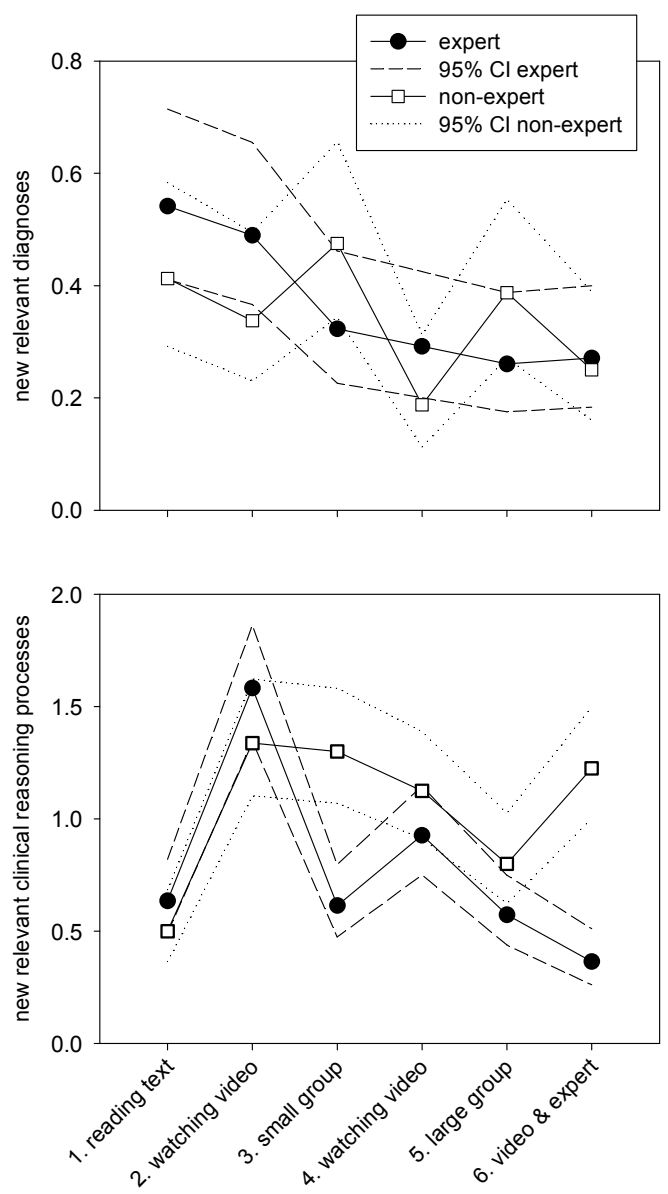

Figure 2 Differences between diagnostic accuracy in experts and non-experts measured by emerging new relevant diagnoses (upper panel), and new relevant clinical reasoning processes (lower panel) per participant and per PVC in each step of the learning process.

The frequencies of relevant new diagnoses and relevant new clinical diagnostic reasoning processes for the groups of experts and non-experts respectively are presented in Figure 2. Relevant new diagnoses were observed at each step suggesting that experts as well as non-experts increased their diagnostic accuracy. No statistical differences were noted across experts and non-experts for the new relevant diagnoses. Remarkably, the frequency of new relevant clinical diagnostic reasoning processes was significantly higher among non-experts at step three, at small group discussion and at step six as well as at the think-aloud procedure by the content expert. (Bonferroni corrected $p$-values: $p<0.0001$ ) 


\section{Discussion}

This study of clinician's learning with PVCs in a 'virtual examination room' shows that the frequency of new relevant diagnoses was fairly stable with each new step. At the same time, less relevant diagnoses decreased steadily (Figure 1, upper panel). It appears that an increase in diagnostic accuracy occurred during steps 2-6, all contributing to the learning of the participants.

A large number of new clinical diagnostic reasoning processes were noted with the first review of the PVC demonstrating the powerful stimulation of cognitive processes in experts as well as in non-experts (Figures 1 and 2, lower panels). Subsequent discussion in small groups generated more new relevant clinical diagnostic reasoning processes (Figure 1, lower panel), confirming that crucial cognitive processes followed the interaction among participants. After the second review of the PVC (step 4), new relevant clinical reasoning processes also appeared, suggesting that the interaction helped the participants to reason more during the second review. A decreasing frequency of less relevant clinical diagnostic reasoning processes was noted with steps 2-6, indicating a desirable focusing of cognitive processes (Figure 1, lower panel).

Studies on PVCs and diagnostic accuracy are scarce. Diagnostic accuracy of middle ear effusion by pneumatic otoscopy has, however, been shown to be improved with PVCs compared to static imaging. ${ }^{17}$

The study of the differential effects showed that the frequency of new relevant clinical diagnostic reasoning processes was significantly higher among non-experts compared with experts at the small group discussion (step 3) and at the think-aloud procedure by a content expert (step 6). This suggests that increase in diagnostic accuracy occurred in the non-experts as a result of the interaction in the small group and of listening to the experts' think-aloud procedure. (Figure 2, lower panel) This suggests that simulated teamwork models with PVCs including small group discussions and/or think-aloud procedures by an expert may improve the diagnostic accuracy of non-experts.

The example in table 1 demonstrates how a relevant diagnosis may be held in abeyance by the non-expert, and later adopted as the correct diagnosis after listening to the content expert. Both of these reactions are well known psychological responses to new, contradictory information. ${ }^{18}$

The main strength of this paper was the emphasis on learning outcomes and concomitant cognitive processes in experts and non-experts, respectively during a sequence of planned learning steps. We were able to demonstrate that small group discussions and listening to a think-aloud procedure by an expert was particularly effective in increasing clinical diagnostic accuracy among non-experts compared to experts. Diagnostic accuracy may thus be enhanced if trainees as well as experienced clinicians participate in small groups analyzing PVCs simulating clinical work. 
The study underlines the value for learning by modelling a think-aloud procedure - a cornerstone in the cognitive apprenticeship model. ${ }^{1,13}$

This study was limited to short term variables for learning and diagnostic clinical reasoning processes. It is likely that the higher frequency of clinical diagnostic reasoning processes observed in non-experts might motivate literature studies and further learning.

The participants of this study were not randomly selected and it could be argued that this study was performed among a group of highly motivated physicians. We do not believe that this will prevent transfer of the results to every day clinical settings, as we advocate the selection of the procedures most likely to improve learning of clinical diagnostic reasoning only. Moreover, it was not the intent of this study to evaluate the performance of the experts as diagnosticians or as clinical teachers.

In a number of clinical settings where experts and non-experts are present simultaneously, educational strategies with PVCs may be adapted to improve learning of clinical diagnostic reasoning i.e. grand rounds, meetings and morning reports where staff physicians as well as fellows, residents and medical students participate and can discuss clinical cases.

Small group discussion and subsequent think-aloud procedure by a content expert appears to be particularly valuable. The latter finding provides compelling evidence that attendance by senior team members is of crucial importance.

In conclusion, it seems that the use of PVCs with small group discussions and a content expert think-aloud procedure in a 'virtual examination room' can be a valuable supplement to traditional training in clinical settings. In particular, we recommend this approach in specialties where observation of movements or behaviour is important in clinical diagnostic reasoning. The sessions lasting a few minutes may be repeated with new PVCs at regular intervals. Modern methods of recording and storage allow the establishment and maintenance of an easily accessible library with high-quality, digital PVCs for different learning purposes.

\section{Appendix}

Sample questions from questionnaire

\section{Case 4, Step 1}

This 14-year-old boy started treatment with oxcarbazepine after 2 generalized tonic-clonic seizures. Now he is referred because of persistent, jerky movements of his left arm. The jerking gets worse and persists at night.

Please respond to the questions after you have read the text. 
(1) At this stage, I think the most likely diagnosis is:

(2) At this stage, my clinical reasoning is like this:

Case 4, Step 2

Please respond to the questions after you have seen the video.

(1) At this stage, I think the most likely diagnosis is:

(2) At this stage, my clinical reasoning is like this:

\section{Acknowledgments}

The staff members in the Department of Paediatrics, Aarhus University Hospital, are thanked for their participation in a number of pilot studies during the early stages of this research project. The participants in the postgraduate course in pediatric neurology are thanked for their active participation in the final study. Consultants Stense Farholt and Uffe S. Hansen, Aarhus University Hospital, are thanked for listing diagnoses and clinical reasoning processes. Consultants Uffe S. Hansen and Annette Haagerup, Aarhus University Hospital, are thanked for valuable feedback on this article. We also thank consultant Robert Smith (Newcastle, Australia) for critical reading and correcting of the English manuscript. 


\section{References}

1. Bowen JL. Educational strategies to promote clinical diagnostic reasoning. New England Journal of Medicine. 2006;355,2217-25

2. Eva KW. What every teacher needs to know about clinical reasoning. Medical Teacher. 2004;39;98106

3. Albanese M. Crafting the lifelong learner: why, what and how. Medical Education. 2006;40:288-90

4. Spargo PM. UK Anaesthetic training and the low of unintended consequences. Cause for concern? Anaesthesia. 2005;60:319-22

5. Derrick S, Badger B, Chandler J, Nokes T, Winch G. The training service continuum: exploring the training/service balance of senior house officer activities. Medical Education. 2006;40:355-62

6. Balslev T, de Grave WS, Muijtjens AMM, Scherpbier AJJA. Comparison of text and video cases in a postgraduate problem-based learning format. Medical Education. 2005;39:1086-92

7. Balslev T, de Grave WS, Muijtjens AMM, Eika B, Scherpbier, AJJA. The development of shared cognition in paediatric residents analysing a patient video versus a paper patient case. Adv in Health Sci Educ. 2008; Oct 10 (epub ahead of print)

8. Clark RE, Craig TG. What about multimedia effects on learning? In: Clark RE, ed. Learning from media. Arguments, analysis and evidence. Greenwich, Connecticut: Information Age Publishing, 2001:89-101

9. Jaques D. ABC of learning and teaching in medicine. BMJ. 2003;326;492-4

10. Slavin RE. Research on cooperative learning and achievement: what we know and what we need to know. Contemporary Educational Psychology. 1996;21,43-69.

11. Dolmans DHJM. Motivational and cognitive processes influencing tutorial groups. Academic Medicine. 1998;73:22-4

12. Bielaczyk K, Collins A. Learning communities in the classroom: A reconceptualization of educational practice. In: Reigeluth CM, ed. Instructional-design theories and models: A new paradigm of instructional theory. Mahvah, NJ: Lawrence Erlbaum Associates; 1999: 269-292

13. Xun GE, Land SM. A conceptual framework for scaffolding III-structured problem-solving processes using question prompts and peer interactions. Educational technology research and development. 2004;52(2):5-22

14. Collins A. Cognitive apprenticeship. In: Sawyer RK, ed. The Cambridge handbook of the learning sciences. Cambridge, Cambridge University Press, 2006:47-60

15. Bye AME, Connolly AM, Netherton C, Looker P, Burgess A, Lonergan A. A triangulated approach to the assessment of teaching in childhood epilepsy. Medical Teacher. 2007; 29:255-57

16. Mamede S, Schmidt HG, Rikers RMJ, Penaforte JC, Coelho-Filho JM. Breaking down automaticity: case ambiguity and the shift to reflective approaches in clinical reasoning. Medical Education. 2007;41:1185-92

17. Jones WS, Kaleida PH. How helpful is pneumatic otoscopy in improving diagnostic accuracy? Pediatrics. 2003;112:510-13

18. Chinn CA, Brewer WF. The role of anomalous data in knowledge acquisition: A theoretical framework and implications for science instruction. Review of Educational Research. 1993;63(1):1-49 



\section{Chapter 5 \\ Visual expertise in pediatric neurology}

Accepted by The European Journal of Paediatric Neurology, 2011;

doi:10.1016/j.ejpn.2011.07.004

Thomas Balslev

Halszka Jarodzka

Kenneth Holmqvist

Willem de Grave

Arno Muijtjens

Berit Eika

Jeroen van Merriënboer

Albert JJA Scherpbier 


\begin{abstract}
Background

Visual expertise relies on perceptive as well as cognitive processes. At present, knowledge of these processes when diagnosing clinical cases mainly stems from studies with still pictures. In contrast, patient video cases constitute a dynamic diagnostic challenge that may simulate seeing and diagnosing a patient in person.
\end{abstract}

\title{
Aims
}

This study investigates visual attention and the concomitant cognitive processes of clinicians diagnosing authentic pediatric video cases.

\section{Methods}

A total of 43 clinicians with varying levels of expertise took part in this crosssectional study. They diagnosed four brief video recordings of children: two with seizures and two with disorders imitating seizures. We used eye tracking to investigate time looking at relevant areas in the video cases and a concurrent think-aloud procedure to explore the associated clinical reasoning processes.

\section{Results}

More experienced clinicians were more accurate in visual diagnosis and spent more of their time looking at relevant areas. At the same time, they explored data less, yet they built and evaluated more diagnostic hypotheses.

\section{Conclusions}

Clinicians of varying expertise analyse patient video cases differently. Clinical teachers should take these differences into account when optimising educational formats with patient video cases. 


\section{Introduction}

Neurologic education is going through a period of change and uncertainty. Economic limitations and increasing service demands often seriously limit learners' exposure to and hence opportunities to learn about clinical pictures and principles in adult as well as in child neurology. ${ }^{1,2}$ Therefore, there is a need for neurological education research to clarify approaches to effective, efficient and lifelong learning. ${ }^{3}$ As diagnostic evaluation of patients involves visual examination and conceptual understanding of classification systems, ${ }^{4}$ it is pertinent for this research to elucidate what clinicians do and what they think when they make a diagnosis based on visual observations.

For experienced physicians, making a visual diagnosis may be a rapid and unconscious pattern recognition process involving effortless connecting of clinical information to knowledge stored in long term memory. ${ }^{5,6}$ Pattern recognition may also be supplemented by a more analytic approach requiring conscious analysis of clinical information.

In visual domains, the physician searches the stimulus visually (perception) and attempts to render an interpretation (cognition). ${ }^{7,8}$ Studies on visual expertise in medical still-image diagnosis show that experienced physicians compared to residents or novices are faster diagnosticians, raise more hypotheses and are more successful in connecting perceptual and cognitive processing. ${ }^{7}$

Next to meeting and diagnosing a patient in real life, diagnosing a patient video case (PVC) may be the most realistic situation with high authenticity. ${ }^{9}$ Video recordings of patients often aid in diagnosis ${ }^{4}$, may demonstrate novel aspects of semiology of epileptic or nonepileptic events ${ }^{11,12}$ and can be used in telemedicine. ${ }^{10}$ PVCs may benefit learning, ${ }^{13,14}$ and in neurology they are recognized as essential teaching tools. ${ }^{4,15}$ Although PVCs may accelerate learning, we know too little about the associated perceptive and cognitive processes of clinicians. This knowledge would be essential for the development of new video-based approaches to learning, particularly in visual domains.

In this study of clinicians' perceptive and cognitive processes, we hypothesized that more experienced clinicians would be diagnostically more accurate and would use more of their time visually inspecting relevant areas. Likewise, concerning the cognitive processes, we hypothesized that more experienced clinicians would explore data less and would build and evaluate more diagnostic hypotheses compared to their more inexperienced colleagues. 


\section{Materials and methods}

We enrolled 43 participants from the Northern Region of Denmark and the Medical School at Aarhus University. (Table 1) To reduce bias, invitations were given both verbally and in writing to all eligible participants in the area. The experience of a participant, measured as a continuous variable in years of paediatric training after graduation, was used as an indicator of expertise.

Table 1 Demographic data of the 43 participants

\begin{tabular}{lccc}
\hline & $\begin{array}{c}\text { Medical students } \\
\text { within } 18 \text { months of } \\
\text { graduation }\end{array}$ & Residents & Experts \\
\hline Number of participants (eligible participants) & $15(150)$ & $16(50)$ & $12(16)$ \\
Average age (range), years & $26.8(25-30)$ & $32.8(25-42)$ & $50.8(37-64)$ \\
Number of females (\%) & $9(60)$ & $12(75)$ & $4(33)$ \\
Duration of postgraduate pediatric experience, years & 0 & $1.5(0.5-3.0)$ & $18.3(5-32)$ \\
\hline
\end{tabular}

The study took place during September 2009 at the Centre for Medical Education (MEDU), Aarhus University, Aarhus, Denmark. Participants were compensated with a ten-Euro movie ticket voucher.

We used authentic PVCs to stimulate and examine visual search patterns along with the associated cognitive processes. The material consisted of four PVCs in an audio video interleave format (-avi), (Table 2) and each participant watched all of the PVC's. The experiment consisted of individual sessions of approximately 30 minutes long. A presentation of the patient's age, gender and a few words indicating the nature of their problem was given via on-screen text prior to each PVC. The PVCs were looped automatically. Each PVC lasted 26-49 seconds and depicted a single infant. The PVCs included conditions sufficiently difficult to challenge the students and the residents, yet common and typical enough that an expert would be expected to reach a correct diagnosis.

Attention to the dynamic features of the movements and their change over time was crucial for diagnosing cases. The original sound, which was not necessary to reach a correct diagnosis, was removed from the PVCs to prevent interference with the verbal report. 
Table 2 Four PVCs. Representative screen dump pictures from the PVCs. Coding systems for diagnostic accuracy. Overview of areas of interest (AOI) in the patient video cases.

\begin{tabular}{|c|c|c|c|c|}
\hline & \multicolumn{3}{|c|}{ CODES FOR THE DIAGNOSTIC ACCURACY } & \multirow[t]{2}{*}{ AREAS OF INTEREST (AOI) } \\
\hline & 0 & 1 partly correct & 2 correct & \\
\hline PVC 1 & $\begin{array}{l}\text { No or wrong } \\
\text { diagnosis }\end{array}$ & Benign disorder & Benign sleep myoclonus & $\begin{array}{l}\text { Face, left arm, right arm, } \\
\text { legs }\end{array}$ \\
\hline PVC 2 & $\begin{array}{l}\text { No or wrong } \\
\text { diagnosis }\end{array}$ & Epilepsy, seizure & Sturge Weber syndrome & $\begin{array}{l}\text { Face, left arm, right arm, } \\
\text { legs }\end{array}$ \\
\hline PVC 3 & $\begin{array}{l}\text { No or wrong } \\
\text { diagnosis }\end{array}$ & Epilepsy, seizure & Infantile spasms & Face, left arm, right arm \\
\hline PVC 4 & $\begin{array}{l}\text { No or wrong } \\
\text { diagnosis }\end{array}$ & $\begin{array}{l}\text { Developmental delay or } \\
\text { ataxia or cerebral palsy }\end{array}$ & $\begin{array}{l}\text { Developmental delay with } \\
\text { ataxia or cerebral palsy }\end{array}$ & $\begin{array}{l}\text { Face, left arm, right arm, } \\
\text { legs }\end{array}$ \\
\hline
\end{tabular}

To study the visual search strategies, we implemented eye tracking. ${ }^{16,17}$ In nonmedical domains, important differences in perception between experts and novices studying dynamic stimuli have been documented. For instance, experts have been shown to attend more to relevant aspects of the stimulus than novices. ${ }^{18}$ Likewise, novices performed more slowly and not as accurately and were distracted by salient, but irrelevant features. ${ }^{18}$ However, in the more complex medical domain and specifically in the clinically relevant domain of authentic patient video cases, we lack knowledge regarding perception and the related cognitive processes. Eye movements were recorded with an SMI High Speed eye tracking system with a temporal resolution of $240 \mathrm{~Hz}$ and the iView X 2.2 software. The stimulus material was presented via Experiment Center 2.2. The eye-tracking data were analysed with BeGaze 2.3 software. $^{19}$ The verbal data were recorded using iView Sound recording 1.0 software via a flat microphone (IMG) attached to the eye-tracking computer.

To analyse the eye tracking data, so-called areas of interest (AOIs) were created. The AOls accurately specified areas on the patient video (e.g., an arm, the face or the legs), and were defined by two domain experts (Table 2). These AOls were dynamic, i.e., they moved across the screen, changed in shape and size, and could appear and disappear depending on the focus of the video camera. ${ }^{16,18}$ The AOls were defined as polygons superimposed on the PVCs surrounding each relevant area of the video (e.g., a leg of the patient) in the BeGaze software. ${ }^{19}$ Each time a relevant body part came out of focus and reappeared, a new AOI was created. These AOls were adapted in shape and size for each video frame for the entire, looped video. Afterwards, the coordinates for the polygons were exported as .txt files and looped by a self-programmed MatLab code. The number of loops depended on the longest viewing times of all participants. Percentages of time looking at AOls relative to the total duration of the looped PVCs were calculated.

Clinical diagnostic reasoning is a problem-solving process of interpreting information and refining hypotheses to identify processes causing a patient's illness. ${ }^{20,21}$ We chose a concurrent think-aloud design ${ }^{22}$ to tap into these cognitive processes. 
After a brief instruction and familiarization with giving verbal reports, participants could think aloud without systematic changes to the sequential structure of their thought processes. ${ }^{23}$ The think-aloud protocols were transcribed verbatim.

Using a consensus procedure, two domain experts decided upon the criteria for the diagnostic accuracy and scored it (Table 2) from the transcripts. The verbal protocols were investigated using a coding system originally developed for use in paediatrics (Table 3). ${ }^{24,} 25$ Two raters analysed all transcripts with four PVCs from 43 participants. The clauses were categorized according to the following categories: data exploration, theory building and theory evaluation. Inter-rater reliability analy$\operatorname{sis}^{26}$ revealed generalisability coefficients equal to $0.94,0.91$ and 0.85 , indicating that the categorization showed sufficient reliability for all three categories.

Table 3 Coding system for the levels in think-aloud transcripts. Representative examples taken from an expert are presented.

\begin{tabular}{ll}
\hline LEVEL & EXAMPLES OF UTTERANCES \\
\hline Data exploration & "Ok, I am looking at the movements" \\
Theory building & "Oh, oh, oh, this looks like Blitz Nick Salaam convulsions" \\
Theory evaluation & "Yes, there it is again - it occurs in a series - it must be infantile spasms" \\
\hline
\end{tabular}

Pretraining for thinking aloud was standardized, and the participants were instructed as follows: ${ }^{22}$ "Please take a look at the way the infant behaves/moves. Think aloud all the time. Mention a likely diagnosis when or if you think of it. The video is repeated until you say stop." Eye-tracking and recording of concurrent thinking aloud were then performed with PVCs 1, 2, 3, and 4.

No risks were associated with the use of eye-tracking equipment or otherwise by the participation in this study. Verbal and written information was provided before informed consent was sought and documented. Data were anonymised prior to analysis and used only for research purposes. Ethical approval was sought through the Regional Danish Ethical Committee, and the study was exempted from formal ethical approval. Eye-tracking data and investigator remarks were screened for invalid data, and only 10 eye-tracking data sets (5.8\%) were excluded from analysis.

\section{Results}

A total of $12 \%$ of the medical students, $45 \%$ of the residents and $94 \%$ of the experts were able to make a correct diagnosis in the cases. Duration of postgraduate experience was highly correlated with diagnostic accuracy. The diagnostic accuracy (\% correct) increased by 37.2 when experience increased by a factor of 10 . (Table 4) In the logarithmic representation of years of experience (Fig 1 and 2), the regression coefficient indicates the increase (or decrease) of a variable when years of experi- 
ence increases with a factor of 10 . Note that an offset of 0.25 year was chosen in order to avoid problems with the logarithm (the logarithm of 0 is undefined). So for all participants the number of years of experience is increased by 0.25 , resulting for all students in a value of 0.25 .

The total time used for the task was not associated with duration of postgraduate experience. Remarkably, more experienced clinicians spent more of their time attending to relevant AOIs (Fig 1).
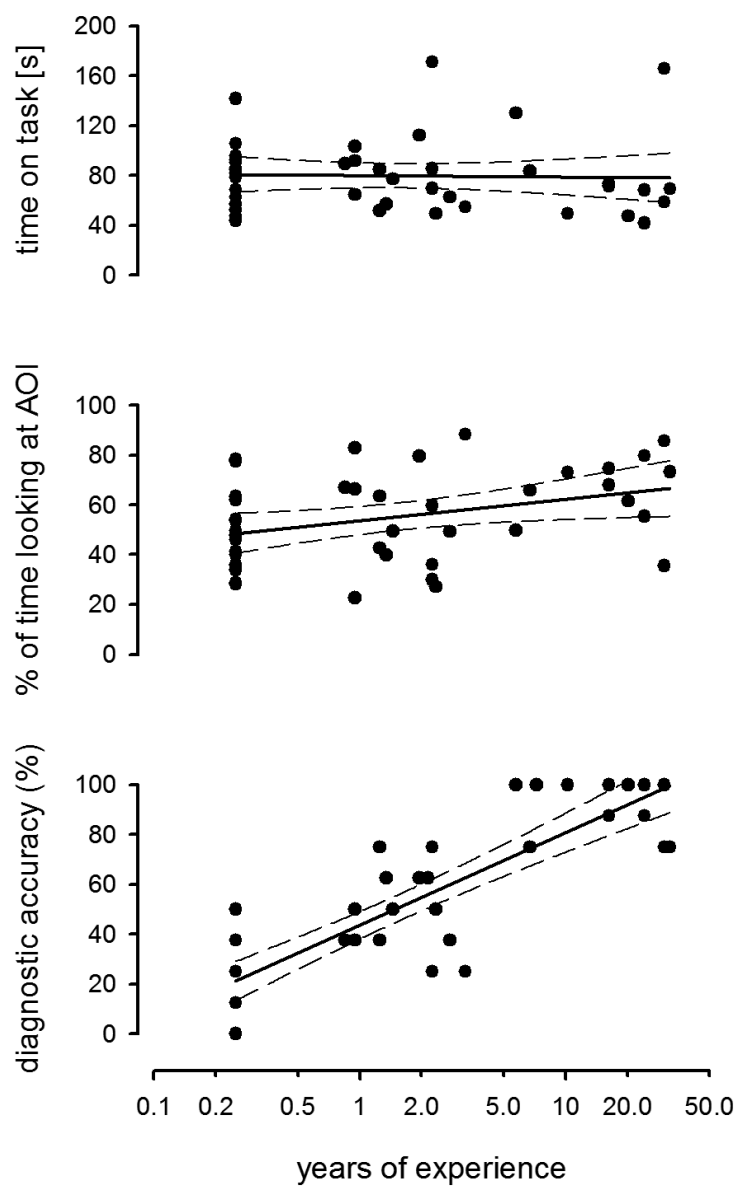

Figure 1 Time on task, \% of time looking at AOI and diagnostic accuracy as a function of years of (log) postgraduate experience. Overall values for four PVCs are indicated per participant (dots) and the regression line (solid line) and 95\% confidence interval (broken lines) are presented. 

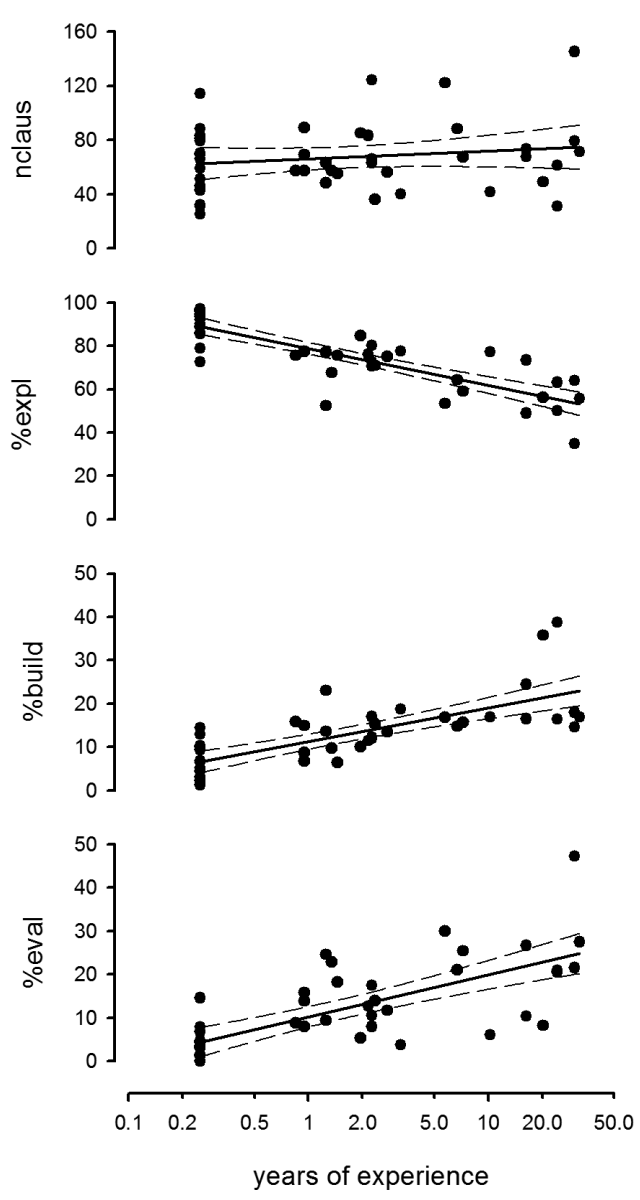

Figure 2 Cognitive processes identified in the transcripts (total number of clauses, percentage of clauses on data exploration, theory building and theory evaluation) as a function of years of (log) postgraduate experience. Overall values in four PVCs are indicated per participant (dots) and the regression line (solid line) and 95\% confidence interval (broken lines) are presented.

The cognitive processes of the participants in terms of the relative frequencies of data exploration, theory building and theory evaluation are illustrated graphically (Fig 2). For an increase of factor 10 in years of experience, the percentage of exploration clauses decreased by 16.9 , whereas the percentages of building and evaluating increased by 7.8 and 9.7, respectively (Table 4). The total number of clauses did not significantly change with years of experience. More experienced participants' explored data less, built more theory and evaluated more theories. The regression equation explains a considerable amount of the total variation of diagnostic accuracy, data exploration, hypothesis building and evaluation, as is indicated by the $\mathrm{R}^{2}$ values, which range between 50 and 72 per cent. 
Table 4 Linear regression of cognitive variables, diagnostic accuracy, time on task and percentage of time spent looking at areas of interest. In this logarithmic representation of years of experience, the regression coefficient (b) indicates the increase (or decrease) of a variable when years of experience increases by a factor 10 .

\begin{tabular}{lcccc}
\hline Dependent variable & $\begin{array}{c}\text { Regression } \\
\text { coefficient (b) }\end{array}$ & $\begin{array}{c}\text { Standard regression } \\
\text { coefficient (beta) }\end{array}$ & $\begin{array}{c}\text { Significance } \\
\text { (one-sided p) }\end{array}$ & Rsquare (\%) \\
\hline Number of clauses & 5.8 & 0.17 & $\mathrm{P}=0.15$ (NS) & 3 \\
\% Exploration & -16.9 & -0.83 & $\mathrm{p}<0.0005$ & 69 \\
\% Building & 7.8 & 0.73 & $\mathrm{p}<0.0005$ & 53 \\
\% evaluating & 9.7 & 0.70 & $\mathrm{p}<0.0005$ & 50 \\
Diagnostic accuracy (\% correct) & 37.2 & 0.85 & $\mathrm{p}<0.0005$ & 72 \\
Time on task [s] & -1.4 & -0.03 & $\mathrm{P}=0.47[\mathrm{NS}]$ & 0 \\
\% Time at AOI & 8.5 & 0.35 & $\mathrm{P}=0.013$ & 12 \\
\hline
\end{tabular}

Total time on task did not change significantly with years of experience, but percentage time looking at an AOI significantly increased by 8.5 when experience increased by a factor 10 , although the explained variance was modest (Rsquare $=12$ $\%)$.

\section{Highlights}

- We examined eye movements and think-aloud in clinicians analysing video cases

- Clinicians of varying expertise analysed patient video cases differently

- More experienced clinicians looked more at relevant areas

- More experienced clinicians were more accurate in visual diagnosis

- More experienced clinicians built and evaluated more diagnostic hypotheses

\section{Discussion}

Not surprisingly, this study shows that more experienced clinicians have high diagnostic accuracy; i.e., they have visual expertise. They are simply effective diagnosticians, and the finding adds to the validity of our measure of diagnostic accuracy.

The main findings of the present study are the concomitant perceptive and cognitive data, revealing how more experienced clinicians compare to less experienced clinicians. Experienced clinicians use relatively more of their time looking at AOIs in the PVCs. With decreasing duration of clinical experience, clinicians use less and less of their time looking at relevant areas, and more and more of their time searching other areas. Thus, it seems that experienced clinicians process visual data more efficiently; i.e., their visual search is more effective. The combination of perceptual and cognitive data adds a new perspective to theory of how expertise de- 
velops. The cognitive data show that with longer experience, clinicians do not need to invest so much effort exploring data. Instead, they can focus their clinical reasoning processes on active building and evaluation of diagnostic hypotheses. Through effortless matching of the new case with illness scripts stored in the extensive, coherent knowledge base in long term memory, ${ }^{27}$ they are able to make a probable diagnosis with high diagnostic accuracy.

In the research setting used here, the time on task for all participants is similar (Fig 2). We speculate whether the PVCs used were so difficult that the experts did not finish the task quickly but instead purposefully kept looking for additional data to evaluate or confirm a diagnostic hypothesis. For instance, in PVC 2 or 3 (Table 2), an expert may carefully and purposefully pay attention to an AOI, waiting for signs of seizure recurrence in that particular AOI. Experts are known to be able to continuously monitor for, and if necessary, build and evaluate alternative hypotheses. ${ }^{5}$ By simultaneously tracking visual attention and cognitive processes, this study shows how clinicians with increasing experience are able to focus their attention more while building and evaluating hypotheses.

Conversely, the cognitive processes of less experienced clinicians are characterized by extensive data exploration. They try to integrate the data; they stumble over many points that need clarification or they indicate there is insufficient data. ${ }^{24}$ They cannot easily build hypotheses, let alone evaluate them. We know from think-aloud studies that medical students have extensive knowledge, but this knowledge is qualitatively different and not so easily accessible. ${ }^{5}$

Some noteworthy conclusions can be drawn from the combined perceptual and cognitive data, adding new perspectives on clinical reasoning with complex moving pictures. Firstly, experts' visual search is effective and accurate, strongly suggesting a non-analytical approach. Secondly; our study shows experts are highly skilled in evaluating diagnostic hypotheses. This skill certainly is of importance in domains like paediatric neurology, in which alternative diagnoses mimicking each other occur frequently. ${ }^{4}$ Thirdly; less experienced clinicians are less effective in visual search. They do not always possess illness scripts that match, and thus their diagnostic accuracy is lower. They are therefore more likely to make diagnostic errors. Fourth; less experienced clinicians do not possess the ability to evaluate hypotheses, i.e., monitor for alternative diagnoses.

The validity of the eye-tracking data is high because of the high quality and accuracy of the eye-tracking equipment used and the skilfulness of the operator. The stringency of the think-aloud protocol adds to the trustworthiness of the concurrent think-aloud reporting.

Although this study included clinicians from 5 hospitals, and therefore must have some external validity, all of the medical students were associated with a single medical school. In spite of this limitation, we do not expect generalisability of the medical student results to be low. We succeeded in recruiting 12 out of 16 eligi- 
ble specialists in paediatric neurology, yet a smaller proportion of the eligible residents and medical students were included. This difference might introduce potential sampling bias, as those participating could be relatively motivated or skilled diagnosticians. If this source of potential bias was present, the regressions in Table 4 would be underestimated. We believe the size of the bias would be small, as the medical students were within 18 months of graduation and therefore were expected to possess similar diagnostic skills.

The findings may help clinical teachers, using patient video cases in a broad variety of specialties, to better understand why learners pick up - or alternatively miss - important details in a representation, or could not commence the relevant reasoning processes. ${ }^{28,29}$ A study on medical students identified conditions that video cases used for teaching should meet: the content of video cases should be in line with learners' previous knowledge; cases should be short and should be viewed in a structured, purposeful manner. ${ }^{30}$ Examples of simple strategies using PVCs in clinical settings might include asking residents or medical students cognitive explorative questions, such as: 'what is important to note in this patient video case?' or signalling modelling behaviour as follows: 'listen to what I would think while examining this case'. ${ }^{14}$

In conclusion, when more experienced paediatricians analyse a PVC, they spend more time looking at relevant areas and explore data less, yet they build and evaluate more diagnostic theories. These differences have implications for the development of effective teaching environments with PVCs in clinical settings.

\section{Acknowledgements}

This work was partly funded by The Quality Development Foundation for Education of Residents, Aarhus, Denmark. Consultant Thomas Thelle, Regional Hospital, Viborg, Denmark is thanked for assistance in designation of AOls in the PVCs. 


\section{References}

1. Ferriero D, Hauser SL. Supply does not satisfy demand in child neurology. Annals of Neurology 2010;67(5):A5-6.

2. Derrick S, Badger B, Chandler J Nokes T, Winch G. The training/service continuum: exploring the training/service balance of senior house officer activities. Med Educ 2006;40(4):355-362.

3. Josephsen SA, Hauser SL. Neurologic education 2011: New Challenges and Opportunities. Annals of Neurology 2011;68(6):A9-10.

4. Singer H, Mink JW, Gilbert D, Jankovic J. Diagnostic evaluation of children with movement disorders, In: Singer H, Mink JW, Gilbert D, Jankovic J (eds) Movement disorders in childhood. Philadelphia: Saunders, 2010:19-29

5. Schmidt HG, Rikers RMJ. How expertise develops in medicine: knowledge encapsulation and illness script formation. Med Educ 2007;41:1133-39.

6. Eva KW. What every teacher needs to know about clinical reasoning. Med Educ 2005;39:98-106.

7. Morita J, Miwab K, Kitasaka T et al. Interactions of perceptual and conceptual processing: Expertise in medical image diagnosis. Int. J. Human-Computer Studies 2008;66:370-90.

8. Krupinski EA. Current perspectives in medical image perception. Attention, Perception \& Psychophysics 2010;72(5):1205-17.

9. Westberg J, Jason H. Using video for illustrating, modeling, and demonstrating. In: Westberg J, Jason H. Teaching creatively with video. New York: Springer series on medical education, 1994:27-51.

10. Williams R. Neurology at a distance. Lancet neurology 2010;9:346-47

11. Nechay A, King MD, Stephenson JBP. Benign non epileptic contractions in infancy: novel aspects recognized on video recordings. Eur J of Paediatr Neurol 2009;13(1):S12.

12. Hansen J, Balslev T. Hand activities with infantile masturbation. Video analysis of 13 cases. European Journal of Paediatric Neurology 2008;13,508-510.

13. Kamin CS, O'Sullivan PS, Younger M, Deterding R. (2001). Measuring critical thinking in problembased learning discourse. Teaching and Learning in Medicine 2001;13:27-35.

14. Balslev T, de Grave W, Muijtjens A, Scherpbier A. Enhancing diagnostic accuracy among non-experts by use of video-cases. Pediatrics, 2010;125(3):e570-6.

15. http://library.med.utah.edu/neurologicexam/html/home_exam.html (Assessed May 24 2011)

16. Holmqvist $\mathrm{K}$, Nyström $\mathrm{N}$, Andersson $\mathrm{R}$ et al. Eye tracking: a comprehensive guide to methods and measures, Oxford: Oxford University Press, 2011.

17. Duchowski A. Eye tracking methology. Theory and Practice. London: Springerverlag, 2007.

18. Jarodzka H, Scheiter K, Gerjets P, Van Gog T. In the eyes of the beholder: How experts and novices interpret dynamic stimuli. Learning and Instruction 2010;20:146-54.

19. http://www.smivision.com (Assessed May 24.2011)

20. Vleuten CPM, Newble DA. How can we test clinical reasoning? Lancet 1995;345:1032-34.

21. Norman G. Research in clinical reasoning: past history and current trends. Medical Education 2005;39:418-27.

22. van Gog T, Paas F, van Merriënboer JJG, Witte P. Uncovering the Problem-Solving Process: Cued Retrospective Reporting Versus Concurrent and Retrospective Reporting. Journal of Experimental Psychology: Applied 2005;11(4):237-244.

23. Ericsson KA. Valid and non-reactive verbalization of thoughts during performance of tasks. Towards a solution to the central problems of introspection as a source of scientific data. Journal of Consciousness studies 2003;10:1-18.

24. Hassebrock F, Prietula MJ. A protocol-based coding scheme for the analysis of medical reasoning. International Journal of Man-Machine Studies 1992;37:613-52.

25. De Grave WS, Boshuizen HPA, Schmidt HG. Problem based learning: Cognitive and metacognitive processes during problem analysis. Instructional Science 1996;24:321-41.

26. Brennan RL. Statistics for social science and public policy: generalisability theory. New York, SpringerVerlag, 2001. 
27. van de Wiel MWJ. Boshuizen HPA, Schmidt HG, Schaper NC. The explanation of clinical concepts by expert physicians, clerks and advanced students. Teaching and Learning in Medicine 1999;11(3):15363.

28. Vickrey BG, Samuels MA, Ropper AH. How neurologists think. A cognitive psychology perspective on missed diagnoses. Ann Neurol 2010;67:425-33.

29. Norman GR, Eva KW. Diagnostic error and clinical reasoning. Med Educ 2010:44:94-100.

30. De Leng BA, Dolmans DHJM, van de Wiel MWJ, Muijtjens AMM, van der Vleuten CPM. How video cases should be used as authentic stimuli in problem-based medical education. Med Educ 2007;41:181-188 



\section{Chapter 6 Conveying Clinical Reasoning based on Visual Observation via Eye Movement Modeling Examples}

Submitted to Instructional Science

Halszka Jarodzka

Thomas Balslev

Kenneth Holmqvist

Katharina Scheiter

Marcus Nyström

Peter Gerjets

Berit Eika 


\begin{abstract}
Complex perceptual tasks, like clinical reasoning based on visual observations of patients, not only require knowledge about diagnostic classes but also the skill to visually search for symptoms and interpret these observations. However, medical education has focused very little on how visual observation can be conveyed to novices in an efficient manner. Research has shown that decisions based on visual observations may be facilitated by showing the eye movements of a model to the observers and, thus, guiding their attention to the relevant visual features (i.e., eye movement modeling examples, EMMEs). The current study applied EMMEs to the teaching of clinical reasoning associated with visual observation. Example videos of patients were verbally explained by a model (control condition) and presented to students. The experimental conditions also involved recordings of the model's eye movements superimposed on the example videos. The eye movements were displayed by either highlighting with a circle the features the model paid attention to (circle condition) or by blurring the features the model did not attend to (spotlight condition). Results show that the use of a spotlight in the example videos better guides the students' attention to the relevant features compared to the other two conditions. Subsequent testing of the students' clinical reasoning skills with videos of new patient cases without any guidance showed that participants who studied spotlight examples beforehand improved the visual search and enhanced interpretation performance of the symptoms in contrast to participants who studied the circle condition or the control examples.
\end{abstract}


Clinical practice often requires detecting and diagnosing disorders based upon visual observations such as observation of the occasionally occurring ictal (i.e., seizureinduced) movement patterns of epileptic seizures in infants. In such cases, it is crucial to carefully observe which parts of the infant's body are involved, how and when these body parts move, and assess the level of consciousness of the infant (i.e., diagnosis based on the semiology of ictal events, cf. International League Against Epilepsy 2010; Lüders et al. 1998). According to Nordli, Bazil, Scheuer, and Pedley (1997) infantile seizures are often so subtle that even skilled observers may fail to identify them correctly. Moreover, some of these movement patterns occur only occasionally, are short-lived, subtle, and therefore not salient compared to other movements or characteristics of the infant (Hansen and Balslev 2009). As a result, epileptic seizures may easily be mistaken for normal behavior (Egger, Grossmann, and Auchterlonie 2003; Hansen and Balslev 2009). In general, subtle visual features may either not be recognized at all or attributed to other diseases (Nordli 2002).

Clinical reasoning based on visually observing a patient can be seen as a knowledge-rich (Van Lehn 1989) and perceptual task (Chi 2006). Hence, such a task requires prior knowledge and training. Moreover, this task requires not only knowledge about diagnostic classes, but also the skill to visually search for the symptoms and to correctly interpret these observations (cf. Krupinski 2010).

\section{Role of Visual Observations in Clinical Reasoning}

Many studies of various perceptual tasks have shown that experts possess sophisticated visual observation skills that enable them to visually search for the relevant features of a stimulus among the irrelevant features and interpret these observations correctly (e.g., Antes and Kristjanson 1991; Charness, Reingold, Pomplun, and Stampe 2001; Jarodzka, Scheiter, Gerjets, and van Gog 2010; Underwood, Chapman, Brocklehurst, Underwood, and Crundall 2003). Novices, on the other hand, get easily distracted by salient, but potentially irrelevant elements of a visual stimulus and overlook relevant information (Jarodzka, Scheiter, Gerjets and van Gog, 2010) Lowe 1999).

Similar effects were also found in the medical domain, for instance, with regard to clinical reasoning and diagnostic classification based on static and rather abstract stimuli like x-ray films (radiographs), microscopy slides, and mammograms (e.g., Krupinski 2005; Krupinski, Tillack, Richter, Henderson, Bhattacharyya, and Scott 2006; Kundel, Nodine, Krupinski, and Mello-Thoms 2008; Lesgold et al. 1988) as well as on realistic static stimuli like photographs of patients (Brooks, LeBlanc, and Norman 2000). Although no studies have yet investigated the effect of dynamic stimuli in the medical domain with regard to the use of patient video cases (see below), expertise differences in visual observation skills were shown for dynamic, realistic 
stimuli in other domains (biological classification of motion patterns: Jarodzka, Scheiter et al. 2010; car driving: Underwood et al. 2003).

Taken together, novices have been shown to experience difficulties in clinical reasoning based on visual observation of static medical images (and in other domains using dynamic stimuli), while experts have sophisticated skills that enable them to perform these tasks. Thus, it can be assumed that this finding will also hold true for a medical task based on dynamic stimuli, namely diagnostic classification of epileptic seizures in infants. In other words, novices require the training of clinical reasoning skills based on visual observations to appropriately perform this task. The next section addresses the question of how best to convey these skills.

\section{Teaching Clinical Reasoning Based on Visual Observations}

Complex perceptual tasks like clinical reasoning based on visual observations not only require knowledge about diagnostic classes but also the skill to visually search for symptoms and interpret these observations (Krupinski 2010, Helle, Nivala, Kronqvist, Gegenfurtner, Björk, and Säljö 2011). The focus in the education of medical students about epileptic seizures, however, does not lie specifically on teaching such skills. Instead, the motion patterns of epilepsy are often described in writing and accompanied by static pictures (e.g., Schmidt and Schachter 2000, p. 10). However, a written text is not adequate to teach the skill of clinical reasoning based on visual observation (Balslev, de Grave, Muijtjens, Eika, and Scherpbier 2009). Hence, medical education often makes use of so-called patient video cases (PVCs; e.g., Dequeker and Jaspaert 1998). These PVCs show patients video recorded while displaying movement that is potentially abnormal. Using PVCs for educational purposes has been shown to improve clinical reasoning compared to traditional written descriptions of a patient case (Balslev et al. 2009; Kamin, O'Sullivan, Deterding, and Younger 2003; de Leng, Dolmans, van de Wiel, Muijtjens, and van der Vleuten 2007). However, none of the studies on PVCs focused on individual learning effects. This is particularly problematic, as the research described in the previous section suggests that novices would not be able to perceive the relevant features and to interpret them correctly when shown PVCs.

Hence, this study explored whether visually cueing PVCs in different modes could improve the individual learning of clinical reasoning based on visual observations by means of eye movement modeling examples.

\section{Facilitating Decisions Based on Visual Observations via Eye Movement Modeling Examples}

Eye movement modeling examples (EMMEs) were developed to teach the performance of perceptual tasks (EMME; Jarodzka, van Gog, Dorr, Scheiter, and Gerjets 
2011; van Gog, Jarodzka, Scheiter, Gerjets, and Paas 2009). In this system, an expert model verbally explains how to perform the task while his eye movements are recorded. In a next step, these recordings are replayed as instructional videos to the learner. This type of instruction was developed in the tradition of example-based learning.

Research on instructional design has shown that example-based learning is a powerful method for early skill acquisition. Examples demonstrate a problem solution to the learner either by presenting a written, worked-out solution of a problem (i.e., worked examples; see, Atkinson, Derry, Renkl, and Wortham 2000; Sweller, van Merriënboer, and Paas 1998) or the learner observes an expert model performing the task live or on video (i.e., modeling examples; Bandura 1977; Collins, Brown, and Newman 1989). For cognitive tasks in which nonobservable cognitive processes are crucial the model verbalizes her/his cognitive processes by explaining why and how certain solution steps were chosen (cognitive modeling: Collins, et al. 1989; process-oriented worked examples: van Gog, Paas, and van Merriënboer 2008).

For perceptual tasks that require visual inspection (Chi 2006), it is crucial that the learner can see the stimulus the expert is looking at. To actually learn from such examples, however, learners have to attend to the relevant features of the modeled behavior (Bandura 1977). Otherwise, they may miss those visual features relevant for understanding and learning from the example. However, as seen by the research presented above, novices experience difficulties when dealing with complex visual stimuli. Thus, when learning from examples that involve visual stimuli, novices might need attention guidance.

One common form of attention guidance in instructional design is cueing. Although many studies exist on cueing, these studies often failed to find positive effects on learning (for a review: De Koning, Tabbers, Rikers, and Paas 2009). One reason might be that the cues used are usually based on what area an instructional designer or domain expert thinks a novice learner should be looking at at any particular moment. Experts, however, may not know what the most important feature for novices is, because they often have difficulties in correctly assessing the knowledge state of novices (Hinds 1999; Nückles, Winter, Wittwer, Herbert, and Hübner 2006). Thus, simply asking experts about what information should be cued might not be the appropriate way to proceed. One cueing technique that did prove successful is the one used by Grant and Spivey (2003), who have shown that choosing a cue based on eye movements of successful problem solvers enhances the probability for correctly solving an insight problem. However, the task used by Grant and Spivey (2003) consisted of a very simple stimulus (a circle with a large dot in it: Duncker's radiation problem). Hence, it was easy to detect which feature the successful problem solvers attended to and to cue this clearly distinguishable feature (the circle). In medical diagnosis, however, the visual stimuli are far more complex. Visual features are not easily distinguishable and more importantly, several visual 
features need to be inspected and compared. In this case, it might be important to cue an entire process and not just a single visual feature. In line with this, Litchfield, Ball, Donovan, Manning, and Crawford (2010) displayed perceptual processes by means of eye movements of a model superimposed onto a complex medical image, namely X-ray images. Results showed that this type of display improved the diagnostic assessment of X-ray images. Hence, for teaching perceptual tasks, the perceptual processes of the model should be externalized.

The question remains, however, whether attention guidance based on the model's eye movements not only influences performance of the task at hand, but also enhances learning. Here, learning refers to the robust change in a person's skills that enable him or her to independently perform a specific task after practice without any instructional support (Simon 1983). EMMEs are directly relevant to this research question by combining insights of example-based instruction of both cognitive and perceptual tasks. Hence, EMMEs consist of three components: the problem (i.e., the to-be-inspected visual stimulus), the externalizations of cognitive processes (i.e., verbal explanations), and perceptual processes (i.e., eye movements) of the model.

An unresolved issue is how the eye movements are best displayed in modeling examples. Eye movements can be displayed as additional information superimposed onto the stimulus (i.e., as a dot on the features the model attended to) or by reducing the visual information provided by the stimulus (i.e., as a spotlight, where the features that the expert model did not attend to are blurred). Early studies of EMMEs in connection with structurally simple tasks (a Tower-of-Hanoi-like task: van Gog, Jarodzka, Scheiter, Gerjets, Paas 2009) ; and a simple biological classification task: (Jarodzka, van Gog, Dorr, Scheiter, Gerjets 2010) have provided interesting insights into teaching learners how to take decisions based on visual observations: On the one hand, displaying eye movements directly as additional information has been shown to impose such high cognitive demands on learners that use of this technique may even hamper task performance (van Gog, Jarodzka, Scheiter, Gerjets and Paas 2009). On the other hand, it has also been shown to improve the skill to interpret relevant visual features, but without a positive effect on visual search (Jarodzka, van Gog, Dorr, Scheiter and Gerjets 2010). Reducing existing information instead has been shown to guide attention and to foster visual search, but not to improve interpretation performance (Dorr, Jarodzka, and Barth 2010; (Jarodzka, van Gog, Dorr, Scheiter, and Gerjets 2010). ). Moreover, blurring videos have been shown to guide the observers' attention without them even noticing it (Nyström 2008). Thus, no display type has yet been proven to be superior.

Hence, the current study aims to answer two questions, namely, can displaying eye movements in modeling examples be beneficial, provided that the display does not cover the relevant areas, and what type of display is beneficial? To investigate these questions, a control condition that consisted of video examples that were 
verbally explained by an expert model, but without eye movement display was compared to two experimental conditions that additionally included the display of the expert model's eye movements. In this set-up, two display types were compared: a display that adds information (circle display) and one that reduces information (blurring display). Instead of a solid dot as used in prior studies (Jarodzka, van Gog, Dorr, Scheiter and Gerjets 2010). ; (van Gog, Jarodzka, Scheiter, Gerjets and Paas 2009) the expert model's eye movements are displayed as a circle. For the spotlight display, we decided to use a very subtle blurring so that an impression of the overall scene was still apparent (could still be obtained). The domain of the current study is a diagnostic classification task based on video cases of infant patients. The task not only requires visual observation skills, as has been shown by the expertise differences reported above, but also requires access to a complex underlying decision tree and, hence, requires an instructional teaching method that focuses on teaching the relevant underlying processes (Helle, Nivala, Kronqvist, Gegenfurtner, Björk, and Säljö 2011).

\section{Research Questions - Hypotheses}

The main research question investigated was whether EMMEs can foster clinical reasoning skills based on visual observations of epileptic seizures in infants. The following hypotheses were tested:

We assume that a prerequisite for learning from EMMEs is that they successfully guide the attention of the learners toward what the expert model looked at. Hence, hypothesis 1 is as follows:

We hypothesize that participants' learning with both types of EMMEs would be guided by the eye movement display, resulting in a scan path that is highly similar to the expert model's scan path, whereas the scan paths from participants in the control group would be more diverse.

It is not clear which type of EMMEs would best guide learners' visual attention to what the expert model attended (paid attention) to. Since the spotlight display is only little intrusive, and the circle display does not obscure any elements, both should strongly guide attention.

We assume that EMMEs would foster learning of clinical reasoning based on visual observation as measured both by the efficiency of the visual search during a test (by means of eye tracking) and the interpretation of the motion pattern observed (by means of a multiple choice questionnaire). Hence, hypothesis 2 , which addresses the visual search variables, is as follows:

We hypothesized that the EMME groups would learn better what to attend to, thereby yielding a more efficient visual search than the control group for novel test videos, by attending faster and longer to relevant areas, while ignoring irrelevant areas. 
Since both displays should guide learners' attention equally well toward the relevant features, it is unclear which display would yield a more efficient visual search.

Hypothesis 3 that addresses the interpretation is as follows: We hypothesized that EMMEs would also result in an enhanced interpretation performance of the motion patterns compared to the control group.

Since the spotlight display was improved as compared to a prior study, it is not clear which condition would be more successful in fostering interpretation performance.

\section{Method}

\section{Participants}

Participants were 60 medical students in their final year at the University of Aarhus (41 women, 19 men, $M_{\text {age }}=26.57$ years, $S D=2.03$ ). All participants had no prior knowledge of the task and had normal or corrected-to-normal vision and were randomly assigned to the conditions ( $n=20$ each). Participants were compensated by $€ 10$ for their participation.

\section{Apparatus and Materials \\ Eye Tracking Equipment}

The model's eye movements were recorded with an SMI High Speed eye tracking system with a temporal resolution of $240 \mathrm{~Hz}$ on a 17" monitor and the iView X 2.2 software. This eye tracking system has a high accuracy of below 0.5 degrees of visual angle. The model's eye tracking data were edited with BeGaze 2.3 software (www.smivision.com ) and self-programmed MatLab algorithms. The same system was used to record participants' eye movements. The participants' eye tracking data were analyzed with BeGaze 2.3 software (www.smivision.com ) and selfprogrammed MatLab algorithms. All video material was presented to the participants via Experiment Center 2.2. The questionnaire in the testing was presented via e-prime 2.0 software.

\section{Modeling Examples}

Diagnosing epileptic seizures in infants may result in many different diagnostic classes. This study, however, does not focus on the final diagnostic step, but rather on the clinical reasoning underlying this step (as explained above). Hence, it was not the aim to give training with regard to all possible seizure types, but rather, to train the procedure of collecting observations of symptoms crucial for a diagnosis. Thus, 
for the purpose of the current study, two exemplary patient cases of focal seizures were chosen to train clinical reasoning based on visual observations. These modeling examples for the control group consisted of two digital PVCs in an audio interleave format (.avi), sized $720 * 576$ pixels and presented in full screen on a $1280 *$ 1024 pixels resolution (corresponding to $17.07 * 13.65$ inches). Each PVC depicted a single infant. One depicted a 3-week old infant and the other a 7-month old infant. Both infants deployed a motion pattern corresponding to a specific type of an epileptic seizure. The duration of the videos was $71 \mathrm{~s}$ and $73 \mathrm{~s}$.

The original sound was removed from the videos, because parents and clinical staff were talking during the screening and this would disturb the use of verbal explanations. Instead the videos included a spoken description and diagnosis of the motion patterns by a model. The model was a pediatrician with extensive clinical and teaching experience in diagnosing epileptic seizures. Rather than using the expert's natural performance of these tasks as an example, we decided to instruct the model to behave didactically, that is, to explain to novice students what the relevant aspects of the motion pattern shown in each PVC were. Each recording was replayed to the model so that he could evaluate the replay data based on a number of questions (e.g., for a novice, is the disease explained in enough detail, in comprehensible terms, et cetera; cf. Jucks, Schulte-Löbbert, and Bromme 2007), and, if necessary, he could re-record it. This was done, since several studies have shown that experts use shortcuts in medical diagnosis (Boshuizen and Schmidt 1992).

In both experimental conditions, participants received the same recordings as did the control group but in addition, the recordings included the model's eye movements. In the circle display condition, the displays were created using "fixation scan path display function" provided by the manufacturer (www.smivision.com). The settings for the velocity-based saccade detection algorithm were set at a peak velocity threshold of $40^{\circ} \mathrm{s}$. The fixations were displayed as yellow circles with a line thickness of one pixel and a gaze trail for a temporal window of $1 \mathrm{~s}$.

In the spotlight display condition, potentially distracting features in unattended areas were low pass filtered. That is, regions around the model's gaze position were displayed as normal, whereas other regions were smoothly "blurred" away from this position through a process known as foveation (for a detailed description of the proceeding, cf. Nyström and Holmqvist 2008). To reduce noise, the eye movements of the model were smoothed before foveation was implemented. This was done by applying a so-called median filter of $200 \mathrm{~ms}$ in length (corresponds to 48 samples in the eye tracking recording). Figure 1 shows a screenshot of each of the three conditions. 


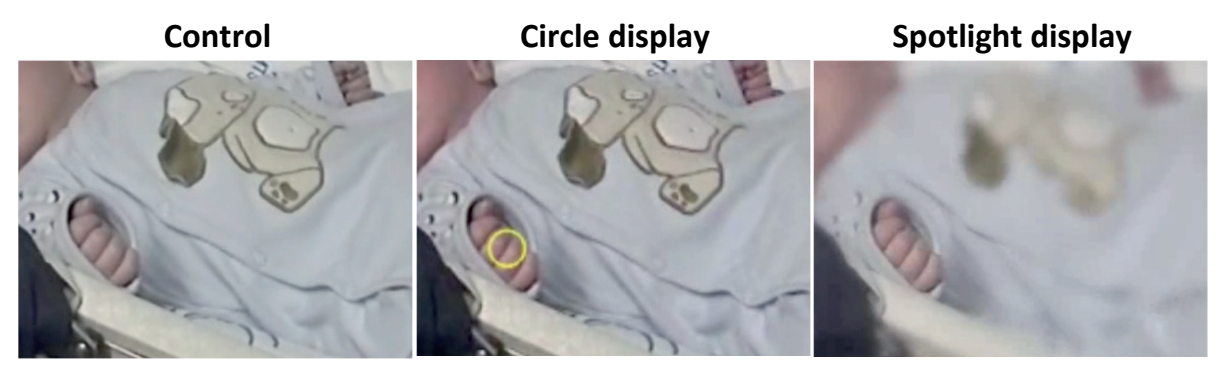

Figure 1 Screenshots from the three conditions used in the study.

In order to estimate whether participants were able to follow the attention guidance, their eye movements were recorded during the instruction (i.e., during the learning process), and the degree of similarity of the participants' eye movements to the eye movements of the model displayed on the EMME videos was calculated.

\section{Tests}

To test for learning effects, participants were shown three new PVCs without verbal explanations or any eye movement display for a mean duration of 29.67 S (SD = 17.79) of different children, each displaying one type of seizure. The duration of the test video depended on the duration of the seizure. Based on these test videos, two different measures of learning were obtained: the efficiency of the visual search and the ability to interpret areas important for the diagnosis of epileptic seizures. While watching the test videos, participants' eye movements were recorded to gain information on their visual search. From these recordings, two different eye movement measures were obtained. First, time spent until participants looked at all relevant areas on the test videos was recorded. The relevant areas were determined a priori by domain expert (Antes and Kristjanson 1991; Charness, Reingold, Pomplun, and Stampe 2001). Second, time spent looking at the relevant areas on the test videos was recorded. Afterwards, their interpretation performance was assessed by answering multiple-choice questions relevant to the interpretation of the visual features of those videos: deciding which body parts move (1), how these body parts move (2), whether touching the infant changes these movements (3), the involvement of the infant's face and its meaning for diagnosis (4), and the infant's state of consciousness (5).

\section{Procedure}

The recording was conducted in individual sessions of approximately 30 minutes each. At the beginning, participants filled in a questionnaire on their prior knowl- 
edge of pediatric epilepsy and their demographic data. Then, they received a short introduction to the topic that contained very general information on seizures. Then, the learning phase started. The eye tracking system was adjusted to the individual features of the participant based on a 13-point calibration. Participants were told that they would subsequently receive videos of the to-be-learned disease, in which a model explains the disease shown in the video. Depending on the experimental condition they were allocated to, they were also told that they would see where in the video the model looked. Before watching the learning videos, participants received information on the age, gender, and a short problem description of the patient. While watching the corresponding learning video, the eye movements of the participants were tracked.

In the testing phase, participants watched three novel PVCs without verbal explanations or any eye movement display. A fixation cross appeared for two seconds followed by the test video, which was replayed once. Participants watched the video while their eye movements were recorded. Afterwards, the video disappeared, resulting in a blank screen. Then, the participants had to answer the multiple-choice questions as described in the section above. This procedure was repeated for the remaining two patient video cases.

\section{Data Analysis}

\section{Analysis of Eye Movement Data during Example Study}

The similarity between participants' eye movements and the displayed eye movements of the model was analyzed by calculating the Euclidean distance between simultaneous gaze points of the model and the participant over time (cf. Rao, Zielinsky, Hayhoe, and Ballard 2002). Subsequently, the mean Euclidean distance was calculated for each participant.

\section{Analysis of Learning Outcomes}

To analyze participants' learning outcomes in terms of their visual search skills, two eye movement measures were derived: (1) time spent until all AOls had been looked at for the first time and (2) time spent on relevant AOIs (total dwell time). Each video included several AOIs that had to be looked at in order to exhaustively describe the infant's disease. In order to obtain the time spent visually searching all of the relevant AOls, only the time that participants spent "outside" of any relevant $\mathrm{AOI}$ until all AOI had been looked at was taken into account. Thus, this duration was calculated as follows: time until all relevant AOls were looked at for the first time, minus the time spent looking at other relevant AOIs. Because the test videos were of different durations, both eye tracking measures were normalized by the video length. 
The construction and scoring of the learning outcomes in terms of interpretation performance (as assessed by the multiple-choice questionnaire) was developed with the help of domain experts. Accordingly, in judging the diagnosis of a focal seizure, the following guidelines were followed with regard to participant responses: (1) correctly stating which part of the body is involved in the movement, (2) correctly stating how this part moves, (3) correctly stating whether touching the child would change the movement, (4) correctly stating whether the face was involved and whether or not this is important for the diagnosis, (5) correctly stating the child's level of consciousness. Hence, participants could receive a maximum of five points per video (1 point for each category).

\section{Statistical Analysis}

All statistical analyses for main effects were conducted using ANOVAs. For each dependent variable, an ANOVA was conducted with a condition (control vs. circle display vs. spotlight display) as independent variable. In sum, four ANOVAs were conducted for mean Euclidean distance from participant to expert model gaze, time while watching the test videos before all relevant AOIs had been looked at the first time, dwell time on relevant AOls, and correctness scores in the multiple-choice questionnaire.

To analyze differences between each condition, Bonferroni post-hoc tests were conducted. All directional hypotheses are reported with one-tailed $p$ values (i.e., all "a") parts of the hypotheses), while all non-directional hypotheses are reported with two-tailed $p$ values (i.e., all "b)" parts of the hypotheses).

For all statistical tests reported here, a significance level of .05 was used.

\section{Results}

\section{Eye Movement Data during Example Study}

An ANOVA was conducted with mean Euclidean distance as dependent variable and condition (control vs. circle display vs. spotlight display) as independent variable. The comparison of participants' eye movement data with the model's eye movement data during example study showed a main effect of condition, $F(2,57)=3.60$, $p=.03, \eta_{p}{ }^{2}=.11$. Bonferroni post-hoc tests revealed that the spotlight display condition guided the participants' attention significantly better than in the control condition ( $\left.p_{\text {one-tailed }}=.04\right)$ and marginally better than in the circle display condition $\left(p_{\text {two- }}\right.$ tailed $=.07)$. Circle condition and control condition did not differ significantly in their potential to guide attention, ns. Results are summarized in Figure 2. 


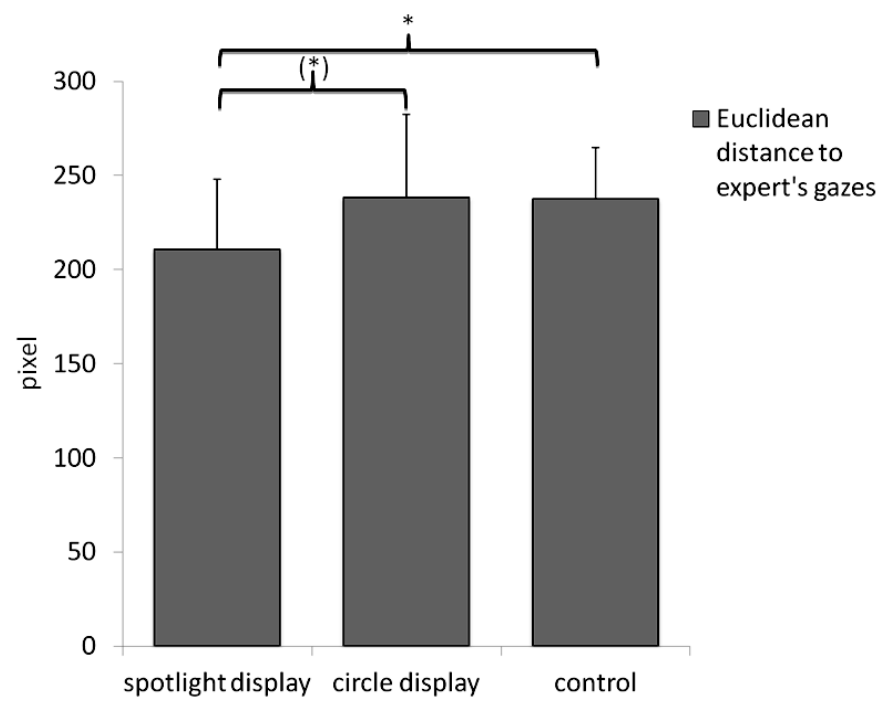

Figure 2 Means and standard deviations for Euclidean distance (in pixel) between models' and participants' gaze points over time during example study.

\section{Learning Outcomes}

\section{Eye Movement Data during Testing}

An ANOVA was conducted with time spent until all AOIs had been looked at for the first time while watching the test videos as dependent variable and condition (control vs. circle display vs. spotlight display) as independent variable. The conditions significantly differed with regard to the time participants spent before having looked at all relevant AOls for the first time, $F(2,57)=3.41, p=.04, \eta_{p}{ }^{2}=.11$. Bonferroni post-hoc tests indicated that the spotlight display group looked significantly earlier at all relevant AOIs than did the control group, $p_{\text {one-tailed }}=.03$. The circle condition did not differ significantly from the other two groups, ns. Results are summarized in Figure 3. 


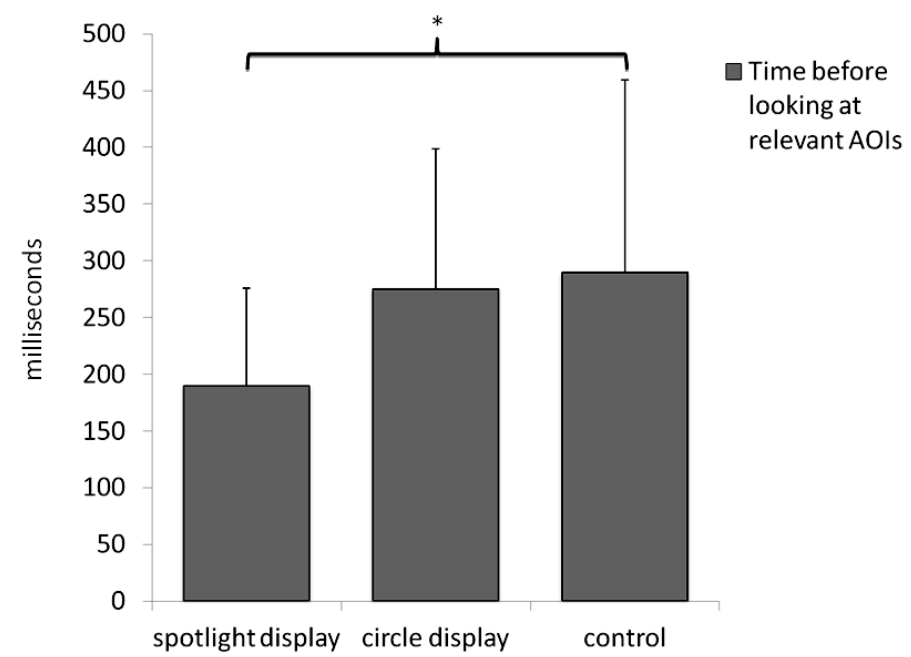

Figure 3 Means and standard deviations for time before having looked at all relevant $\mathrm{AOIs}$ (in $\mathrm{ms}$ ) during testing.

An ANOVA with dwell time on relevant AOIs as dependent variable and condition (control vs. circle display vs. spotlight display) as independent variable showed significant differences between conditions in dwell time on relevant $A O I s, F(2,57)=$ $3.64, p=.03, \eta_{p}{ }^{2}=.11$. Bonferroni post-hoc tests indicated that the spotlight display group looked significantly longer at the relevant AOIs than did the control group, $p_{\text {one-tailed }}=.04$, and marginally longer than did the circle group, $p_{\text {two-tailed }}=.07$. The circle and the control group did not differ significantly, ns. The results are summarized in Figure 4.

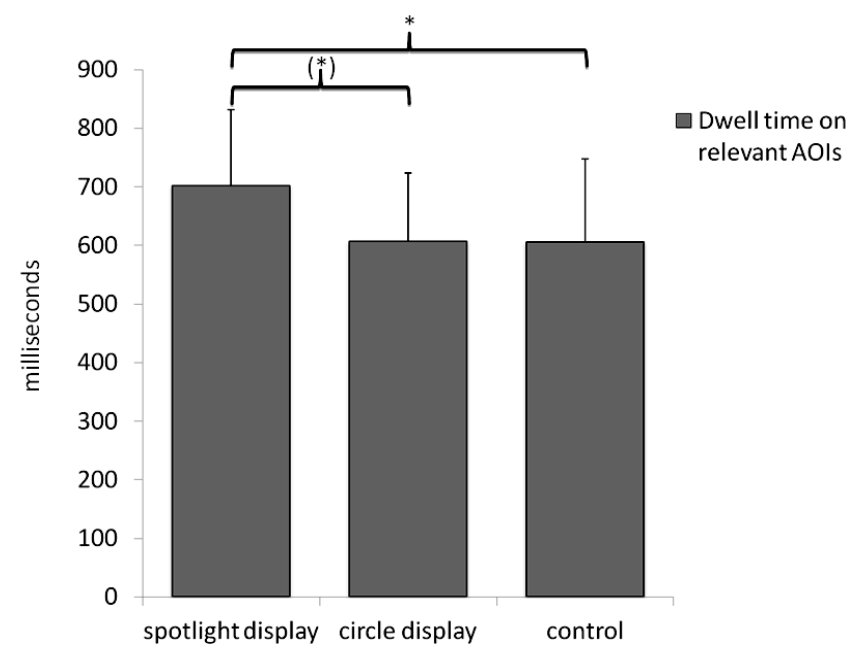

Figure 4 Means and standard deviations for dwell time on relevant AOIs (in ms) during testing. 


\section{Multiple-Choice Questionnaire}

An ANOVA with correctness scores in the multiple-choice questionnaire as dependent variable and condition (control vs. circle display vs. spotlight display) as independent variable showed significant differences between conditions in interpretation performance, $F(2,57)=4.71, p<.01, \eta_{\mathrm{p}}{ }^{2}=.14$. Bonferroni post-hoc tests indicated that the spotlight display condition outperformed the control condition, $p_{\text {one- }}$ tailed $<.01$, but did not differ significantly from the circle display condition, $p_{\text {two-tailed }}=$ .11. The control condition and the circle condition did not differ significantly from each other, $n s$. Results are shown in Figure 5.

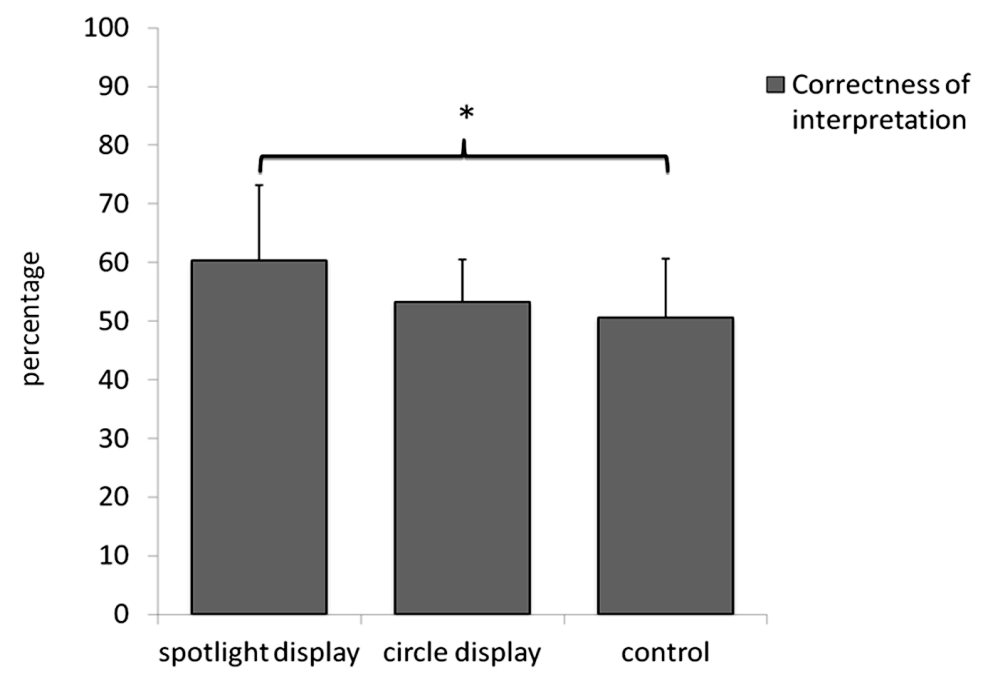

Figure 5 Means and standard deviations for correctness of interpretation score (in percent) for the test videos.

\section{Discussion}

The aim of this study was to teach clinical reasoning based on visual observations necessary for diagnosing epileptic seizures in infants by means of EMMEs. The EMMEs used in this study were recordings of a domain expert model, who was instructed to act as if teaching novices. These EMMEs consisted of two components, namely, first, the model's verbal explanation of the symptoms accompanying the epileptic seizures he saw on the PVCs (i.e., modeling of cognitive processes). Second, it consisted of the model's eye movements superimposed onto the PVC (i.e., modeling of perceptual processes). Moreover, two ways of displaying the model's eye movements were compared: a manufacturer-provided circle display (SMI) and a subtle spotlight display (cf. Nyström and Holmqvist 2008). 
Results of this study showed that learners' attention can be guided by displaying the model's eye movements in PVCs. Analyses of participants' eye movements during example study indicated that the spotlight display of the model's eye movements guided learners' attention during learning stronger than did the circle display or no attention guidance (Hypothesis 1). Moreover, the results showed that this type of attention guidance fostered learning, both in terms of improved visual search (as measured by means of eye tracking, Hypothesis 2) and interpretation ability (as measured by means of multiple choice questionnaires, Hypothesis 3). Participants in the spotlight display group outperformed the circle display group as well as the control condition with regard to both measures. Surprisingly, the circle display condition did not differ from the control group in terms of either attention guidance or learning (i.e., efficiency of visual search and interpretation performance). In sum, this study was the first to show that EMMEs have the potential to promote clinical reasoning based on visual observation. In particular, blurring of irrelevant areas during learning may be the key.

This leads to the question of why the two presentation types of EMMEs resulted in such different effects. The reason for the failure of the circle group might lie in the fact that the circle cue could not help the learners to refrain from focusing on salient, but irrelevant features. Another possible explanation is that the circle display might have tempted the learners' to try to "look through" the small circle instead of attending to the entire body part that the circle pointed to. Trying to look through a very small circle might, however, have been a very difficult visual search that overwhelmed learners' capacities. Furthermore, trying to look through the circle instead of attending to the body part the circle pointed to might have hampered obtaining a holistic overview over the body part. In contrast, the spotlight display in this study did blur very subtly (in contrast to the one in the study by Jarodzka, Van Gog et al. 2010); it guided the learners to the not-blurred areas, but still allowed for an overview of the motion and shape of the entire object. This might have facilitated the understanding of the motion as explained by the model and, thus, enabled learning.

Irrespective of the promising results of this study, its main limitation has to be acknowledged: the effects were found on the basis of only three test videos. This is due to the fact that eye tracking data preparation on videos is very time consuming - and consequently such preparations are still rare. On the other hand, the fact that these effects could be found even with such a low number of items suggests that these effects may be quite strong.

\section{Implications for Instructional Practice}

This study underlines the need to effectively guide visual attention when teaching clinical reasoning based on visual observation. EMMEs seem to provide an appro- 
priate instructional format to address this need provided that the way of displaying eye movements is optimized with regard to the processing demands imposed on the learner.

The question now arises regarding how to transfer the findings of this study into practice. What we have clearly seen is that some tasks (here: diagnosing epileptic seizures in infants) require visual observation skills that are not focused on in present-day education. The same is probably true for several other tasks that require substantial visual observation as well (e.g., clinical reasoning based on all types of medical images, sports judging, playing computer games, air traffic control, car driving, ... . . When instructors teach novices to execute this kind of task, they should keep in mind to teach visual observations as well. EMMEs might be an appropriate way to do this for many tasks. Of course, it is not always possible to use the eye movement recordings of experts, because eye trackers are not easily accessible. Still, if teachers are aware of the fact that visual observation skills play a crucial role in the task they are teaching, they could use videos of the task and make their visual observation explicit, i.e., point as detailed as possible to the relevant areas and explain how they should be interpreted. Moreover, teachers, researchers, and developers of educational software could start exploring the benefits of blurring techniques to guide the attention of the learners. Furthermore, EMMEs could be used in online teaching where pointing is not possible (e.g., during a surgery). An eye tracking device from which the novices receive the recordings might help them to rapidly learn new perceptual tasks. These recordings could be later re-used in offline teaching situations.

In sum, this study showed that EMMEs may be helpful to better convey clinical reasoning based on visual observations in the diagnosis of epileptic seizures in infants. The effects of EMMEs, however, might strongly depend on the task under investigation and the presentation used to show the model's perceptual processes. This study suggests that the best effect - in terms of attention guidance during learning as well as visual search and interpretation performance during testing might be achieved by an EMME that displays the perceptual processes of the expert model as a spotlight that subtly blurs the areas the model did not attend to while the attended areas remain unaltered. 


\section{References}

Antes, J.R., \& Kristjanson, A.F. (1991). Discriminating artists from nonartists by their eye-fixation patterns. Perceptual and Motor Skills, 73, 893-894.

Atkinson, R.K., Derry, S.J., Renkl, A., \& Wortham, D. (2000). Learning from examples: Instructional principles from the worked examples research. Review of Educational Research, 70, 181-214.

Balslev, T., De Grave, W.S., Muijtjens, A.M.M., Eika, B., \& Scherpbier, A.J.J.A. (2009). The development of shared cognition in paediatric residents analysing a patient video case versus a paper patient case. Advances in Health Science Education, 14, 557-565.

Bandura, A. (1977). Social learning theory. Englewood Cliffs, NJ: Prentice-Hall.

Boshuizen, H.P.A., \& Schmidt, H.G. (1992). On the role of biomedical knowledge in clinical reasoning by experts, intermediates, and novices. Cognitive Science, 16,153-184.

Brooks, L.R., LeBlanc, V.R., \& Norman, G.R. (2000). On the difficulty of noticing obvious features in patient appearance. Psychological Science, 11,112-117.

Charness, N., Reingold, E.M., Pomplun, M., \& Stampe, D. (2001). The perceptual aspect of skilled performance in chess: Evidence from eye movements. Memory and Cognition, 29, 1146-1152.

Chi, M.T.H. (2006). Laboratory methods for assessing experts' and novices' knowledge. In K.A. Ericsson, N. Charness, P.J. Feltovich, \& R.R. Hoffman (Eds.), The Cambridge Handbook of Expertise and Expert Performance (pp. 167-184). Cambridge: Cambridge University Press.

Collins, A.F., Brown, J.S., \& Newman, S. (1989). Cognitive apprenticeship: Teaching the craft of reading, writing, and mathematics. In L. Resnick (Ed.), Cognition and instruction: Issues and agendas (p. 453494). Mahwah, NJ: Erlbaum.

De Koning, B.B., Tabbers, H.K., Rikers, R.M.J.P., \& Paas, F. (2009). Towards a framework for attention cueing in instructional animations: Guidelines for research and design. Educational Psychology Review, 21,113-140.

De Leng, B.A., Dolmans, D.H.J.M., Van de Wiel, M., Muijtjens, A.M.M., \& Van der Vleuten, C.P.M. (2007). How video cases should be used as authentic stimuli in problem-based medical education. Med Educ, 41,181-188.

Dequeker, J., \& Jaspaert, R. (1998). Teaching problem-solving and clinical reasoning: 20 years experience with video-supported small-group learning. Med Educ, 32, 384-389.

Dorr, M., Jarodzka, H., \& Barth, E. (2010). Space-variant spatio-temporal filtering of video for gaze visualization and perceptual learning. In C. Morimoto \& H. Instance (Eds.), Proceedings of Eye Tracking Research \& Applications ETRA '10 (p. 307-314). New York, NY: ACM.

Egger, J., Grossmann, G., \& Auchterlonie, I.A. (2003). Benign sleep myoclonus in infancy mistaken for epilepsy. BMJ, 326,975-976.

Grant, E.R., \& Spivey, M.J. (2003). Eye movements and problem solving: Guiding attention guides thought. Psychological Science, 14, 462-466.

Hansen, J.K., \& Balslev, T. (2009). Hand activities in infantile masturbation: A video analysis of 13 cases. European Journal of Paediatric Neurology, 13,508-510.

Helle, L., Nivala, M., Kronqvist, P., Gegenfurtner, A., Björk, P., \& Säljö (2011). Traditional microscopy instruction versus process-oriented virtual microscopy instruction: A naturalistic experiment with control group. Diagnostic Pathology, 6 (Suppl 1):S8

Hinds, P.I. (1999). The curse of expertise: The effects of expertise and debiasing methods on predictions of novice performance. Journal of Experimental Psychology: Applied, 5, 205-221.

International League Against Epilepsy. (2010). Revised terminology and concepts for organization of the epilepsies: Report of the commission on classification and terminology. Epilepsia, 51, 676-685.

Jarodzka, H., Scheiter, K., Gerjets, P., \& Van Gog, T. (2010). In the eyes of the beholder: How experts and novices interpret dynamic stimuli. Journal of Learning and Instruction, 20,146-154.

Jarodzka, H., Van Gog, T., Dorr, M., Scheiter, K., \& Gerjets, P. (2010). How to convey perceptual skills by displaying experts' gaze data. In N.A. Taatgen, \& H. van Rijn (Eds.), Proceedings of the 31st Annual Conference of the Cognitive Science Society (p. 2920-2925). Austin, TX: Cognitive Science Society. 
Jucks, R., Schulte-Löbbert, P., \& Bromme, R. (2007). Supporting experts' written knowledge communication through reflective prompts on the use of specialist concepts. Journal of Psychology, 215, 237247.

Kamin, C., O'Sullivan, P., Deterding, R., \& Younger, M. (2003). A comparison of critical thinking in groups of third-year medical students in text, video, and virtual pbl case modalities. Academic Medicine, 78,204-211.

Krupinski, E.A. (2010). Current perspectives in medical image perception. Attention, Perception, \& Psychophysics, 72, 1205-1217.

Krupinski, E.A. (2005). Visual search of mammographic images: Influence of lesion subtlety. Academic Radiology, 12, 965 - 969.

Krupinski, E.A., Tillack, A.A., Richter, L., Henderson, J.T., Bhattacharyya, A.K., Scott, K.M., et al. (2006). Eye-movement study and human performance using telepathology virtual slides: Implications for medical education and differences with experience. Human Pathology, 37, 1543-1556.

Kundel, H., Nodine, C., Krupinski, E., \& Mello-Thoms, C. (2008). Using gaze-tracking data and mixture distribution analysis to support a holisitc model for the detection of cancers on mammograms. Academic Radiology, 15, 881-886.

Lesgold, A., Rubinson, H., Feltovich, P., Glaser, R., Klopfer, D., \& Wang, Y. (1988). Expertise in a complex skill: Diagnosing x-ray pictures. In M.T.H. Chi, R. Glaser, \& M. Farr (Eds.), The nature of expertise (p. 311-342). Hillsdale, NJ: Erlbaum.

Litchfield, D., Ball, L.J., Donovan, T., Manning, D.J., and Crawford, T. (2010). Viewing another person's eye movements improves identification of pulmonary nodules in chest X-ray inspection. Journal of Experimental Psychology: Applied, 16, 251-262.

Lowe, R.K. (1999). Extracting information from an animation during complex visual learning. European Journal of Psychology of Education, 14, 225-244.

Lüders, H., Acharya, J., Baumgartner, C., Benbadis, S., Bleasel, A., Burgess, R., et al. (1998). Semiological seizure classification. Epilepsia, 39, 1006-1013.

Nordli, D. (2002). Infantile seizures and epilepsy syndromes. Epilepsia, 43, 11-16.

Nordli, D., Bazil, C.W., Scheuer, M.L., \& Pedley, T.A. (1997). Recognition and classification of seizures in infants. Epilepsia, 38, 553-560.

Nückles, M., Winter, A., Wittwer, J., Herbert, M., \& Hübner, S. (2006). How do experts adapt their explanations to a layperson's knowledge in asynchronous communication? An experimental study. User Modeling and User-Adapted Interaction, 16, 87-127.

Nyström M. (2008). Off-line foveated compression and scene perception: An eye tracking approach. Unpublished doctoral dissertation, Lund University.

Nyström M., \& Holmqvist, K. (2008). Semantic override of low-level features in image viewing - both initially and overall. Journal of Eye Movement Research, 2, 1-11.

Rao, R.P.N., Zielinsky, G.J., Hayhoe, M.M., \& Ballard, D.H. (2002). Eye movements in iconic visual search. Vision Research, 42, 1447-1463.

Schmidt, D., \& Schachter, S.C. (2000). Epilepsy: Problem solving in clinical practice. London: Martin Dunitz.

Simon, H.A. (1983). Why should machines learn? In R.S. Michalski, J.G. Carbonell, \& T.M. Mitchell (Eds.), Machine learning: An artificial intelligence approach (p. 25-38). Palo Alto, CA: Tioga.

Sweller, J., Van Merriënboer, J.J.G., \& Paas, F. (1998). Cognitive architecture and instructional design. Educational Psychological Review, 10,251-296.

Underwood, G., Chapman, P., Brocklehurst, N., Underwood, J., \& Crundall, D. (2003). Visual attention while driving: Sequences of eye fixations made by experienced and novice drivers. Ergonomics, 46, 629-646.

Van Gog, T., Jarodzka, H., Scheiter, K., Gerjets, P., \& Paas, F. (2009). Attention guidance during example study via the model's eye movements. Computers in Human Behavior, 25, 785-791.

Van Gog, T., Paas, F., \& Van Merriënboer, J.J.G. (2006). Effects of process-oriented worked examples on troubleshooting transfer performance. Learning and Instruction, 16, 154-164. 


\section{CHAPTER 6}

Van Lehn, K. (1989). Problem solving and cognitive skill acquisition. In M. Posner (Ed.), Foundations of cognitive science. (p. 527-579). Mahwah, NJ: Erlbaum. 
Chapter 7

Discussion 
This thesis started with the observation that a working diagnosis is the key to the work-up and management of disorders. This is still true in a period in which medical education is changing due to the ever increasing complexity of medical conditions. As conditions become more and more complex, a rapidly increasing number of sophisticated imaging and genetic testing opportunities also become available to diagnosticians. Although these opportunities sometimes help to clear up difficult diagnoses, diagnostic testing methods frequently have shortcomings like high cost, suboptimal specificity, and sensitivity (Elstein 2009). Therefore, the need for diagnostic experts who can recognise patterns most of the time and also recognise when the symptoms, signs and test-results do not fit a pattern, is still important (Norman 2006, Crompton and Berkowic 2009).

The present work pursued methods likely to foster expertise in clinicians at work. Firstly, a difficult-to-learn topic with clinical relevance suitable for closer examination was selected. The topic selected for in-depth study was epilepsy (Chapters 2-6) and conditions mimicking epilepsy (Chapters 4-6). This topic is important for a number of reasons. Firstly, conditions within this topic frequently appear in every paediatric practice or department (Crompton and Berkovic 2009). Furthermore, work-up or management may often be difficult or time-consuming for paediatricians, and the uncertainty prior to final diagnosis may be stressful for families. Establishing a diagnosis is obviously particularly desirable when a treatment is available. However, parents generally want their physicians to make a diagnosis, even if no medical treatment is available (Singer et al. 2010).

The studies performed in this thesis were prompted by the presence of a tradition of using PVCs together with the availability of a number of authentic, brief PVCs recorded during work in clinical paediatric neurology settings. The need to investigate this topic was furthermore underlined by the apparent lack of knowledge about how PVCs might support learning.

\section{How the chapters combine to form a line of clarifying research}

The thesis was carried out to build a solid basis for the use of PVCs in learning and the teaching of clinical presentations in a highly visual domain: paediatric neurology. This section provides a short summary of the research findings, the formats examined, and how the projects in this thesis build upon each other.

Chapters 2 and 3 illuminated the first main research question by examining how collaborative efforts in groups of clinicians might lead to learning, and application of PVCs in interactive formats improved cognitive processes associated with learning. In addition to the improvements in theory building and theory evaluation demonstrated in Chapter 2, improved sharing of cognition among collaborating individuals was demonstrated in Chapter 3. 
In postgraduate training, teams are generally small, members have different levels of expertise ranging from the novice learner to the expert clinician, and the composition of the group changes from day to day. These working or learning teams exist in a constant state of flux, inherent in the complex reality of hospital departments, and they have a number of competing duties. One primary duty is the diagnosis of clinical cases. Therefore, the logical next step should be to focus on interactive approaches involving video cases that support diagnostic accuracy within a spectrum of learners as well as experienced clinicians by simulating work in clinical departments.

Taking these circumstances into account, the study in Chapter 4 was planned. A series of interactive team-work approaches to learning were tested with teams that included postgraduate non-experts as well as experts. It turned out that diagnostic accuracy in nonexperts was clearly enhanced by interaction in small-group discussions and by subsequent listening to a content expert. This study therefore exposed differences in behaviour and thinking processes among nonexperts and experts, characterising the processes used by clinicians when they make a diagnosis. Thus, the second main research question was illuminated. This knowledge would be important for any approach to teaching and learning with PVCs. With this background, we then examined an entire spectrum of clinicians, ranging from the novice medical student to the experienced paediatrician.

In chapter 5 visual expertise was examined. We know that in visual domains, experienced physicians search the stimulus visually (attention) and attempt to render an interpretation (cognition). Paediatric neurology is indeed a highly visual domain. Up to now, we did not know much about the co-occurrence of these perceptual and cognitive processes in clinicians. By showing that the diagnostic accuracy of non-experts was clearly enhanced by the interaction in small group discussions and subsequent listening to a think-aloud procedure by a content expert elucidation of the third main research question was obtained. This knowledge is essential for the development of new video-based approaches to learning and might also influence bed-side teaching and learning in clinical settings.

Chapter 6 examined whether displaying an expert's eye movements in modelling examples could benefit learning, and if so, which type of display would be the most effective. Thus, eye movement modelling can be seen as a specific type of scaffolding provided by the expert. This study provides convincing evidence that eye movement modelling may guide the learners' attention, and moreover, that it may support clinical reasoning skills. It also shows that teachers using PVCs for teaching should remember to teach visual observation skills. Chapter 6 thus provided clarification of the fourth main research question.

Therefore, the results of this line of papers build on each other, thereby giving a comprehensive understanding of the perceptual and cognitive processes occurring 
in a range of clinicians exposed to and/or working with PVCs in paediatric neurology.

\section{Contextual, authentic learning}

This section elaborates the results in relation to contextual learning and literature findings, thereby contributing to a deeper understanding of how learners can learn to diagnose with use of paediatric PVCs.

Clark recommended media research should describe in detail the instructional methods with which the media are to be used (Clark 1994, Clark and Salomon 2001). This was attempted in the studies included here. In chapters 2,3 , and 4 the instructional methods used are described, and in all five studies recommendations were given as to how they should be used in practice. In chapters 2 and 3, a postgraduate problem-based learning (PBL) format was applied at a university hospital. The PBL framework was applied to facilitate a rigorous scientific data sampling process. Admittedly, PBL does not have a strong tradition in postgraduate training. Thus, PVCs and PBL may be combined more adequately in pregraduate formats (de Leng et al. 2007) than in postgraduate environments.

In chapter 4, a team-based, stepwise learning approach was designed based on a series of pilot studies done during rounds in clinical settings. While piloting of the learning environments was done in hospital, the study itself was subsequently performed off-hospital at a postgraduate course at a conference centre. In this way, we sought to ensure the relevance of cases and the content of and duration of interactive sessions, and then perform the study in the off-hospital setting. Such a stepwise learning approach is relevant for a number of clinical settings in which experts and nonexperts are present simultaneously, such as grand rounds, meetings, and morning reports in which staff physicians, fellows, residents, and medical students participate. The approach is relevant for a multitude of hospital settings: i.e., the application of small group analysis of authentic PVCs preferably followed by listening to think-aloud by content experts (Cantillon 2006).

The experimental set-up in chapter 5 included eye tracking with concurrent think-aloud in a spectrum of clinicians. Our study shows that in clinicians analysing PVCs, the perceptual and cognitive processes are closely connected. This is interesting in terms of cognitive processing within the multimedia model, including the triad of selecting, organising, and integrating information (Mayer 1999, Mayer 2001). The learners' selection, unconscious or conscious, of relevant aspects of incoming images, involves perceptual processes. Also included in the active cognitive processing is the organising and integration of verbal and pictorial models with prior knowledge. The study shows that use of authentic PVCs not only may expand learners' 
exposure to common and uncommon pictures, it may also offer in-context opportunities to learn more with and from senior colleagues in neurology.

Chapter 6 gives a new approach to in-context learning by concurrent perceptual and cognitive modelling. The study illustrates that attention guiding in a spotlight fashion improves attention in terms of speed and accuracy and improved clinical reasoning. While eye trackers are not easily accessible in clinical practice, the findings can still be applied by clinical teachers, who can bring clinical observations into focus by asking learners what they are paying attention to, and by pointing to relevant areas and explaining why the learners should be paying attention to them.

\section{Collaborative learning in postgraduate paediatrics}

This section particularises the findings relating to collaborative learning and relates them to the literature. As mentioned in the introduction, residents learn a great deal by working with cases in a community of practice. Learning is therefore an everyday practice. It is developed through newcomers and old-timers working together, and language is a central part of this practice (Mann 2011). Work-based learning favours interactive forms of learning where individual interpretations, reflections, and understandings meet each other (Raelin 2000, Morris and Blaney 2010). Thus, social interaction is seen as being crucial to cognitive development.

Cognitive elaboration takes place when group members answer each other's questions, and elaboration is a central method in cognitive apprenticeship learning (Collins 2006). Elaboration in these studies occurred in a PBL format in chapters 2 and 3 and in small and large groups in chapter 4 . In chapter 5 , analysis of thinkaloud was used to tap into the cognitive processes of a spectrum of clinicians. In chapter 6 , explaining by a content expert was used as part of the modelling procedure. Thus, elaboration was used in most of the present studies, illustrating the central role of language and elaboration in teaching and learning with the use of PVCs. Previous research on patient video cases in medical education also highlights interaction, with elaboration as central to learning (Dequeker and Jaspaert 1998, Kamin 2001, Kamin, O’Sullivan et al. 2003, de Leng, Dolmans et al. 2006, Azer 2007).

\section{Strengths and weaknesses}

The material used in the studies was original and authentic PVCs of children in spontaneous activity. None of the infants or children appearing in the video recordings were instructed to play a certain role or to simulate any particular movement. All of the children were videotaped at the hospital by staff nurses or physicians or at home by the parents. All of the movements were therefore natural - they were "the 
real thing". This is a strength underlining the validity and relevance of the findings. It is likely that PVCs already existing at paediatric departments can be used for interactive teaching formats to improve learning.

It is a strength of the first two studies that they are controlled studies conducted with residents, and that the dependent variables in both of them include cognitive measures. In this way, a window on thinking processes relevant for residents' learning is opened. The main strength of the second study is that it affords additional insight into the collaborative activation of concept links by the use of stimulated recall. This gives insight into residents' thoughts that were not expressed during group discussion. As the first two studies included a small number of residents analysing one PVC only, humility about the results is warranted. On the other hand, it is a strength that actual paediatric residents were used, increasing the relevance for clinical settings. An important, strong point of the present studies is the enrichment provided by the collaborative work in our multi-institutional and multinational group of researchers, adding clarity and scientific rigour to research questions and applying relevant, cutting-edge methodology.

While chapters 2-4 studied collaborative analysis of PVCs, chapters 5 and 6 studied concomitant individual attention and cognitive processes entertained when individuals analysed PVCs. One could argue that it would also be interesting to continue the collaborative line of research initiated with chapters 1-3. For two reasons, however, it was decided to focus on individual analysis of PVCs in chapters 5 and 6. Firstly, in-depth knowledge about individual attention and cognitive processing can inform practice in settings with collaborative learning. Chapter 4 allowed for detailed, concurrent measurements of cognition and attention, outweighing the shortcoming due to not being performed in a collaborative setting. Secondly, technology had not yet been fully developed that allowed concomitant eye tracking and recording of a think-aloud procedure from individuals participating in an interactive session analysing a PVC.

A limitation of the study reported in chapter 6 is the participation of medical students only. Medical students were available in sufficient numbers for this controlled study with three groups, while it would not have been possible to recruit a similar number of paediatric residents. An important advantage of using medical students is that they have homogenous background knowledge about the topic, reducing the risk of bias. Another limitation of this study is the low number of test videos: i.e., three. It was not possible to include more test videos, because analysis of the eye tracing data on videos is extremely time-consuming. Due to the experimental rigour of the study, we believe that the results are valid and thus have implications for instructional practice. 


\section{Implications for practice}

The studies that form this thesis show that PVCs used in interactive environments can benefit learning by improving the building of hypotheses and the sharing of cognition. We also showed that diagnostic accuracy of non-experts is enhanced by a discussion of PVCs in small groups and subsequent listening to a content expert thinking aloud. We documented that clinicians with more expertise spend more time looking at relevant areas in the PVCs than do learners, while at the same time building and evaluating more hypotheses. Finally, we learned that displaying a model's eye movements in PVCs can foster learning in terms of a learner's attention and interpretation performance. This coherent sum of knowledge has wide implications for the interactive use of PVCs in practice.

The interactive use of PVCs can benefit learning, and the formats are very adaptable. They are relevant in graduate as well as in postgraduate clinical settings: at rounds, during meetings, or in the outpatient clinic. They may be used for large or for small groups. In postgraduate clinical settings, teams are typically rather small, consisting of 2 to 6 members with a wide range of expertise, ranging from the novice medical student to the experienced specialist in paediatrics.

PVCs may be used in clinical settings to create or extend work-based learning. As is often the case in clinical practice, direct observation of intermittent symptoms in real patients may be impossible or difficult due to lack of cooperation from the infant or child. In such a situation, a PVC demonstrating a similar event can be extremely valuable. Such a case can be used to generate attention and cognitive processes in a small group of learners. PVCs can be adapted to formal as well as informal methods. The senior colleague can choose to focus not only on his or her role as a medical expert, but also on other roles as well. Examples of PVCs and corresponding challenges within the framework of the 7 CanMeds roles (Royal College of Physicians and Surgeons of Canada 2005) are given in table A.

Educational meetings outside the hospital may also be appropriate for interactive sessions with PVCs, allowing a large number of participants to contribute to the teaching and learning processes. (Chapter 4, Cantillon 2003) Large groups may, for a few minutes, be broken up into smaller groups of two to five learners for the purpose of analysing a PVC. These groups are termed "buzz groups" after the sound produced during interaction (Cantillon 2003). Buzz group activity is an advantageous means of getting learners to process and use new information to analyse a PVC. At the end of the buzz group session, the teacher can check the results of the exercise by asking a few of the groups to elaborate on their observations or views. This will give the opportunity for learners to compare their understanding with that of others, and may thus contribute to shared cognition. (Chapter 3 )

Chapter 6 shows that displaying a model's eye movements in PVCs can foster learning in terms of a learner's attention and interpretation performance. The best 
effect might be achieved by displaying the perceptual processes as a spotlight that subtly blurs the contrast of the remaining video. The main point, however, is the need to guide visual attention when teaching clinical reasoning based on visual observation. On this basis, teachers and developers of educational software could start exploring the benefits of blurring techniques to guide the attention of the learners. Wide-spread use of experts' eye movements in teaching may be not feasible because eye trackers are not easily accessible. Instead, teachers can use videos and make their visual observations explicit by pointing to relevant areas and explaining when and why they attend to those areas.

Table A Clinical examples classified after the 7 CanMEDs roles (Royal College of Physicians and Surgeons of Canada 2005) illustrating challenges that may be used by clinical teachers to facilitate perceptive or cognitive processes in learners.

\begin{tabular}{|c|c|c|c|}
\hline \multirow[t]{2}{*}{ CanMeds role } & \multicolumn{3}{|c|}{ Patient video case Examples Challenges } \\
\hline & & Novice learner & Advanced learner \\
\hline Medical expert & $\begin{array}{l}\text { A 6-month-old infant with } \\
\text { infantile spasms }\end{array}$ & $\begin{array}{l}\text { Please describe this event to } \\
\text { me } \\
\text { What is important to look at? } \\
\text { Let me show you what I pay } \\
\text { attention to }\end{array}$ & $\begin{array}{l}\text { Do you think this is a typical } \\
\text { case of infantile spasms? } \\
\text { What else might this be? }\end{array}$ \\
\hline Communicator & $\begin{array}{l}\text { A 6-year-old girl with ab- } \\
\text { sences }\end{array}$ & $\begin{array}{l}\text { Please describe this event to } \\
\text { me Let me show you what I } \\
\text { pay attention to in this case }\end{array}$ & $\begin{array}{l}\text { Please tell me what you } \\
\text { would report in the chart } \\
\text { after seeing this event }\end{array}$ \\
\hline Scholar & $\begin{array}{l}\text { A } 2 \text { day-old infant with } \\
\text { benign sleep myoclonus } \\
\text { simulating epileptic fits }\end{array}$ & What do you think this is? & $\begin{array}{l}\text { This is a remarkable case. } \\
\text { What can we learn from it? }\end{array}$ \\
\hline Health advocate & $\begin{array}{l}\text { A 14-year-old boy with who } \\
\text { keeps forgetting his medi- } \\
\text { cine and has a seizure }\end{array}$ & $\begin{array}{l}\text { Please give me two common } \\
\text { causes of break-through } \\
\text { seizures in patients with } \\
\text { epilepsy }\end{array}$ & $\begin{array}{l}\text { What would you advice the } \\
\text { patient to do to prevent } \\
\text { more seizures? }\end{array}$ \\
\hline Professional & $\begin{array}{l}\text { A 2-year-old boy with new } \\
\text { onset ataxia and a head tilt }\end{array}$ & $\begin{array}{l}\text { Who will you consult to deal } \\
\text { with this case - and why? }\end{array}$ & $\begin{array}{l}\text { Do you know enough to } \\
\text { plan the work-up of a case } \\
\text { like this? }\end{array}$ \\
\hline Manager & $\begin{array}{l}\text { A 2-year-old girl with cere- } \\
\text { bral palsy and complex } \\
\text { needs }\end{array}$ & $\begin{array}{l}\text { How do you think we can } \\
\text { manage the complex needs in } \\
\text { a } 15 \text {-minute consultation in } \\
\text { the out-patient clinic? }\end{array}$ & $\begin{array}{l}\text { How will you plan a follow- } \\
\text { nup consultation in the out- } \\
\text { patient clinic? }\end{array}$ \\
\hline Collaborator & $\begin{array}{l}\text { A 1-year-old drowsy girl } \\
\text { with multiple suggilations }\end{array}$ & $\begin{array}{l}\text { What would you expect the } \\
\text { nurse to do in this case? }\end{array}$ & $\begin{array}{l}\text { Who would you like to } \\
\text { consult to manage this } \\
\text { case? }\end{array}$ \\
\hline
\end{tabular}

\section{New research questions}

This section focuses on the new research questions that can be raised as natural consequences of the current studies. The thesis was performed to clarify an empiri- 
cal and theoretical basis for the use of PVCs in learning and teaching of clinical presentations in the highly visual domain of paediatric neurology. We now know that interactive environments can benefit learning by improving the building of hypotheses and the sharing of cognition and by enhancing the diagnostic accuracy of nonexperts. We also know that clinicians with more expertise spend more time looking at relevant areas in the PVCs while building more hypotheses, and modelling by means of eye movements can foster learning. This comprehensible sum of knowledge also has implications for other investigations of the interactive use of PVCs in practice.

Firstly, one could look for approaches that might help learners think deeper and thus learn more from PVCs. One such approach is the collaborative analysis of cases that contrast each other. These may help learners generate more differentiated knowledge and thereby enhance learning from lectures (Schwartz and Bransford 1998). In a recent study, Ark et al. presented evidence that deliberate instruction to compare contrastive EKG cases may enhance diagnostic accuracy in novices (Ark, Brooks et al. 2007). While these studies performed with static stimuli suggest that the contrasting of cases enhances learning, a paucity of studies examined dynamic stimuli (de Leng, Dolmans et al 2006). The environment might include simultaneous or sequential replay of contrasting PVCs being analysed collaboratively.

Secondly, as the important findings in this thesis concern the improvement of cognitive processes occurring during on-going analysis of PVCs, new researchers may build on the conceptual frameworks of work-based learning (Morris and Blaney 2010) and ask: if these are the short term effects - what are the long term effects in terms of literature studies, diagnostic accuracy, or benefits for patients (Kirkpatrick 1996)? A difficulty that researchers pursuing this research question in controlled designs will meet is participant reactivity (Hawthorne effect) confounding the dependent variables (Wikström and Bendix 2000). Attractive research questions might be: does the active contrasting of cases influence immediate diagnostic accuracy when a group of paediatric residents analyses video cases? - or: will active contrasting of cases influence the long-term diagnostic accuracy of residents?

Thirdly, technology that records eye tracking of several team members collaborating on the analysis of a PVC may be available within a short time span. Building on a theory describing cognitive apprenticeship learning (Collins 2006), researchers will be able to pursue new research questions like: How do perceptual and cognitive processes develop when clinicians interact during the analysis of a PVC? 


\section{References}

Ark TK, Brooks LR, Eva KW. (2007). The benefits of flexibility: the pedagogical value of instructions to adopt multifaceted diagnostic reasoning strategies. Medical Education, 41, 281-287.

Azer SA. (2007). Twelve tips for creating trigger images for problem-based learning cases. Medical teacher, 29, 93-7.

Beitzel BD, Derry SJ. (2009) When the book it better than the movie: how contrasting video cases influence text learning. J Educational Computing Research, 40(3), 337-355.

Cantillon P. (2003). ABC of learning and teaching in Medicine. Teaching large Groups. BMJ, 326, 437-440.

Clark RE. (1994) Media will never influence learning. Educational Technology, Research and Development, 42(2), 21-29.

Clark RE, Salomon G. (2001) Why should we expect media to teach anyone anything? In: Clark RE. Learning from media. Arguments, analysis and evidence. Connecticut: IAP, pp. 37-70.

Collins A. (2006). Cognitive apprenticeship. In Sawyer RK (ed.). The Cambridge Handbook of the Learning Sciences. Cambridge: Cambridge University Press, pp 47-60.

Crompton DE, Berkovic SF. (2009). The borderland of epilepsy: clinical and molecular features of phenomena that mimic epileptic disorders. Lancet Neurology, 8, 370-81.

Elstein AS. (2009). Thinking about diagnostic thinking: a 30-year perspective. Adv in Health Sci Educ, 14, 7-18.

Kamin CS, Deterding RD, Wilson B, Armacost M, Breedon T. (1999). Development of a collaborative distance learning program to facilitate pediatric problem-based learning. The Med Educ Online , 4, 2.

Kirkpatrick, D. (1996). Great ideas revisited. Techniques for evaluating training programs. Revisiting Kirkpatrick's four level model. Training and Development, 50, 54-59.

de Leng BA, Dolmans DHJM, van de Wiel MWJ, Muijtjens AMM, van der Vleuten CPM. (2007) How video cases should be used as authentic stimuli in problem-based medical education. Medical Education, 41, 181-8.

Morris C, Blaney D. (2010). Workbased Learning. In: Understanding Medical Education. Tim Swanwick Ed, Oxford: Wiley-Blackwell, pp. 69-82

Norman G. (2006) Building on experience - the development of clinical reasoning. NEJM, 355, $2251-2$.

Dequeker J, Jaspaert R. (1998). Teaching problem-solving and clinical reasoning: 20 years' experience with video-supported small-group learning. Medical Education 32(4), 384-9.

Raelin JA. (2000) The grounds for work-based learning. In: Raelin JA. Work-based learning. The new frontier of management development. New Jersey: Prentice Hall, pp 8-26.

Royal College of Physicians and Surgeons of Canada. The CanMEDS Physician Competency Framework. (Accessed June 11, 2011)

Schwartz DL, Bransford JD. (1998) A time for telling. Cognition and Instruction, 16(4):475-522.

Singer H, Mink JW, Gilbert D, Jankovic J. (2010) Diagnostic evaluation of children with movement disorders. In: Singer H, Mink JW, Gilbert D, Jankovic J, eds. Movement disorders in childhood. Philadelphia: Saunders, pp 19-29.

Wickstrom G, Bendix T. (2000) The "Hawthorne effect" - what did the original Hawthorne studies actually show? Scand J Work Environ Health, 26(4): 363-367. 
Chapter 8

Summary 
This thesis presents research on work-based learning with brief patient video cases (PVCs). The thesis was performed to clarify a solid basis for the use of PVCs in learning and teaching how to interpret clinical presentations in a highly visual domain: paediatric neurology.

Chapter 1 contains the introduction to the thesis, describing the relevance and context of the research. For clinicians, learning to diagnose is a priority. In the workplace, learning to diagnose can come about by a variety of learning methods ranging from the formal, organized learning approaches to the, more frequent, informal on-the-spot, near spontaneous type of approaches. Workplace interaction among clinicians may accelerate collaborative learning and even promote shared cognition. The concept of cognitive apprenticeship learning indicates a desirable, deep type of learning designed to help learners gain conscious access to their own problem solving strategies and compare them with those of experts.

Learning about common neurological symptoms, like movement disorders or epileptic seizures, is complicated by symptoms being periodic or episodic. Hence, an emphasis on teaching and learning of these disorders is important. Research has shown that expertise is built through matching cases against previously encountered similar ones. It therefore appears desirable to supplement real patients trainees see during clinical work with additional cases, and to encourage active analysis and comparison of cases. The additional cases may take the form of authentic PVCs, recorded in homes or in the hospital, demonstrating characteristic signs and symptoms. While PVCs are already frequently used for contextual, authentic learning in graduate and postgraduate paediatric settings, published research on learning from PVCs is scarce.

The chapter concludes by formulating the main research questions: 1) How does adding a PVC enhance the cognitive processes and sharing of cognition among learners? 2) How can interactive approaches with PVCs improve diagnostic accuracy? 3) What do clinicians with varying experience attend to and think while analysing PVCs? 4) How does visual attention guidance in analysing PVCs benefit learning?

Chapter two investigates the first main research question by investigating whether adding a brief video case instead of an equivalent written text improves residents' cognitive processes in problem-based learning. We used a controlled before-andafter design with two groups. Both groups analysed an identical, written vignette of a patient case. Immediately after this, one group watched a 2.5-minute video recording with a seizing infant, and the other group read a description of the same video recording. The members of each group collaboratively reanalysed the case. Thinking processes were tapped by recording and analysing the verbal group interaction. Statistically significant improvements after the video case were documented 
in data exploration, theory building and theory evaluation. The use of collaborative analysis of patient video recordings may therefore be a valuable supplement to postgraduate paediatric training.

Chapter three also investigates the first main research question by augmenting insight into the cognitive processes during collaborative analysis of the case analysed in chapter 2 . As learning from the case must be related to what the participants think, we were interested in all of the cognitive processes occurring during analysis of the case. The silent cognitive processes were examined using a stimulated recall procedure. The causal reasoning links in the stimulated recall procedure outnumbered those during the verbal interaction by three to one. Thus, the verbal interaction showed really only the tip of the iceberg. We labelled the causal reasoning concept links as individual or collaborative depending on whether they originated from individual residents or were directly elicited by verbal utterances from others. This novel process approach to chronological registration of concept link formation offered evidence that shared cognition by means of co-elaboration of concept formation is stimulated by the use of patient video recordings in small group learning. This suggests that the benefits of PVCs are not only rooted in the media itself, but also in the shared cognition stimulated by PVCs.

Chapter four examines research question two by exploring selected learning environments using patient video cases that may improve the diagnostic accuracy of non-experts. In this study, performed during a postgraduate course in paediatric neurology, participants of varying levels of experience analysed four PVCs using a stepwise approach. Individual as well as collaborative approaches were incorporated. The diagnostic accuracy of non-experts was clearly enhanced by the interaction in small group discussions and subsequent listening to a think-aloud procedure by a content expert. The research in this chapter suggests that learning by videocases in clinical settings can be improved by the interactive participation of junior as well as senior clinicians. Such an environment, a 'virtual examination room', may be introduced at grand rounds, case conferences or morning rounds to stimulate the development of diagnostic accuracy in non-experts.

Chapter five investigates visual expertise in paediatric neurology by examining the perceptive and the underlying cognitive processes in a spectrum of clinicians diagnosing PVCs, thereby shedding light on the third main research question. In this descriptive study among individual clinicians, we used eye-tracking and a simultaneous think-aloud procedure. Time looking at areas of interest, diagnostic accuracy, hypothesis generation and hypothesis evaluation increased significantly with duration of postgraduate experience. In contrast, less experienced clinicians looked less at important areas of interest, had a lower diagnostic accuracy and generated and 
evaluated fewer hypotheses. This information may be helpful to clinical teachers using PVCs in a broad variety of specialties.

Chapter six examines the fourth main research question by investigating learning via eye movement modelling examples with PVCs. We know from non-medical research that decisions based on visual observations can be facilitated by showing the eye movements of a model and thereby guiding attention (i.e., eye movement modelling examples; EMME). In this randomized controlled study, medical students in three groups saw a display of the expert's eye movements while he was analysing a PVC, and listened to a recording of the same expert speaking aloud in a didactic manner. Results showed that a spotlight on the example videos guided the students' attention better to the relevant features compared to guidance of visual attention in a circle fashion or no visual attention guidance at all. The study also showed that guiding attention in a spotlight fashion improved subsequent visual search and enhanced the participants' performance in interpreting symptoms in PVCs compared to the other two conditions.

Chapter seven presents a general discussion of the research, beginning with a brief review of the context and relevance of the studies performed. The findings are related to the framework of work based and collaborative learning. The main conclusions with regard to the main research questions are: 1) The collaborative, interactive use of PVCs can benefit learning and sharing of cognition. 2) Interactive approaches to the analysis of patient video cases benefit the diagnostic accuracy of non-experts. 3) In a spectrum of clinicians with varying duration of clinical experience, more experienced clinicians are superior in terms of time spent looking at areas of interest, diagnostic accuracy, hypothesis building and hypothesis evaluation. In addition, 4) visual attention guidance seems to benefit learning.

The key strengths of the studies include the remarkable authenticity of the PVCs that were used and the use of clinicians from paediatric departments for the majority of the studies. This underlines the validity and relevance of the findings. One aspect of this thesis may be considered a drawback. The focus on collaborative analysis of PVCs in chapters 2-4 moved to a focus on individual analysis of PVCs in chapters 5 and 6 . It is important to note, however, that the in-depth knowledge about individual attention and cognitive processing added by chapters 5 and 6 is not only fundamental for practice in individual settings, but can also inform practice for individual clinicians participating in collaborative learning environments.

The results of the studies have practical implications for clinicians. The use of authentic PVCs may not only expand learners' exposure to common and uncommon clinical pictures, but also offer in-context opportunities to learn more with and from colleagues in paediatric neurology. Interactive use of PVCs may be applied in a variety of clinical settings to create or extend work based learning. The formats are very 
adaptable and relevant at rounds, during meetings or in the outpatient clinic. Attention guidance in PVCs is a new approach. Teachers and developers of educational software could start exploring the benefits of blurring techniques to guide learners' attention. While the use of experts' eye movements in teaching may be not feasible as eye trackers are not easily accessible, teachers can use videos and make their visual observations explicit by pointing to relevant areas and explaining when and why they attend to those areas.

The studies included in this thesis open new avenues of research on the use of PVCs in education. While the studies in this thesis focus on immediate and short term learning effects, new research may focus on longer term effects in terms of learners' behaviour, diagnostic accuracy or, ultimately, benefits for patients. In the future, technological improvements in tracking eye movements may allow a focus on attention and cognitive processes occurring when two or more clinicians collaborate. 

Chapter 9

Resume (summary in Danish) 
Denne Ph.d. afhandling handler om arbejdsbaseret læring vha. korte patient video cases. Afhandlingen blev udført for at klarlægge en solid, empirisk baggrund for brug af patient video cases for klinikere i det stærkt visuelle domæne: neuropædiatri.

Kapitel 1 udgør introduktionen og beskriver forskningens relevans og kontekst. Det er naturligvis vigtigt for alle klinikere at kunne stille en diagnose. På arbejdspladsen er der mange læringsmetoder til rådighed, hvoraf nogle er formelle og planlagte og andre er mere uformelle og spontane. Interaktion mellem klinikere kan accelerere læring gennem samarbejde og dermed fremme vidensdeling. Det centrale begreb kognitiv mesterlære omfatter en dyb læringsmetode som kan give den lærende forståelse for egne problemløsningsstrategier og sammenligne dem med eksperternes.

Bevægeforstyrrelser og epileptiske anfald er almindelige symptomer i pædiatrien. De er ofte varierende i udtryk eller episodiske, hvilket gør det vanskeligt for klinikere at lære noget om dem, og netop derfor er det vigtigt at lægge vægt på læring af disse. Der er allerede forskning, som viser at expertise kan opbygges ved at sammenligne nye cases med cases man har mødt før. Det er derfor nærliggende at supplere virkelige patienter som de uddannelses $\varnothing$ gende møder med et antal ekstra cases, og at opmuntre til analyse og sammenligning af disse cases. De ekstra patient cases kan være autentiske video cases, optaget i hjemmene eller i hospitalet, og de kan demonstrere karakteristiske symptomer og tegn. Selv om patient video cases allerede bruges flittigt i pædiatrien til kontekstuel, autentisk læring såvel prægraduat som postgraduat, er der ikke publiceret ret meget forskning om læring med patient video cases.

Til sidst i kapitlet angives de centrale forskningsspørgsmål: 1) Hvordan kan en patient video case forbedre de kognitive processer og hjælpe med til vidensdeling blandt de lærende? 2) Hvordan kan interaktiv brug af patient video cases forbedre den diagnostiske præcision? 3) Hvad fokuserer klinikere med forskellig varighed af klinisk erfaring på i patient video cases - og hvad tænker de samtidigt? 4) Hvordan kan visuel vejledning indbygget i patient video cases forbedre læring?

Kapitel 2 undersøger om analyse af en video case i stedet for analyse af en tilsvarende tekst forbedrer de kognitive processer hos reservelæger i problem-baseret læring. I et kontrolleret $\varnothing \varnothing$ - og efter-studie analyserede to grupper hver for sig en identisk, skriftlig sygehistorie. Den ene gruppe analyserede derpå en videocase, mens kontrolgruppen analyserede en tilsvarende beskrivelse af video optagelsen. Den verbale interaktion blev optaget på lydbånd, og bagefter afskrevet fra ord til andet. Der var statistiske forbedringer i data eksploration, teoribygning og teorievaluering efter video casen. Kollaborativ analyse af videocases kan derfor være et værdifuldt supplement til postgraduat pædiatrisk træning. 
Kapitel 3 giver yderligere indsigt i de kognitive processer blandt individer som sammen analyserer en videocase. Da læring må være relateret til hvad individerne tænker, var vi interesseret i alle de kognitive processer. De ellers tyste kognitive processer blev unders $\emptyset$ gt vha. en stimuleret hukommelsesprocedure, og den verbale interaktion udgjorde blot toppen af isbjerget. Vi optalte de kliniske ræsonnementer, som blev udløst af at et af de $\varnothing$ vrige individer udtalte sig. Denne nye metode til kronologisk at registrere klinisk ræsonnementer viste at man kan fremme fælles forståelse når man lader en gruppe reservelæger analysere patient video cases. Det betyder at fordelene ved brug af video ikke kommer fra selve mediet: fordelene kommer også af den fælles kognition de er med til at skabe.

Kapitel 4 undersøger udvalgte video case læringsmiljøer, som kunne tænkes at forbedre den diagnostiske akkuratesse blandt ikke-eksperter. I det aktuelle studie, som blev udført ved et kursus i børneneurologi, analyserede klinikere med varierende erfaring trinvist fire patient video cases. Der blev brugt såvel individuelle som kollaborative metoder. Det viste sig, at ikke-eksperters diagnostiske præcision blev klart forbedret af interaktion i små grupper og efterfølgende lytning til en ekspert, som tænkte højt, mens han eller hun analyserede casen. Forskningen i dette kapitel tyder derfor på at læring med patient video cases i kliniske omgivelser vil forbedres af interaktiv deltagelse af såvel yngre som mere erfarne klinikere. Sådanne omgivelser, et 'virtuelt unders $\varnothing$ gelses rum', kan introduceres ved konferencer eller møder for at stimulere den diagnostiske præcision hos ikke-eksperter.

Kapitel 5 undersøger visuel ekspertise i neuropædiatri ved at undersøge de perceptive og underliggende kognitive processer hos et spektrum af klinikere mens de er i gang med at diagnosticere patient video cases. I dette deskriptive studie af individuelle klinikere brugte vi eye-tracking og simultan højt tænkning. Tid brugt til at se på relevante områder i videoerne, diagnostisk præcision samt hyppigheden af hypotesedannelse og hypoteseevaluering steg signifikant med varigheden af postgraduat erfaring. I modsætning hertil så mindre erfarne klinikere mindre på relevante områder i videoerne, havde en lavere diagnostisk præcision og de dannede og evaluerede færre hypoteser. Denne information kan hjælpe klinikere som bruger patient video cases i en bred vifte af specialer.

Kapitel 6 unders $\varnothing$ ger læring vha. video cases med indlagte eksempler på øjenbevægelser. Vi ved fra ikke medicinsk forskning, at beslutninger baseret på visuelle observationer kan faciliteres hvis man demonstrerer en models $\emptyset$ jenbevægelser og på denne måde lede opmærksomhed. I dette randomiserede, kontrollerede studie så medicinske studenter, delt i tre grupper, video med en eksperts indlagte øjenbevægelser mens han analyserede en video case mens de lyttede til en optagelse af ham mens han tænkte højt på en didaktisk måde. Resultaterne viste at sløring af de om- 
råder, eksperten ikke så på, var bedst til at styre deltagernes opmærksomhed mod de relevante områder (spotlight) sammenlignet med deltagere som så en video med en ringmarkering eller så en video helt uden markeringer. Studiet viser også at opmærksomhedsstyring vha. spotlight - i forhold til de to andre grupper - forbedrede efterfølgende visuel søgning samt analyse og fortolkning af symptomer i video cases.

Kapitel 7 begynder med en kort oversigt over kontekst og relevans af de udførte studier. Fundene relateres til teorierne bag arbejdsbaseret læring og kollaborativ læring. Hovedkonklusionerne relateres til de centrale forskningsspørgsmål: Kollaborativ, interaktiv brug af patient video cases kan forbedre læring og diagnostisk præcision. Erfarne klinikere er bedre til at se på relevante områder, har bedre diagnostisk præcision, hypotese dannelse og hypotese evaluering. Desuden er det vist at visuel opmærksomhedsstyring kan gavne læring.

Styrken af disse studier omfatter især den bemærkelsesværdige autenticitet patient video cases giver og anvendelsen af klinikere fra børneafdelinger fra de fleste studier. Det understreger validiteten og relevansen af fundene. Man kan pege på en svaghed i rækken af studier, idet fokus skifter fra kollaborativ analyse i kapitlerne 24 til individuel analyse af patient video cases i kapitel 5.6. Det er dog vigtigt at bemærke at den nye viden som kapitel 5-6 giver ikke begrænser sig til individuelle forhold - den vil også være basal for individer som deltager i kollaborative lærings miljøer.

Resultaterne har praktiske følger for klinikere. Anvendelse af autentiske patient video cases kan ikke blot udvide de lærendes erfaring med almindelige eller ualmindelige kliniske billeder, anvendelsen kan også give in-kontekst lejligheder for at lære med og af kolleger i neuropædiatri. Interaktiv anvendelse af patient video cases er relevant i forskellige sammenhænge for at skabe eller udvide arbejds baseret læring. Formaterne kan tilpasses og er relevante ved konferencer og møder eller $\mathrm{i}$ ambulatoriet. Opmærksomhedsstyring med patient video cases er en ny fremgangsmåde. Undervisere og udviklere af software kan nu begynde at undersøge mulighederne ved opmærksomhedsstyring vha. spotlight teknik. Selv om konkret udnyttelse af eksperters øjenbevægelser kan være vanskelig fordi eye-tracking ikke er alment tilgængelig, kan undervisere som bruger patient video cases gøre deres visuelle observationer eksplicitte ved at pege på relevante områder og forklare hvorfor de ser på netop disse områder.

Studierne i denne afhandling åbner for nye muligheder for forskning med patient video cases. Mens de aktuelle studier fokuserer på læringseffekt på kort sigt, vil ny forskning kunne fokusere på læringseffekt på lidt længere sigt i form af adfærd, diagnostisk præcision eller ultimativt: fordele for patienterne. I fremtiden kan teknologiske forbedringer indenfor eye-tracking måske endda tillade at man unders $\emptyset$ - 
ger opmærksomhed og kognitive processer mens ikke bare én, men to eller flere klinikere sammen analyserer patient video cases. 

Chapter 10

Samenvatting (summary in Dutch) 
Dit proefschrift bestaat uit verschillende onderzoeken naar de toepassing van korte video-opnames van patiëntencasus (VPC's) in het klinisch onderwijs. Het doel van de onderzoeken was om een goed onderbouwde basis te creëren voor de toepassing van VPC's in het onderwijs, met name betreffende het leren herkennen en interpreteren van klinische beelden op een terrein van de geneeskunde waarin visuele aspecten een uiterst belangrijke rol spelen: de kinderneurologie.

Hoofdstuk 1 bevat de inleiding van het proefschrift, waarin de relevantie en de context van het onderzoek beschreven worden. Het leren stellen van een juiste diagnose heeft hoge prioriteit in het klinisch onderwijs. Hiervoor bestaan verschillende onderwijsmethoden die in de klinische werkplaats toegepast kunnen worden, variërend van formele, gestructureerde benaderingen tot de, veel vaker voorkomende, informele leermomenten die zich ter plekke en min of meer spontaan voordoen tijdens het werken in de klinische praktijk. Interactie tussen clinici in de klinische werkplaats kan samenwerkend leren bevorderen en leiden tot het ontwikkelen van gedeelde kennis. Het concept 'cognitive apprenticeship' verwijst naar een gewenste vorm van diep leren waarin lerenden geholpen worden om zich bewust te worden van hun eigen strategieën om problemen op te lossen en ook om deze te vergelijken met de strategieën toegepast door experts.

Clinici moeten veelvoorkomende neurologische symptomen zoals bewegingsstoornissen of epileptische aanvallen kunnen herkennen en interpreteren, maar het leren hiervan wordt bemoeilijkt doordat deze symptomen slechts periodiek of episodisch voorkomen. Het is daarom van belang dat er in het onderwijs gericht aandacht besteed wordt aan dergelijke ziektebeelden. Uit onderzoek is gebleken dat de ontwikkeling van expertise gebaseerd is op het vergelijken van casus met daarop lijkende casus die men eerder heeft gezien. Het is dan ook wenselijk dat AIOS tijdens hun opleiding veel gevallen zien van veelvoorkomende aandoeningen waardoor zij kunnen oefenen in het actief analyseren en vergelijken van symptomen. Extra casus, naast de casus die AIOS in de praktijk zien, kunnen worden aangeboden in de vorm van authentieke VPC's, opgenomen in een authentieke omgeving, zoals het ziekenhuis, en waarin karakteristieke symptomen getoond worden. Hoewel VPC's veelvuldig toegepast worden in contextueel, authentiek leren in de kindergeneeskunde, is er weinig gepubliceerd over onderzoek naar het leren met VPC's.

Het hoofdstuk wordt besloten met de belangrijkste onderzoeksvragen van het proefschrift: 1) Hoe versterkt de toepassing van VPC's, als aanvulling op casus in de klinische praktijk, de cognitieve processen en het ontwikkelen van gedeelde kennis tijdens het leren in de praktijk? 2) Hoe kunnen interactieve leermethoden met VPC's diagnostische vaardigheden bevorderen? 3) Waar besteden clinici met verschillende ervaringsniveaus aandacht aan en waar denken zij over na tijdens het analyseren van VPC's? 4) Hoe wordt het leren bevorderd door sturing van de aandacht tijdens het analyseren van VPC's? 
In Hoofdstuk 2 staat de eerste onderzoeksvraag centraal. Er wordt een studie beschreven waarin onderzocht werd of toevoeging van een korte videocasus aan een patiëntenvignet de leerprocessen tijdens probleemgestuurd leren meer stimuleert dan toevoeging van een korte tekst met een beschrijving van de videocasus. Twee groepen namen deel aan een gecontroleerd onderzoek met een pre- en posttest. Beide groepen analyseerden dezelfde tekst waarin een vignet van een patiëntencasus beschreven werd. Direct daarna bekeek de ene groep een 2,5 minuut durende video-opname van een kind met een toeval en las de andere groep een beschrijving van wat getoond werd in de video. Daarna analyseerden de leden van elke groep gezamenlijk de casus. Hun denkprocessen werden onderzocht door middel van geluidsopname en analyse van de verbale interacties in de groep. Vergeleken met de resultaten van de groep die de beschrijving had gelezen, waren de resultaten van de groep die de video had bekeken statisch significant beter met betrekking tot exploratie van gegevens, theorievorming en evaluatie van theorieën. Dit wijst erop dat het gezamenlijk analyseren van een patiëntenvideo een waardevolle aanvulling kan zijn op het onderwijs tijdens de vervolgopleiding in de kindergeneeskunde.

Hoofdstuk 3 presenteert een onderzoek naar de eerste onderzoeksvraag met als doel meer inzicht te verwerven in de cognitieve processen tijdens het gezamenlijk analyseren van de casus uit hoofdstuk 2 . Aangezien het leren naar aanleiding van een casus gerelateerd is aan de denkprocessen van de lerenden, wilden we alle cognitieve processen in kaart brengen die zich voordeden tijdens het analyseren van de casus. Met behulp van een 'stimulated recall procedure' onderzochten wij de cognitieve processen die niet verbaal geuit werden tijdens het analyseren in de groep. Het bleek dat tijdens de stimulated recall causaal redeneren driemaal zo vaak voorkwam als tijdens de verbale interactie in de groep. Blijkbaar laat verbale interactie alleen maar het topje van de ijsberg van de cognitieve processen zien. Verbindingen gelegd op basis van causaal redeneren werden geclassificeerd als individueel of collaboratief, afhankelijk van het feit of ze door individuele deelnemers zelf gelegd werden of rechtstreeks voortkwamen uit verbale uitingen van anderen. Deze nieuwe benadering met chronologische registratie van de vorming van conceptuele verbindingen leverde bewijs op dat gedeelde kennis, ontstaan naar aanleiding van gezamenlijk elaboreren tijdens conceptvorming, gestimuleerd kan worden door het gebruik van patiëntenvideo's bij het leren in kleine groepen. Dit wijst erop dat de voordelen van VPC's niet beperkt blijven tot het medium als zodanig, maar ook samenhangen met de door VPC's gestimuleerde gezamenlijke kennisvorming.

Hoofdstuk 4 beschrijft een studie betreffende onderzoeksvraag 2, waarin gekeken werd naar verschillende leeromgevingen met videocasus die de diagnostische vaardigheid van niet-experts mogelijk konden verbeteren. Het onderzoek werd uitgevoerd tijdens een cursus kinderneurologie als onderdeel van de specialistenoplei- 
ding. Deelnemers met verschillende ervaringsniveaus voerden een stapsgewijze analyse uit van vier VPC's. Er werd gebruikgemaakt van individuele en collaboratieve benaderingen. De diagnoses van de niet-experts gaven een duidelijke verbetering te zien tengevolge van de interactie tijdens de groepsdiscussie gevolgd door het luisteren naar een hardop-denk-procedure van een inhoudsexpert. Het onderzoek geeft aan dat het leren met behulp van patiëntenvideo's in een klinische omgeving verbeterd kan worden door interactieve deelname van zowel beginnende als meer ervaren clinici. Een dergelijke omgeving, een 'virtuele onderzoekskamer', zou toegepast kunnen worden tijdens de grote visite, patiëntenbesprekingen of patiëntenpresentaties teneinde het ontwikkelen van de diagnostische vaardigheid van nietexperts te stimuleren.

Hoofdstuk 5 beschrijft een onderzoek naar visuele expertise in de kinderneurologie waarbij de perceptuele en onderliggende cognitieve processen onderzocht werden bij een groep clinici die een diagnose stelden op basis van een VPC. Dit onderzoek betrof dus de derde onderzoeksvraag. In dit beschrijvende onderzoek bij individuele clinici werd gebruikgemaakt van het volgen van oogbewegingen (eye tracking) en het analyseren van een hardop-denk-procedure. Naarmate clinici meer ervaring hadden, waren er sterkere significante verbeteringen te zien in hun prestaties in termen van tijd besteed aan het kijken naar relevante gebieden, het aantal juiste diagnoses en het ontwikkelen en toetsen van diagnostische hypothesen. Minder ervaren clinici keken minder naar belangrijke gebieden, stelden minder correcte diagnoses en vormden en evalueerden minder diagnostische hypothesen. Deze bevindingen kunnen nuttig zijn voor klinisch docenten in verschillende specialismen die in hun onderwijs gebruikmaken van VPC's.

In hoofdstuk 6 staat de vierde onderzoeksvraag centraal in een onderzoek naar het leren met VPC's met behulp van modelvoorbeelden van oogbewegingen. Uit onderzoek buiten de geneeskunde weten we dat het nemen van beslissingen op basis van visuele waarneming vergemakkelijkt kan worden door de oogbewegingen van een model (oogbewegingsvoorbeelden (eye movement modelling examples (EEME)) te laten zien en op die manier de aandacht te sturen. In een gerandomiseerd gecontroleerd onderzoek kregen drie groepen geneeskundestudenten een weergave te zien van de oogbewegingen van een expert tijdens het analyseren van een VPC en luisterden zij naar een opname van een didactische tekst uitgesproken door dezelfde expert. De resultaten lieten zien dat een spotlight op de voorbeeldvideo's ertoe leidde dat de studenten hun aandacht beter richtten op relevante aspecten dan wanneer de visuele waarneming gestuurd werd in een cirkelvorm of wanneer er helemaal geen sturing was. Het onderzoek toonde ook aan dat, in vergelijking met de twee andere onderzoekscondities, het sturen van de aandacht met behulp van een spotlight leidde tot verbetering van het daaropvolgende visuele onderzoek en 
van de prestaties van de deelnemers in het interpreteren van symptomen in de VPC.

Hoofdstuk 7 bevat de algemene discussie van het onderzoek dat beschreven is in dit proefschrift, beginnend met een kort overzicht van de context en de relevantie van de onderzoeken. De bevindingen van het onderzoek worden geplaatst in het kader van leren in de werkplaats en samenwerkend leren. De belangrijkste conclusies ten aanzien van de onderzoeksvragen zijn: 1) Samenwerken en interactie tijdens het leren met behulp van VPC's heeft een gunstige invloed op het leren en het ontwikkelen van gedeelde kennis. 2) Interactieve benaderingen bij het analyseren van patiëntenvideo's leiden tot betere diagnoses van niet-experts. 3) In een groep clinici die verschillen in klinische ervaring zijn de prestaties van de meer ervaren clinici beter in termen van tijd besteed aan het kijken naar belangrijke aandachtsgebieden, correcte diagnoses en het ontwikkelen en evalueren van diagnostische hypothesen. Daarnaast lijkt 4) sturing van visuele aandacht te leiden tot beter leren.

Sterke punten van de onderzoeken zijn de authenticiteit van de VPC's en het feit dat aan de meeste onderzoeken werd deelgenomen door clinici uit afdelingen kindergeneeskunde. Dit versterkt de validiteit en de relevantie van de bevindingen. Een zwak punt van dit proefschrift is de verschuiving die optrad in de focus van de onderzoeken. In hoofdstuk 2, 3 en 4 ligt de nadruk op het samenwerkend analyseren van VPC's, maar in hoofdstuk 5 en 6 verschuift de nadruk naar het individueel analyseren van VPC's. Opgemerkt dient echter te worden dat de diepere kennis van individuele aandacht en cognitieve processen die resulteerde uit de onderzoeken in hoofdstuk 5 en 6 niet alleen van fundamenteel belang is voor situaties waarin clinici individueel werkzaam zijn, maar ook voor de activiteiten van individuele clinici bij het functioneren in collaboratieve leeromgevingen.

De resultaten van de onderzoeken hebben praktische implicaties voor clinici. Het gebruik van authentieke VPC's biedt niet alleen meer mogelijkheden tijdens de opleiding om ervaring op te doen met veelvoorkomende en minder vaak voorkomende klinische beelden, maar biedt clinici ook meer mogelijkheden om in de klinische praktijk te leren met en van collega's in de kinderneurologie. De interactieve toepassing van VPC's in verschillende klinische omgevingen kan meer mogelijkheden creëren voor het leren in de werkplaats. De methoden kunnen op verschillende manieren toegepast worden en zijn bruikbaar voor patiëntenpresentaties, tijdens bijeenkomsten of in de polikliniek. Een nieuwe benadering die beschreven wordt in dit proefschrift is het sturen van de aandacht bij het analyseren van VPC's. Docenten en ontwikkelaars van onderwijssoftware zouden onderzoek kunnen doen naar de mogelijkheden van vervagende ('blurring') technieken om de aandacht tijdens het leren te sturen. Hoewel het door de beperkte beschikbaarheid van 'eye trackers' nog niet praktisch haalbaar is om in het onderwijs gebruik te maken van de oogbewegingen van experts, kunnen docenten wel gebruikmaken 
van video en hun visuele waarnemingen expliciteren door belangrijke gebieden te benoemen en uit te leggen wanneer en waarom ze hun aandacht daarop richten.

De onderzoeken in dit proefschrift openen nieuwe wegen voor onderzoek naar het gebruik van VPC's voor onderwijsdoeleinden. Alle beschreven onderzoeken waren gericht op onmiddellijke leereffecten en leereffecten op de korte termijn; verder onderzoek zou zich kunnen richten op effecten op de langere termijn in termen van het gedrag van lerenden, het aantal correcte diagnoses of op de uiteindelijke gunstige effecten voor de patiëntenzorg. Toekomstige technologische ontwikkelingen op het terrein van het volgen van oogbewegingen kunnen het mogelijk maken om gericht onderzoek te doen naar aandachts- en cognitieve processen die zich voordoen wanneer twee of meer clinici samenwerken. 
Chapter 11

Acknowledgements 
CHAPTER 11 
My warm gratitude goes to those children and families who accepted the video recording of the children. These significant persons appreciated that the recordings might help medical students and physicians become better diagnosticians and thereby benefit future patients.

Professor John R Østergaard, Aarhus University Hospital Skejby, early on encouraged my interest in obtaining patient video cases and in using them for documentation, diagnosis and teaching. I appreciate the continuing and fruitful discussions of patient video cases I had during a number of years with John, with Robert Smith, Newcastle, NSW, Australia and with several more dedicated clinicians. I keep on learning from the sharing of cognition occurring during joint analysis of patient video cases. It never stops amazing me.

Consultant Stense Farholt and consultant Uffe S Hansen, Aarhus University Hospital Skejby are thanked for listing diagnoses and clinical reasoning processes. Consultant Uffe S Hansen and Consultant Annette Haagerup, Aarhus University Hospital Skejby, are thanked for their valuable feedback on parts of this thesis. Consultant Thomas Thelle, Regional Hospital, Viborg, Denmark is thanked for his enjoyable and constructive advice and for his assistance in designating areas of interest (AOIs) in the patient video cases (PVCs).

I thank the staff at the Departments of Paediatrics, Regional Hospital, Viborg, and Aarhus University Hospital, Skejby for their participation in a number of pilot studies. The participants at the Danish Neuropaediatric Society course in paediatric neurology and a number of faculty, residents and medical students are thanked for their active participation.

The international collaboration undertaken in this thesis has been most inspiring. In particular, I thank Kenneth Holmqvist and Halszka Jarodzka for introducing me to the area of eye tracking. I wish to express my gratitude to my supervisors Willem de Grave, Arno Muijtjens and Albert Scherpbier who supported me all the way. They asked me the right questions at the right moments, thereby prompting me to perform and finish the papers - and finally completing the thesis. I wish to thank Professor Berit Eika, Aarhus, who always had valuable advice ready when we met and discussed papers on patient video recordings.

This research was in part supported financially by the KUL-fund for quality improvement in postgraduate medical education, Aarhus County, Denmark. I thank Robert Smith, Mereke Gorsira and Edwin Stanton Spencer for linguistic service. 

Curriculum Vitae 
Thomas Balslev was born in 1956. He graduated from the Medical School at Aarhus, Denmark, in 1984. He developed his interest in paediatric neurology during his postgraduate training in Randers and Aalborg. During that period, he gained a deep interest in the diversity of clinical presentations in paediatric neurology, and started building a library of authentic, illustrative and brief video recordings. Early on, he was astonished by the interest and discussions often generated when PVCs were used for teaching groups of clinicians. He gained his certificate as a specialist in Paediatrics in 1994. He was appointed for a one year clinical fellowship 1995-1996 at the Hospital for Sick Children, Toronto, Canada. He conducted research in a number of areas in paediatric neurology and has continued research to the present time. He was appointed Consultant Paediatrician to the Aarhus University Hospital, Skejby in 1997. He registered with the University of Maastricht in 2001 for the MHPE degree, which he was awarded cum laude in 2003. During that time, he started working on this thesis. He has practised paediatric neurology at the Regional Hospital, Viborg since 2009. At the same time, he is a part-time pre- and postgraduate lecturer in paediatrics at the Centre of Medical Education, Aarhus University. He is married to Mette, who works as a general practitioner, and has three adult children, Laura, Niels and Line. He enjoys cross country and Telemark-skiing, mountain biking, kayaking, travelling and visits with his family and friends to the Ödegaard "Tömte" in Värmland, Sweden. 


\section{SHE dissertations series}

In the SHE Dissertation Series dissertations are published of PhD candidates from the School of Health Professions Education (SHE) who defended their PhD thesis at Maastricht University. The most recent ones are listed below. For more information go to: www.maastrichtuniversity.nl/she

Stalmeijer, R. E. (07-07-2011) Evaluating Clinical Teaching through Cognitive Apprenticeship.

Malling, B.V.G. (01-07-2001) Managing word-based postgraduate medical education in clinical departments

Veldhuijzen, J.W. (17-06-2011) Challenging the patient-centred paradigm: designing feasible guidelines for doctor patient communication.

Van Blankenstein, F. (18-05-2011) Elaboration during problem-based, small group discussion: A new approach to study collaborative learning.

Van Mook, W. (13-05-2011) Teaching and assessment of professional behavior: Rhetoric and reality.

De Leng, B. (8-12-2009). Wired for learning. How computers can support interaction in small group learning in higher education.

Maiorova, T. (29-05-2009). The role of gender in medical specialty choice and general practice preferences.

Bokken, L. (04-03-2009). Innovative use of simulated patients for educational purposes.

Wagenaar, A. (18-09-2008). Learning in internships. What and how students learn from experience.

Driessen, E. (25-06-2008). Educating the self-critical doctor. Using portfolio to stimulate and assess medical students' reflection.

Derkx, H. (18-06-2008). For your ears only. Quality of telephone triage at out-of-hours centres in the Netherlands.

Niessen, Th. (30-11-2007). Emerging epistemologies: making sense of teaching practice.

Budé, L. (05-10-2007). On the improvement of students' conceptual understanding in statistics education.

Niemantsverdriet, S. (26-07-2007). Learning from international internships: A reconstruction in the medical domain.

Marambe, K. (20-06-2007). Patterns of student learning in medical education - A Sri Lankan study in traditional curriculum.

Pleijers, A. (19-01-2007). Tutorial group discussion in problem-based learning.

Sargeant, J. (21-09-2006). Multi-source feedback for physician learning and change.

Dornan, T. (12-06-2006). Experience-based learning.

Wass, V. (12-05-2006). The assessment of clinical competence in high stakes examinations.

Prince, K. (21-04-2006). Problem-based learning as a preparation for professional practice. 